UCRI-ID-120253

\title{
Determination of Plutonium Metal Origins
}

\author{
Kenton J. Moody
}

\author{
Nuclear Science Applications Section \\ Isotope Sciences Division \\ Chemistry \& Materials Science \\ Lawrence Livermore National Laboratory
}

February 1995

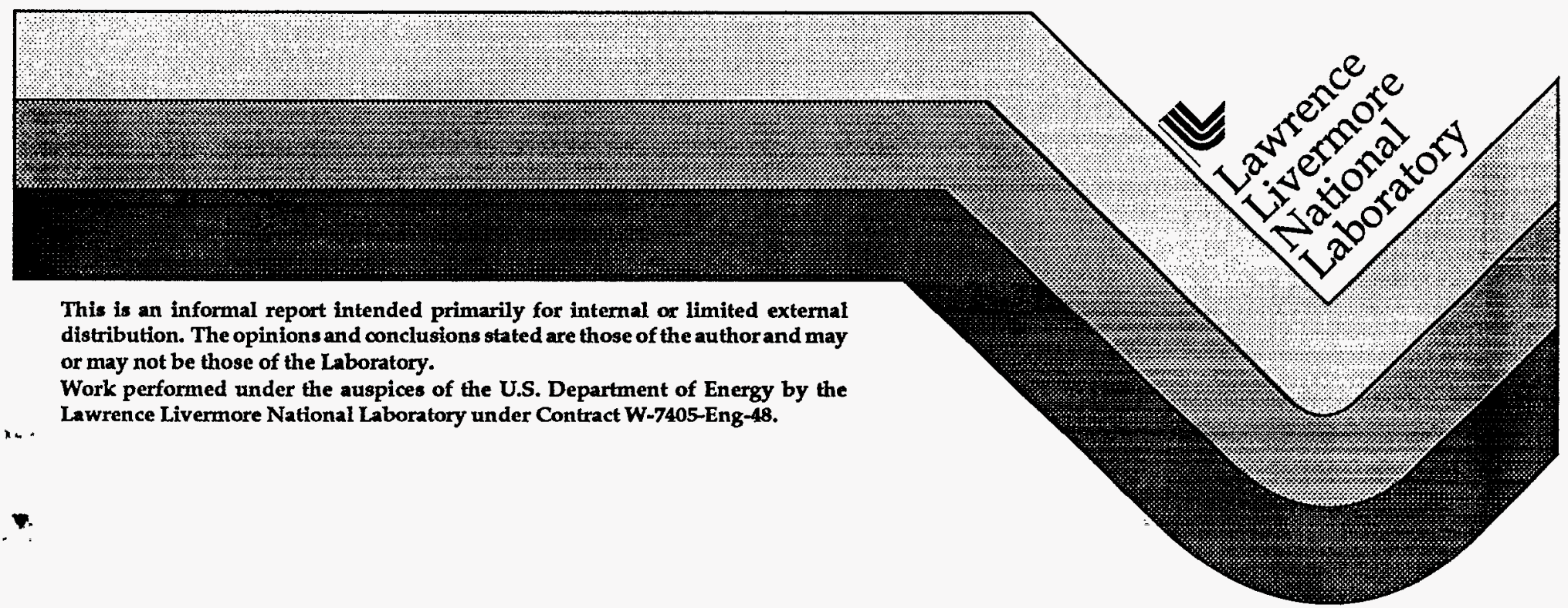

ZFIFIVED

AUG 041995

OSTI 


\section{DISCLAIMER}

This document was prepared as an account of work sponsored by an agency of the United States Government. Neither the United States Government nor the University of California nor any of their employees, makes any warranty, express or implied, or assumes any legal liability or responsibility for the accuracy, completeness, or usefulness of any information, apparatus, product, or process disclosed, or represents that its use would not infringe privately owned rights. Reference herein to any specific commercial products, process, or service by trade name, trademark, manufacturer, or otherwise, does not necessarily constitute or imply its endorsement, recommendation, or favoring by the United States Government or the University of California. The views and opinions of authors expressed herein do not necessarily state or reflect those of the United states Government or the University of California, and shall not be used for advertising or product endorsement purposes.

This report has been reproduced

directly from the best available copy.

Available to DOE and DOE contractors from the office of Scientific and Technical Information

P.O. Box 62, Oak Ridge, TN 37831

Prices available from (615) 576-8401

Available to the public from the National Technical Information Service

U.S. Department of Commerce 5285 Port Royal Rd., Springfield, VA 22161 


\section{DISCLAIMER}

Portions of this document may be illegible in electronic image products. Images are produced from the best available original document. 
- K. J. Moody, Isotope Sciences Division, Lawrence Livermore National Laboratory, Livermore, CA 94551

\section{Introduction}

In the spirit of expanding its defense mission, the Lawrence Livermore National Laboratory is developing the technology to detect nuclear proliferation activities. However, one probably must admit the possibility that any group clever enough to steal or fabricate a nuclear weapon might also be able to circumvent any detection schemes. Fissile materials such as ${ }^{239} \mathrm{Pu}$ or ${ }^{235} \mathrm{U}$ could be susceptible to diversion for use in weapons if they are contained in new, unirradiated fuel elements, in stockpiles, or in existing weapons. They can also be recovered from misappropriated irradiated reactor fuel or fuel specifically irradiated for the purpose of weapons production. Recent seizures of smuggled plutonium and highly-enriched uranium in Europe have underscored already-growing concerns over the possible development of a black market in nuclear-weapon materials. Illicit trade in these materials also increases the danger of nuclear proliferation. In the U.S. and elsewhere, government agencies and other organizations (e.g. IAEA) are examining what more should be done to deal with this problem.

The domestic recovery of samples of special nuclear materials (SNM) from an unknown source, whether obtained through the black market, through counter-proliferation activities, or from a deployed-then-disabled nuclear weapon, could indicate a threat to national security. The first step in developing an appropriate response would be to determine the origin of the sample and to trace the history of its movements. This may only be possible through a forensic approach, where clues obtained from the sample and its surroundings are combined with collateral information (both technical and non-technical) to provide a consistent scenario which forms the basis for Attribution.

One component of Attribution Forensics is the analysis of the SNM samples themselves for the presence of trace radionuclides. The radiochemical "pedigree" of a sample of plutonium could indicate when and how it was produced, under what neutron flux conditions, and what chemistry was employed in the reprocessing. This is based on the premise that the content of minor isotopes $\left({ }^{238,240,241,242} \mathrm{Pu}\right)$, and elements (U, Am, fission products) in a specific plutonium metal sample are determined by its production history in nuclear reactors and the type and efficiency of chemical and metallurgical processes resulting in the final sample. specifically: The ingrowth of daughter activities defines the date 
when the material was chemically processed; the plutonium isotopics define the enrichment of uranium and the neutron spectrum in the reactor starting materials; and residual impurities in the sample identify the chemical techniques used in reprocessing.

The forensic signatures in a sample of highly-enriched uranium (HEU) are different. While ingrowth of daughter activities can still be used to define a separation time, the material need not ever have been resident in a reactor, and residual impurities are very effectively removed by the mass-enrichment process. Nevertheless, a uranium sample may contain radiochemical clues as to its origin. Analytical procedures for use in determining the heavy element content of a sample of enriched uranium and the results of the analyses of specific samples are discussed in separate reports ("Dissolved oralloy standards and the origin of HEU", K. J. Moody, UCRL-ID-117611, 1994; and "Forensic Radiochemistry of PUBLIC Site Inspection Samples", K. J. Moody, UCRL-ID-119658, 1995).

In this report we discuss a method of measuring key radionuclide components in a small (0.05 to 5 grams) sample of plutonium metal, and use the results of the analysis of a specific sample to start developing a set of signatures that will help define the points of origin of other samples. A piece of plutonium of this size could be obtained covertly, through military intervention, from the disablement of a nuclear weapon, or through the interception of black-market materials by a law-enforcement agency. The procedure is based on techniques and facilities that were developed for the Nuclear Test Program, and builds on the Isotope Sciences Division's expertise in the analysis and interpretation of radiochemical data. These techniques include radiochemical separations followed by radiation counting (alpha-

and gamma-spectroscopy, beta counting), spectral analysis, and mass spectrometry to identify the isotopes of interest. We can adapt our procedures as needed to cover a wide range of elements and more than 15 orders of magnitude in activity. In most cases, we are able to detect a small amount of one isotope even when large amounts of other radioactive isotopes of the same element are present.

It is our hope that the Isotope Sciences Division's commitment to and work in the nuclear forensics of SNM provides a basis for LLNL's participation in a national effort in Attribution Assessment, to reduce the danger of nuclear proliferation.

II. Background.

Plutonium is produced by the interaction of neutrons with uranium in a nuclear reactor. The uranium usually constitutes the reactor fuel, though $\mathrm{Pu}$ can be produced with much lower efficiency in a uranium target (or "blanket") external to the reactor core. The uranium fuel may start out with the natural isotopic mixture 
$\left(0.718{ }^{235} \mathrm{U}\right.$, by mass), or may be enriched in ${ }^{235} \mathrm{U}$. The length of the reactor irradiation, the integrated neutron flux, and the energy spectrum of the neutrons in the fuel element determine the isotopic composition of the plutonium product and the buildup of other heavy elements and the fission products. When the reactor irradiation is finished, the uranium target is discharged to a holding area where it is held until the decay of short-lived fission products has reduced the overall radioactivity of the material to an acceptable level. Plutonium is then recovered from the fuel elements with a chemical procedure, usually involving solvent extraction from a nitric acid solution. Production of plutonium metal is usually accomplished by the reduction of a dry plutonium salt with an alkaline earth metal (i.e. Ca or $\mathrm{Mg}$ ) at a high temperature.

The radionuclide inventory of a sample of plutonium can be subdivided into three categories: 1) The intrinsic radionuclides are the isotopes of plutonium, which are not modified or fractionated by post-irradiation reprocessing. From first principles, these isotopes help define the reactor type and the irradiation parameters utilized in producing the sample. If a database of $\mathrm{Pu}$ isotopics is available, comparison with isotopic data for a given sample might provide a correlation with a particular reprocessing run. 2) The contaminant radionuclides are activities that owe their existence to the production reactor irradiation, but whose presence in the plutonium sample is due to incomplete decontamination in the reprocessing of the discharged reactor fuel. The presence of long-lived fission products and heavy-element nuclides, beyond those produced by the radioactive decay of the intrinsic radionuclides, provide clues to the chemical techniques used in reprocessing. There is a fundamental conflict between the complete recovery of the expensive plutonium and the complete removal of contaminant activities that may result in the incorporation of observable contaminant species into the final product, particularly by inexperienced reprocessors. 3) The progeny radionuclides result from the radioactive decay of both intrinsic and contaminant activities. If one makes the assumption that, at some time in the past, all the long-lived decay products were removed from the material resulting in the sample, then the half-lives of the genetically-related species and their relative concentrations at a later time can be used to calculate the date at which the separation took place (the age of the sample). Shortlived progeny species can be considered to be in secular equilibrium with their parent activities, and can be used in the radiochemical analysis as in-situ chemical-yield indicators.

A. Intrinsic Radionuclides (the plutonium isotopes).

The production of ${ }^{239} \mathrm{Pu}$ at the start of a reactor irradiation of uranium fuel is primarily through the capture of a neutron by 
${ }^{238} \mathrm{U}$, followed by two successive beta decays. As the reactor irradiation proceeds, the ${ }^{239} \mathrm{Pu}$ product itself becomes a target, capturing neutrons to form the heavier $\mathrm{Pu}$ isotopes. Some of the neutrons present in the fuel have sufficient energy ( $\geq 5.7 \mathrm{MeV}$ ) to cause ${ }^{239} \mathrm{Pu}$ to lose a neutron, producing ${ }^{238} \mathrm{Pu}$ via the $(n, 2 \mathrm{n})$ reaction. However, there is another path to ${ }^{238} \mathrm{Pu}$ at longer irradiation times, through multiple neutron-capture reactions with the ${ }^{235} \mathrm{U}$ component of the fuel, coupled with the beta decays of two of the intermediate products $\left({ }^{237} \mathrm{U}\right.$ and $\left.{ }^{238} \mathrm{~Np}\right)$.

The plutonium recovered from irradiated uranium fuel elements is always composed of a mixture of plutonium isotopes, providing the basis for "fingerprinting" the material. At very low burnups (low integrated neutron $f l u x$ ) ${ }^{239} \mathrm{Pu}$ dominates the mixture; at higher burn-ups, the other isotopes of plutonium become more important. However, the even-mass isotopes of plutonium have a property (decay by spontaneous fission) that isn't conducive to using the material in nuclear weapons. Therefore, a compromise must be struck between the production of $\mathrm{Pu}$ at low burn-ups (characterized by high-purity ${ }^{239} \mathrm{Pu}$, but very inefficient conversion of uranium) and at high-burn-ups (efficient uranium conversion, but low-purity ${ }^{239} \mathrm{Pu}$ ). This compromise results in a ${ }^{240} \mathrm{Pu}$ content of approximately $6 \%$ by mass in U.S. weapons-grade material; other countries may strike a somewhat difference balance.

Integrated neutron flux is not the only consideration determining the isotopic mixture of a sample of $\mathrm{Pu}$. Neutron capture reactions can be very energy sensitive, particularly for neutron energies near the kinetic-energy equivalent of the reactor operating temperature. The identity of the moderating material (e.g. light water, heavy water, or graphite), the temperature of the moderator and the fuel during reactor operations, and the dimensions of the fuel elements (distance between the point of neutron release and the moderator), all affect the production of $\mathrm{Pu}$ isotopes. The starting composition of the reactor fuel also influences the spectrum of neutrons available for plutoniumproduction reactions: The capture of neutrons by ${ }^{235} \mathrm{U}$ (and its subsequent fission) is also very energy sensitive. An increase in the ${ }^{235} \mathrm{U}$-enrichment of the fuel increases the selective absorption of neutrons at the signature energies of the ${ }^{235} U(n, f)$ reaction, changing the spectrum of the "left-over" neutrons that are available for $\mathrm{Pu}$ synthesis.

The intensity (or flux) of the neutrons in the reactor fuel also affects the production of $\mathrm{Pu}$ isotopes. Consider the formation of ${ }^{240} \mathrm{Pu}$ : A neutron is captured by ${ }^{238} \mathrm{U}$ to result in ${ }^{239} \mathrm{U}$, which decays within minutes to ${ }^{239} \mathrm{~Np}$, which in turn decays with a $2.4-$ day half-life to ${ }^{239} \mathrm{Pu}$. At low flux, the ${ }^{239} \mathrm{~Np}$ atoms decay to ${ }^{239} \mathrm{Pu}$ before they have the opportunity to react with neutrons; ${ }^{240} \mathrm{Pu}$ production is solely through the capture of a neutron by ${ }^{239} \mathrm{Pu}$. However, at higher flux, the probability of a neutron being captured by ${ }^{239} \mathrm{~Np}$ before it can decay increases; ${ }^{240} \mathrm{Pu}$ production has 
a component from the subsequent beta decay of short-lived ${ }^{240} \mathrm{~Np}$. Even though the neutron energy spectrum can be independent of flux, the relative capture probabilities of ${ }^{239} \mathrm{~Np}$ and ${ }^{239} \mathrm{Pu}$ are not, resulting in a flux dependence of the relative amounts of ${ }^{239} \mathrm{Pu}$ and ${ }^{240} \mathrm{Pu}$ in the final product.

The ORIGEN2 code (A. G. Croff, Nucl.Tech. $\underline{62}, 335$ (1983); ORNL RSIC Computer Code Collection, CCC-371, rev. 1991) can be used to calculate the nuclide contents of nuclear fuels at specified burnup intervals for several types of reactor. The energy dependences of the reactions that create and destroy each product of a reactor irradiation are integrated over the spectrum of neutrons expected for a given reactor type. This results in a set of scalar values for the net formation of each product nuclide, specific to a given reactor. These values (the "library" for that reactor) and the decay constants of the reaction products, comprise the parameters of a set of coupled, linear, first-order differential equations as a function of reactor power. starting from the initial composition of the fuel, the code solves these differential equations at a specified exposure time to come up with the total nuclide inventory.

Unfortunately, the set of ORIGEN2 libraries available at LLNL does not include that of a graphite-moderated production reactor. other than this important omission, it is possible to calculate the nuclide inventories of common reactor types at several power levels and burn-ups. Under reasonable operating conditions, we find that reactor power and operating temperatures have smaller effects on the final plutonium isotopics than do changes in moderator type, fuel enrichment, and burn-up; however, even the more subtle effects will be important in establishing the isotopic fingerprint of a reactor.

The calculated correlations between the mass ratio ${ }^{240} \mathrm{Pu} /{ }^{239} \mathrm{Pu}$ and the activity ratio ${ }^{238} \mathrm{Pu} /\left({ }^{239} \mathrm{Pu}+{ }^{240} \mathrm{Pu}\right)$ for three standard reactor types and an external target (Thermal) are given in figure 1 . In all cases, reactor power was held at $37.5 \mathrm{MW}$ (thermal). These parameters are two of the fundamental radiochemistry observables; ${ }^{238} \mathrm{Pu} /\left({ }^{239} \mathrm{Pu}+{ }^{240} \mathrm{Pu}\right)$ by activity is measured directly by alpha spectroscopy, while ${ }^{240} \mathrm{Pu} /{ }^{239} \mathrm{Pu}$ by mass is determined by mass spectrometry. The value of ${ }^{239} \mathrm{Pu}$ used in the calculation of these ratios is the sum of the number of atoms of ${ }^{239} \mathrm{U},{ }^{239} \mathrm{~Np}$, and ${ }^{239} \mathrm{Pu}$ given in the code output at the appropriate irradiation length; since the fuel is allowed to decay quite a while before it is reprocessed, all of the short-1ived ${ }^{239} \mathrm{Pu}$-precursors have decayed to ${ }^{239} \mathrm{Pu}$. If we limit ourselves to discussing plutonium of nominal U.S. composition $\left(68{ }^{240} \mathrm{Pu}\right.$, by mass, or $\left.{ }^{240} \mathrm{Pu} /{ }^{239} \mathrm{Pu}=0.064\right)$, we see a variation of more than two orders of magnitude in ${ }^{238} \mathrm{Pu} /\left({ }^{239} \mathrm{Pu}+{ }^{240} \mathrm{Pu}\right)$ : $2.5 \times 10^{-4}$ for an external target (Thermal), $5 \times 10^{-3}$ for a heavywater-moderated. CANDU reactor with natural-uranium fuel, and approximately $5 \times 10^{-2}$ for light-water-moderated BWRs (BoilingWater Reactors) and PWRs (Pressurized-Water Reactors) operating 
with fuel enriched to 3.28 in ${ }^{235} \mathrm{U}$. Much of the difference between the BWR and PWR curves is due to their different operating temperatures.

Clearly, plutonium isotopics define the reactor type used in their production, and give a strong indication of the starting composition of the fuel and the degree of burn-up attained in the irradiation.

B. Contaminant Nuclides.

The neutrons resulting in the sustained nuclear chain reaction that constitutes normal reactor operations arise in the fission process that they engender; in these terms, plutonium production is the symptom of a mechanism by which neutrons are (temporarily) lost, or made unavailable for energy production. The fission products build up in the reactor fuel more quickly than do the plutonium isotopes, and are the "neutron poisons" that ultimately make it impossible to maintain reactor power. Most of the radioactivity in freshly-discharged reactor fuel exhibiting any significant degree of burn-up is due to the decays of the fission products. The fission yield is distributed amongst hundreds of different nuclides, covering a wide range of atomic numbers and masses.

Most of the fission-product nuclides are radioactive, with half-lives ranging from sub-seconds to millions of years; other fission products are stable, contributing nothing to the radiation environment. There is a general tendency for short-lived fission products to decay to longer-lived products, and eventually to stable species. During the reactor irradiation, this means that the amount of a given short-lived species quickly reaches an equilibrium value, where its rate of loss due to decay (or neutron capture) balances its rate of production. Products with halflives comparable to or longer than the reactor irradiation interval continue to build up in the fuel. When reactor operations stop (e.g. with discharge of the fuel), production of significant amounts of fresh fission products ceases, and radioactive decay provides for a substantial reduction in total radioactivity over the next few months, leaving only longer-lived and stable species to be removed by fuel reprocessing.

Product ${ }^{239} \mathrm{Pu}$ is also a fissile nuclide; as plutonium builds up in the uranium fuel, it also begins to contribute to the fission product yield. Roughly the same number of reactor neutrons induce fission in ${ }^{239} \mathrm{Pu}$ as are captured to form ${ }^{240} \mathrm{Pu}$. There is a small difference in the distribution of fission yield among the fission products between ${ }^{235} \mathrm{U}$ and ${ }^{239} \mathrm{Pu}$; at high burn-ups, this can result in measurable differences in the fission-product inventory of the reactor fuel. At lower burn-ups, appropriate to weapons-grade plutonium production, the contribution from the fission of ${ }^{239} \mathrm{Pu}$ is not very important. 
The ORIGEN2 code can also be used to calculate the fissionproduct inventory in irradiated reactor fuel. Table 1 shows the results of an ORIGEN2 calculation of selected long-lived and stable fission product yields in a hypothetical "natural-uranium-fueled" BWR, operated at 37.5 MW (thermal). (All of the ORIGEN2 calculations presented in this paper were run with fuel containing 1 metric ton of uranium, so quoted power levels are always on a "per ton" basis.) The reasons for considering this (non-viable) reactor type will be discussed later, in section $V$. The calculation was run for an irradiation interval resulting in plutonium containing $6 \%{ }^{240} \mathrm{Pu}$ by mass (1170 $\mathrm{MW}$-days), and the fission product yields given in Table 1 are for that fraction of the fuel containing 1 gram of mixed plutonium isotopes. The Table 1 values are amounts present at the end of the irradiation; the shorter-lived species (e.g. ${ }^{106} \mathrm{Ru},{ }^{125} \mathrm{Sb}$ ) would need a correction for decay to some later time.

The fission products listed in Table 1 span a wide range of chemical properties, from alkali metals $\left({ }^{135} \mathrm{Cs},{ }^{137} \mathrm{Cs}\right)$ to alkaline earths $\left({ }^{90} \mathrm{Sr}\right)$, to lanthanides $\left({ }^{143} \mathrm{Nd},{ }^{155} \mathrm{Eu}\right)$, to transition metals $\left({ }^{93} \mathrm{Zr}\right.$, $\left.{ }^{99} \mathrm{TC}\right)$, to noble metals $\left({ }^{106} \mathrm{Ru}\right)$, to halogens $\left({ }^{129} \mathrm{I}\right)$, to the amphoteric elements $\left({ }^{125} \mathrm{Sb}\right)$. Chemistry used in the recovery of $\mathrm{Pu}$ from irradiated fuel has to provide for a separation from all these elements, other fission and activation products, and the actinides (including a large amount of unburned uranium), and still provide for a complete recovery of plutonium. A further complication: Most of the process must be performed remotely due to the intense radiation field associated with both the mixture and (to a lesser extent) the final product itself. This is a daunting prospect.

Table 1. Long-lived fission products present at discharge in reactor fuel used to produce 1 gram of plutonium containing $68^{240} \mathrm{Pu}$ by weight. ORIGEN2 calculation, "natural-uranium BWR", $37.5 \mathrm{MW}$ thermal.

\begin{tabular}{cccc} 
nuclide & half-life $(\mathrm{yr})$ & $\frac{\text { mass }(\mathrm{mg})}{11}$ & $\frac{3}{3.4 \times 1} \times 10^{12}$ \\
\cline { 2 - 3 }${ }^{90} \mathrm{Sr}$ & 28.5 & $14^{*}$ & $8.0 \times 10^{7}$ \\
${ }^{93} \mathrm{Zr}$ & $1.5 \times 10^{6}$ & 16 & $6.1 \times 10^{8}$ \\
${ }^{99} \mathrm{TC}$ & $2.1 \times 10^{5}$ & 4.1 & $3.0 \times 10^{13}$ \\
${ }^{106} \mathrm{Ru}$ & 1.01 & 0.45 & $1.0 \times 10^{12}$ \\
${ }^{125} \mathrm{Sb}$ & 2.77 & 3.4 & $1.3 \times 10^{6}$ \\
${ }^{129} \mathrm{I}$ & $1.6 \times 10^{7}$ & 2.4 & $7.1 \times 10^{6}$ \\
${ }^{135} \mathrm{Cs}$ & $2.0 \times 10^{6}$ & 22 & $4.2 \times 10^{12}$ \\
${ }^{137} \mathrm{Cs}$ & 30.2 & 20 & --- \\
${ }^{143} \mathrm{Nd}$ & stable & 0.23 & $2.4 \times 10^{11}$ \\
${ }^{155} \mathrm{Eu}$ & 4.96 & &
\end{tabular}

* Lower limit, ${ }^{93} \mathrm{Zr}$ may also be produced in claddings. 
Consider the Butex process, at one time employed at the windscale works in Great Britain, in which the major decontamination step involves a solvent extraction with dibutyl carbitol. This solvent extraction provides for decontamination factors of greater than $10^{6}$ for all the fission products listed in Table 1 except for ruthenium, for which the decontamination factor is only approximately $10^{3}$. This means that a sample of the postprocess solution containing 1 gram of plutonium would also contain approximately $10^{7}$ disintegrations per minute of ${ }^{106} \mathrm{Ru}$, an amount that is observable by gamma spectroscopy without further processing. While later purification steps remove quite a bit of the residual ruthenium, plutonium recovered from irradiated fuel by the Butex process is characterized by a significant ${ }^{106} \mathrm{Ru}$ contamination.

Consider the Hexone process, used at the Hanford works in the $1950^{\prime} \mathrm{s}$, in which the major decontamination step involves a solvent extraction with methylisobutyl ketone. The Hexone process is much more successful at removing ${ }^{106} \mathrm{Ru}$ (decontamination factor $\geq 10^{4}$ ) than is the Butex process, but provides decontamination factors of only about $10^{5}$ for $\mathrm{Zr}, \mathrm{Nb}$, and $\mathrm{Ce}$. A sample of the post-process solution containing one gram of plutonium would also contain approximately 1000 disintegrations per minute of ${ }^{93} \mathrm{Zr}$, easily observable in a clean chemical fraction.

The PUREX process can be prone to neptunium and thorium contaminations. The lanthanum fluoride process can result in $\mathrm{Pu}$ contaminated with the light rare earths. The chemical properties of plutonium and the high radiation environment present in the early separation steps severely limit the number of techniques that could be employed in the reprocessing of plutonium from irradiated fuel. Clearly, these techniques can leave a distinct fuelbyproduct fingerprint in the final $\mathrm{Pu}$ sample.

At low burn-ups, like those employed in the production of weapons-grade $\mathrm{Pu}$, the concentrations of most of the stable fission products are reasonably constant relative to each other and to ${ }^{239} \mathrm{Pu}$, independent of reactor power. In Table 2, we show results of ORIGEN2 calculations of the production of stable neodymium isotopes in a hypothetical "natural-uranium-fueled" BWR as a function of reactor power. In each case, the calculation was run for an irradiation interval resulting in plutonium containing $6 \%{ }^{240} \mathrm{Pu}$ by mass. The required irradiation time is 775 days at $1.25 \mathrm{MW}$, but only 12.15 days at $125 \mathrm{MW}$; we consider these values as reasonable extremes for reactor power, between minimum production requirements and the limitations on reactor performance. Values are given relative to ${ }^{143} \mathrm{Nd}$ production, which is, in turn, given relative to the production of total plutonium. The isotopic composition of naturally-occuring neodymium is also listed for comparison. 
Table 2. Neodymium isotope ratios (by mass) and the production of ${ }^{143} \mathrm{Nd}$ vs. total $\mathrm{Pu}$ production $\left(6{ }^{\circ}{ }^{240} \mathrm{Pu}\right)$ as a function of hypothetical "natural-uranium-fueled" Boiling-Water Reactor power. Natural Nd isotopics are included for comparison.

\begin{tabular}{|c|c|c|c|c|}
\hline Mass ratio & Reactor & power level & (MW thermal) & Natural \\
\hline & 1.25 & 12.5 & 125 & neodymium \\
\hline${ }^{142} \mathrm{Nd} /{ }^{143} \mathrm{Nd}$ & $0 . \overline{00172}$ & 0.00081 & 0.00019 & 2.212 \\
\hline${ }^{144} \mathrm{Nd} /{ }^{143} \mathrm{Nd}$ * & 0.964 & 0.951 & 0.949 & 1.973 \\
\hline${ }^{145} \mathrm{Nd} /{ }^{143} \mathrm{Nd}$ & 0.704 & 0.697 & 0.699 & 0.692 \\
\hline${ }^{146} \mathrm{Nd} /{ }^{143} \mathrm{Nd}$ & 0.571 & 0.567 & 0.572 & 1.478 \\
\hline${ }^{148} \mathrm{Nd} /{ }^{143} \mathrm{Nd}$ & 0.343 & 0.342 & 0.351 & 0.487 \\
\hline${ }^{150} \mathrm{Nd} /{ }^{143} \mathrm{Nd}$ & 0.160 & 0.159 & 0.160 & 0.484 \\
\hline${ }^{143} \mathrm{Nd} /{ }^{\text {tot }} \mathrm{Pu}$ & 0.0202 & 0.0202 & 0.0194 & $\cdots$ \\
\hline
\end{tabular}

* Assumes complete decay of $285-$ day ${ }^{144} \mathrm{Ce}$.

From Table 2, we can see that the isotopic composition of fission-product neodymium (except for the minor isotope ${ }^{142} \mathrm{Nd}$, whose production is largely through neutron capture by fission-product ${ }^{141} \mathrm{Pr}$ ) is relatively insensitive to neutron flux over a broad span of reactor power, as is the production of neodymium relative to total plutonium of fixed composition. However, the distribution of isotopes in fission-product $\mathrm{Nd}$ is significantly different from that in natural $\mathrm{Nd}$. If we measure the distribution of isotopes in a Nd fraction separated from a plutonium sample, we can utilize the flux independence of the fission yields to deconvolute the relative amounts of natural and radiogenic $\mathrm{Nd}$; the amount of natural neodymium provides more information about the chemistry:

Reagent-grade solvents contain approximately 100 parts per billion neodymium (by mass) as impurities; Nd levels in industrial solvents are probably higher. The solubility of reactor fuel (mostly uranium oxide) in nitric acid is certainly less than 500 grams per liter, and the weapons-grade $\mathrm{Pu}$ content of the fuel is probably no more than a few tenths of a percent of the uranium. This means that the total chemical volume involved in the early steps of an aqueous fuel-reprocessing procedure must be on the order 10 liters per gram of $\mathrm{Pu}$. Therefore, impurities in the reagents introduce roughly a milligram of natural neodymium to the process for each gram of plutonium, which is associated with $75 \mathrm{mg}$ of fission-product neodymium (Table 2). Even if decontamination factors of $10^{8}$ for $\mathrm{Nd}$ are achieved in the reprocessing, there will still be approximately a nanogram of the initial Nd content present in the plutonium sample, which may be adequate for a massspectrometric isotopic analysis. Natural neodymium introduced as 
contaminants in the smaller amounts of reagents used in later chemical steps or in metallurgical processes will also be present in the final sample, and with higher chemical yield. The relative amounts of natural and fission-product Nd are defined by the purity and volumes of the reagents used in the chemistry, and are probably unique to the process plant.

The fission products are not the only contaminant nuclides present in irradiated fuel. The unburned uranium isotopes are, in a way, contaminants that vastly dilute the plutonium product. other heavy-element nuclides are also formed in the fuel, through neutron reactions with uranium, plutonium, and their decay products.

In Table 3 we show the concentrations of selected heavyelement nuclides arising in a sample of natural-uranium reactor fuel, from the same ORIGEN2 calculation resulting in the fissionproduct data in Table 1. Once again, the results are scaled to the amount of irradiated fuel containing 1 gram of plutonium that is $6 \%{ }^{240} \mathrm{Pu}$ by mass. As before, short-lived precursor nuclides are assumed to have completely decayed to longer-lived species during the cooling period, but no other corrections for radioactive decay since fuel discharge have been made. In this reactor, plutonium reaches final weapons-grade composition in the time it takes to build up to $0.2 \%$ of the unburned uranium concentration. Even though it is a small component by mass, $\mathrm{Pu}$ is the largest contributor to the alpha-decay rate of the fuel, adding $1.65 \times 10^{11}$ disintegrations per minute to the sum of the values listed in Table 3. The burn-up of the reactor fuel has resulted in a decrease in the fissile ${ }^{235} \mathrm{U}$-concentration from 0.718 of the total uranium (natural composition) to $0.62 \% ; 99.77 \%$ of the ${ }^{238} \mathrm{U}$ in the initial reactor charge remains unconsumed.

Table 3. Production of selected heavy-element nuclides in reactor fuel (at discharge) used to produce 1 gram of plutonium containing $68{ }^{240} \mathrm{Pu}$ by mass. From the same ORIGEN2 calculation resulting in Table 1 data.

\begin{tabular}{|c|c|c|c|}
\hline nuclide & half-life (yr) & mass $(g)$ & activity (dpm) \\
\hline${ }^{234} \mathrm{U}$ & $2.446 \times 10^{5}$ & 0.026 & $3.6 \times 10^{8}$ \\
\hline${ }^{235} \mathrm{U}$ & $7.038 \times 10^{8}$ & 3.14 & $1.5 \times 10^{7}$ \\
\hline${ }^{236} \mathrm{U}$ & $2.342 \times 10^{7}$ & 0.090 & $1.3 \times 10^{7}$ \\
\hline${ }^{238} \mathrm{U}$ & $4.468 \times 10^{9}$ & 505.9 & $3.8 \times 10^{8}$ \\
\hline${ }^{237} \mathrm{~Np}$ & $2.14 \times 10^{6}$ & 0.0056 & $8.8 \times 10^{6}$ \\
\hline${ }^{241} \mathrm{Am}$ & 432.6 & $9.66 \times 10^{-6}$ & $7.4 \times 10^{7}$ \\
\hline${ }^{242 m} \mathrm{Am}$ & 152. & $5.26 \times 10^{-8}$ & $1.1 \times 10^{6}$ \\
\hline${ }^{243} \mathrm{Am}$ & 7370. & $3.88 \times 10^{-6}$ & $1.7 \times 10^{6}$ \\
\hline${ }^{242} \mathrm{Cm}$ & 0.446 & $4.35 \times 10^{-7}$ & $3.2 \times 10^{9}$ \\
\hline${ }^{244} \mathrm{Cm}$ & 18.1 & $7.58 \times 10^{-8}$ & $1.4 \times 10^{7}$ \\
\hline
\end{tabular}


The activities of the the heavy-element contaminants given in Table 3 are similar in magnitude to the activities of the longlived fission products given in Table 1 . Detection techniques based on alpha spectroscopy are more sensitive than those involving the counting of photons or electrons, since alpha-detector background levels can be very low. One might therefore expect that the signatures of incomplete fuel reprocessing would be easier to observe through the heavy-element contaminants than through the fission products. However, many of the nuclides listed in Table 3 are also progeny species that grow into a purified sample from the radioactive decay of the plutonium isotopes. This reduces the effective sensitivity of the technique by several orders of magnitude for these nuclides. The ingrowth of progeny species is discussed in the next subsection.

There are potential contaminants given in Table 3 that are not also progeny nuclides: ${ }^{242 \mathrm{~m}} \mathrm{Am},{ }^{243} \mathrm{Am},{ }^{242} \mathrm{Cm}$, and ${ }^{244} \mathrm{Cm}$. Their precursors (if any) are all short-lived species that completely decay to the observable contaminant nuclides long before fuel reprocessing can take place; since their parent activities cannot be present in the purified $\mathrm{Pu}$ sample, they cannot grow in, and their presence can only be due to incomplete decontamination of the plutonium product. Their activity levels in the unprocessed fuel and the sensitivity of alpha spectroscopy to their detection makes them particularly good chemical-signature species.

Unlike the fission products and the plutonium isotopes, the relative concentrations of ${ }^{242 \mathrm{~m}} \mathrm{Am},{ }^{243} \mathrm{Am},{ }^{242} \mathrm{Cm}$, and ${ }^{244} \mathrm{Cm}$ are very sensitive to changes in reactor power. This is primarily due to the moderately-short half-life of ${ }^{241} \mathrm{Pu}$ : As we mentioned in the discussion of the neodymium fission products and Table 2, a likely irradiation interval in a natural-uranium-fueled reactor for the production of weapons-grade $\mathrm{Pu}$ is between a dozen days and a couple of years. The half-life of ${ }^{241} \mathrm{Pu}$ is 14.4 years, so its decay during the much-shorter irradiation interval does not significantly affect the production of species arising directly or indirectly from neutron reactions with it; this includes ${ }^{242} \mathrm{Pu},{ }^{243} \mathrm{Am}$ (from neutron capture on ${ }^{242} \mathrm{Pu}$ followed by beta decay of 5 -hour ${ }^{243} \mathrm{Pu}$ ), and ${ }^{244} \mathrm{Cm}$ (from neutron capture on ${ }^{243} \mathrm{Am}$ followed by beta decays of both isomeric species of $\left.{ }^{244} \mathrm{Am}\right)$. However, even though the irradiation length has little effect on the amount of undecayed ${ }^{241} \mathrm{Pu}$ available as a target, the amount of the decay product ${ }^{241} \mathrm{Am}$ that is present in a given amount of ${ }^{241} \mathrm{Pu}$ increases almost linearly with time. This means that the effective ${ }^{241} \mathrm{Am}$ target available for neutron reactions during a long irradiation at low flux is larger than that present during shorter irradiations at higher flux, even if the burn-up values are the same. This results in lower relative concentrations of the ${ }^{241} \mathrm{Am}$ reaction products ${ }^{242 \mathrm{~m}} \mathrm{Am}$ and ${ }^{242} \mathrm{Cm}$ at high reactor power than at low power. In figure 2, we plot several concentration ratios (at discharge) for non-progeny heavy-element 
contaminant nuclides as a function of reactor power for a naturaluranium-fueled BWR at burn-ups resulting in plutonium containing $6 \%{ }^{240} \mathrm{Pu}$ by mass. As expected, we see a strong flux dependence in the ratios of concentrations of products arising from ${ }^{241} \mathrm{Am}$ reactions to those arising from ${ }^{241} \mathrm{Pu}$ reactions. The value of ${ }^{244} \mathrm{Cm} /{ }^{243} \mathrm{Am}$ is roughly flux-independent, because both products arise primarily through multiple neutron capture by ${ }^{241} \mathrm{Pu}$.

The half-life of ${ }^{242} \mathrm{Cm}$ is only 163 days. If the concentrations of ${ }^{242 \mathrm{~m}} \mathrm{Am},{ }^{243} \mathrm{Am},{ }^{242} \mathrm{Cm}$, and ${ }^{244} \mathrm{Cm}$ in a plutonium sample can be measured, and if the reactor type and total burn-up are known (e.g. from the $\mathrm{Pu}$ isotopes) so that the equivalent of figure 2 can be constructed for that particular sample, then ${ }^{242 \mathrm{~m}} \mathrm{Am} /{ }^{243} \mathrm{Am}$ can be used to determine the reactor power and define the value of ${ }^{244} \mathrm{Cm} /{ }^{242} \mathrm{Cm}$ at the time of discharge of the fuel. The difference between $\left({ }^{244} \mathrm{Cm} /{ }^{242} \mathrm{Cm}\right)_{\text {discharge }}$ and $\left({ }^{244} \mathrm{Cm} /{ }^{242} \mathrm{Cm}\right)_{\text {observed }}$ is due to the radioactive decay of the curium isotopes, and defines the amount of time that has elapsed between reactor discharge and measurement.

\section{Progeny Radionuclides}

The alpha and beta decays of the plutonium isotopes in a purified sample result in the build-up of heavy-element daughter activities. When the half-lives of these daughters are short compared to the age of the sample (e.g. the 6.7 -day ${ }^{237} \mathrm{U}$ daughter of the ${ }^{241} \mathrm{Pu}$ alpha-decay branch), then a quasi-equilibrium is established wherein the daughter decays away as quickly as it is produced, resulting in a steady-state amount of the daughter activity approximately equal to the activity of the parent. When the daughter half-lives are long compared to the age of the sample (e.g. the $433-$ year ${ }^{241} \mathrm{Am}$ daughter of the ${ }^{241} \mathrm{Pu}$ beta-decay branch), then the concentration of the daughter continues to increase with time. In both cases, the decay production of radioactive daughters has the consequence of causing the ingrowth of grand-daughter nuclides; the progeny nuclides of the plutonium isotopes form genetically-linked "decay chains" all the way from the parent activities to the stable multi-great-grand-daughter bismuth and lead isotopes..

Let's assume that there exists a "separation time" at which all the progeny nuclides have been removed from a sample of plutonium. From this moment forwards, progeny species grow into the sample. At some later time, the determination of the relative concentrations of any two long-lived (non-equilibrium) members of a single decay chain, along with the half-lives of all the intervening species, can be used to calculate the time that has elapsed since separation, which is defined as the age of the sample. For instance: ${ }^{238} \mathrm{Pu}$ decays with an 88 -year half-life to ${ }^{234} \mathrm{U}$, which in turn decays with a $2.45 \times 10^{5}$-year half-life to $7.54 \times 10^{4}-$ year ${ }^{230} \mathrm{Th}$, which decays to 1600 -year ${ }^{226} \mathrm{Ra}$, and so forth. If alI the progeny species were removed at some time in the past, the ratios 
of the concentrations of each pair of nuclides mentioned can be used to calculate six values of the age, all of which should be consistent with one another. However, if only ${ }^{234} \mathrm{U}$ and ${ }^{226} \mathrm{Ra}$ were completely removed at the separation time, leaving some ${ }^{230} \mathrm{Th}$ with the plutonium, then only the relative amounts of ${ }^{238} \mathrm{Pu}$ and ${ }^{234} \mathrm{U}$ could be used to calculate an accurate age. Comparison of ${ }^{230} \mathrm{Th}$ with either of these nuclides would result in an age that was too old, since more ${ }^{230} \mathrm{Th}$ is present in the sample than could have grown in since separation; decay of excess ${ }^{230} \mathrm{Th}$ into subsequent members of the decay chain would result in too much ${ }^{226} \mathrm{Ra}$, also affecting its value as an age indicator, even though it was completely removed at the separation time.

Table 4 shows the amounts of several heavy-element progeny nuclides that would grow into a 1 -gram sample of nominally weaponsgrade plutonium in one year, assuming a complete chemical. separation of the starting material. Several of these activities are also potential chemical-signature species. If we compare the concentrations of these nuclides with the amounts listed in Table 3 , we can see how ingrowth from radioactive decay limits the use of these activities as the characteristic contaminants of a given chemical process.

${ }^{240} \mathrm{Pu}$ decays almost completely by alpha emission; however, one in every $2 \times 10^{7}$ decays is by spontaneous fission. In spontaneous fission, the atom subdivides into two roughly equal parts, with the yield being distributed over products covering a wide range of atomic numbers and masses, similar to the yield distribution arising in the neutron-induced fission of ${ }^{235} \mathrm{U}$ or ${ }^{239} \mathrm{Pu}$. While the fraction of the atoms in a plutonium sample that undergo spontaneous-fission decay doesn't sound like much, it is the neutrons that accompany spontaneous fission that limit the concentration of ${ }^{240} \mathrm{Pu}$ in materials to be used in weapons. 1 gram of weapons-grade plutonium containing $68{ }^{240} \mathrm{Pu}$ by mass undergoes 1480 spontaneous fission decays every minute.

Table 4. Amounts of selected heavy-element progeny nuclides in a sample of 1 gram of plutonium containing $6 \%{ }^{240} \mathrm{Pu}$ by weight, after one year of ingrowth.

$\frac{\text { nuclide }}{{ }^{230} \mathrm{Th}}$
${ }^{231} \mathrm{~Pa}$
${ }^{233} \mathrm{U}$
${ }^{234} \mathrm{U}$
${ }^{235} \mathrm{U}$
${ }^{236} \mathrm{U}$
${ }^{238} \mathrm{U}$
${ }^{237} \mathrm{~Np}$
${ }^{241} \mathrm{Am}$

\begin{tabular}{c} 
half-1ife (yr) \\
\hline $7.54 \times 10^{4}$ \\
$3.28 \times 10^{4}$ \\
$1.59 \times 10^{5}$ \\
$2.45 \times 10^{5}$ \\
$7.04 \times 10^{8}$ \\
$2.34 \times 10^{7}$ \\
$4.47 \times 10^{9}$ \\
$2.14 \times 10^{6}$ \\
432.6
\end{tabular}

mass $(n q)$
0.0013
0.000013
0.000056
915.
26300
6250.
0.42
350.
427000
activity (dpm)
0.058
0.0013
0.0012 26300 . 12700 .

126.

897.

0.00032

547.

$3.25 \times 10^{9}$ 
Table 5 shows the amounts of several fission products that would grow into a 1 -gram sample of nominally weapons-grade plutonium in one year, from the spontaneous fission of ${ }^{240} \mathrm{Pu}$ ( 68 by mass). The ingrowth of ${ }^{236} \mathrm{U}$ in the same sample from the alpha decay of ${ }^{240} \mathrm{Pu}$ is shown for comparison. The relative magnitudes of the spontaneous-fission and alpha-decay branches, coupled with the distribution of the fission-product yield over a large number of nuclides, favors the formation of ${ }^{236} \mathrm{U}$ over any given fission product by a minimum of almost nine orders of magnitude; however, since the decay rate of a radionuclide is inversely proportional to its half-life, the activities of many of the shorter-lived fission products are comparable to that of long-lived ${ }^{236} \mathrm{U}$.

Comparison of the activities of the contaminant nuclides given in Table 1 with the amounts given for the same nuclides in Table 5 shows that the ingrowth of long-lived or stable fission products is of negligible concern in the determination of potential chemical-process signatures. For fission products with half-lives of more than 100 years, the amounts that grow into the sample in one year are not even measurable through their radioactivities. Even the observable ingrown concentrations of the shorter-lived Table-1 species (e.g. ${ }^{90} \mathrm{Sr},{ }^{137} \mathrm{Cs}$ ) are approximately twelve orders of magnitude less than the original content of the reactor fuel, providing the opportunity of observing excess activities from very efficient reprocessing procedures.

An asterisk between the fourth and fifth columns of Table 5 indicates short-lived nuclides that are essentially in equilibrium with ${ }^{240} \mathrm{Pu}$ after one-or-more years of ingrowth. This means that their activities are approximately equal to the spontaneousfission activity of ${ }^{240} \mathrm{Pu}$ ( 1480 decays per minute) times the probability that the fission will result in that product (the cumulative fission yield, column 2). These species are not useful as process contaminant indicators, even though they are also produced in high yields in the reactor irradiation. They decay away during the cooling period following reactor discharge and, even if the reprocessing chemistry is inefficient at removing them from the product plutonium, continue to decay after the final chemical separation step until only the amounts that are continuously replenished by the decay of ${ }^{240} \mathrm{Pu}$ remain.

The short-lived fission-product progeny (and heavy-element progeny like 6.7-day ${ }^{237} \mathrm{U}$ and 25 -hour ${ }^{231} \mathrm{Th}$ ) can be used as chemicalyield indicators for the longer-lived process-contaminant and agedeterminant species. An example: Measurement of the activity due to decays of long-lived ${ }^{129} \mathrm{I}$ in a chemical fraction separated from a gram of plutonium has to be corrected for losses in the separation procedure and sample preparation before it can be considered a signature. If the amount of ${ }^{240} \mathrm{Pu}$ in the sample is measured, then the amount of 8 -day ${ }^{131} I$ in equilibrium with the sample can be calculated. Comparison with the amount of ${ }^{131} \mathrm{I}$ in the 
final iodine fraction, corrected for decay since it was separated from the ${ }^{240} \mathrm{Pu}$ parent, gives the efficiency of recovery of iodine from the plutonium sample.

Table 5. Selected spontaneous fission products present in 1 gram of plutonium containing $68{ }^{240} \mathrm{Pu}$ after 1 year of ingrowth. Ingrowth of ${ }^{236} \mathrm{U}$ from alpha decay of ${ }^{240} \mathrm{Pu}$ in the same sample is included for. comparison.

\begin{tabular}{|c|c|c|c|c|c|c|}
\hline nuclide & cum yield (8) & half-life & & atoms & & activity \\
\hline${ }^{85} \mathrm{Kr}$ & 0.07 & $10.8 \mathrm{Y}$ & $5 . \overline{3}$ & $\times 10^{5}$ & & 0.06 \\
\hline${ }^{86} \mathrm{Kr}$ & 0.47 & stable & 3.7 & $\mathrm{x} 10^{6}$ & & \\
\hline${ }^{89} \mathrm{Sr}$ & 1.1 & $50.5 \mathrm{~d}$ & 1.7 & $\times 10^{6}$ & * & 16.2 \\
\hline${ }^{90} \mathrm{Sr}$ & 1.4 & $28.5 \mathrm{y}$ & 1.1 & $\times 10^{7}$ & & 0.5 \\
\hline${ }^{93} \mathrm{Zr}$ & 3.0 & $1.5 \times 10^{6} \mathrm{Y}$ & 2.3 & $\times 10^{7}$ & & $2 \times 10^{-5}$ \\
\hline${ }^{95} \mathrm{Zr}$ & 4.8 & $64 \mathrm{~d}$ & 9.3 & $\times 10^{6}$ & * & 70 \\
\hline${ }^{99} \mathrm{TC}$ & 6.9 & $2.1 \times 10^{5} \mathrm{y}$ & 5.4 & $\times 10^{7}$ & & $3 \times 10^{-4}$ \\
\hline${ }^{99 m} \mathrm{TC}$ & 5.9 & $6 \mathrm{hr}$ & 4.5 & $\mathrm{x} 10^{4}$ & * & 87 \\
\hline${ }^{103} \mathrm{Ru}$ & 7.9 & $39.4 d$ & 9.6 & $\times 10^{6}$ & * & 117 \\
\hline${ }^{106} \mathrm{Ru}$ & 6.2 & $368 d$ & 3.5 & $\times 10^{7}$ & & 46 \\
\hline${ }^{125} \mathrm{Sb}$ & 0.05 & $2.77 \mathrm{y}$ & 3.4 & $\times 10^{5}$ & & 0.2 \\
\hline${ }^{126} \mathrm{Sb}$ & 0.03 & $12.4 \mathrm{~d}$ & 1.1 & $\times 10^{4}$ & * & 0.4 \\
\hline${ }^{127} \mathrm{Sb}$ & 0.18 & $3.85 \mathrm{~d}$ & 2.1 & $\mathrm{x} 10^{4}$ & * & 2.6 \\
\hline${ }^{129} \mathrm{I}$ & 0.70 & $1.6 \times 10^{7} \mathrm{y}$ & 5.4 & $\times 10^{6}$ & & $4 \times 10^{-7}$ \\
\hline${ }^{131} I$ & 2.3 & $8.02 \mathrm{~d}$ & 5.7 & $\times 10^{5}$ & * & 34 \\
\hline${ }^{133} \mathrm{I}$ & 8.2 & $20.8 \mathrm{hr}$ & 2.2 & $\times 10^{5}$ & * & 122 \\
\hline${ }^{133} \mathrm{Xe}$ & 8.2 & $5.25 \mathrm{~d}$ & 1.3 & $\mathrm{x} 10^{6}$ & * & 119 \\
\hline${ }^{136} \mathrm{Xe}$ & 7.5 & stable & 5.8 & $\times 10^{7}$ & & \\
\hline${ }^{135} \mathrm{Cs}$ & 7.8 & $2.0 \times 10^{6} \mathrm{y}$ & 6.1 & $\times 10^{7}$ & & $4 \times 10^{-5}$ \\
\hline${ }^{136} \mathrm{Cs}$ & 0.08 & $13.2 \mathrm{~d}$ & 3.4 & $\times 10^{4}$ & * & 1.2 \\
\hline${ }^{137} \mathrm{Cs}$ & 7.2 & $30.2 \mathrm{y}$ & 5.5 & $\times 10^{7}$ & & 2.4 \\
\hline${ }^{141} \mathrm{Ce}$ & 5.7 & $32 \mathrm{~d}$ & 5.6 & $\mathrm{x} 10^{6}$ & * & 84 \\
\hline${ }^{144} \mathrm{Ce}$ & 4.0 & $285 d$ & 2.1 & $\mathrm{x} \cdot 10^{7}$ & & 35 \\
\hline${ }^{143} \mathrm{Nd}$ & 4.7 & stable & 3.7 & $x 10^{7}$ & & \\
\hline${ }^{144} \mathrm{Nd}$ & 4.0 & stable & 3.1 & $\times 10^{7}$ & & \\
\hline${ }^{145} \mathrm{Nd}$ & 3.3 & stable & 2.6 & $\times \quad 10^{7}$ & & \\
\hline${ }^{146} \mathrm{Nd}$ & 2.7 & stable & 2.1 & $\times \quad 10^{7}$ & & \\
\hline${ }^{147} \mathrm{Nd}$ & 2.1 & $11 \mathrm{~d}$ & 7.1 & $\times 10^{5}$ & * & 31 \\
\hline${ }^{148} \mathrm{Nd}$ & 1.6 & stable & 1.2 & $\times 10^{7}$ & & \\
\hline${ }^{150} \mathrm{Nd}$ & 0.75 & stable & 5.8 & $\times 10^{6}$ & & \\
\hline${ }^{155} \mathrm{Eu}$ & 0.08 & $4.96 \mathrm{Y}$ & 5.8 & $\times 10^{5}$ & & 0.2 \\
\hline${ }^{156} \mathrm{Eu}$ & 0.05 & $15 \mathrm{~d}$ & 2.3 & $\times 10^{4}$ & * & 0.7 \\
\hline${ }^{236} \mathrm{U}$ & & $2.3 \times 10^{7} \mathrm{y}$ & 1.6 & $\mathrm{x} 10^{16}$ & & 920 \\
\hline
\end{tabular}


Krypton and xenon are gaseous elements that are chemically inert. Table 5 contains entries for some of the isotopes of these elements that are produced in the spontaneous fission of ${ }^{240} \mathrm{Pu}$. The chemical properties of these nuclides provide an opportunity to determine a sample age more associated with metallurgy than with chemical process: Plutonium is converted to the metal from a salt at some time after the last chemical purification step. Most of the fission products are chemically reactive species; even fairly volatile elements will be retained to some extent by the melt, which provides no additional chemical separation from many species. However, the inert gases will be completely flushed out of the melt by the byproduct process gases. The subsequent ingrowth of xenon and krypton defines the casting time of a metal sample. Since the isotopic distributions of fission-product $\mathrm{Kr}$ and $\mathrm{Xe}$ are different from those of the naturally-occuring gases, a minor admixture of the natural isotopes can be deconvoluted (see the discussion of the Nd isotopes, above). However, the measurement becomes impossible in the presence of a significant amount of air, which must be rigorously excluded in the early steps of the analytical procedure; $1 \mathrm{~cm}^{3}$ of air at STP contains $3 \times 10^{13}$ atoms of $\mathrm{Kr}$ and $2 \times 10^{12}$ atoms of $\mathrm{Xe}$, introducing a background that would make it impossible to observe the radiogenic species.

III. Radiochemical Analysis.

From the discussion in the previous section, it should be clear that the nuclides that could be present in a sample of plutonium metal provide the clues by which the origin of the material can be determined. This is summarized in Table 6, where chemical elements containing the nuclides of interest are listed along with the purpose for isolating each element, the chemical yield indicator, and the method(s) by which the isotopes are measured. The vast differences in the chemical properties of the listed elements, which make the measurement of contaminant species so interesting, also contribute to making the radiochemical analysis of a plutonium sample a challenging undertaking. Furthermore, each chemical fraction must be isolated in a time that is compatible with the half-lives of the chemical-yield indicators; the plutonium reprocessors are under no such time constraint.

We obtained a 1-gram sample of weapons-grade plutonium metal and analyzed it according to the radiochemical procedure given in Appendix A. This procedure was designed to enable a single chemist to produce all of the chemical fractions listed in Table 6 in ten calendar days. Clearly this is not an optimal situation, as will be discussed below. An abbreviated description of the procedure, including some of the reasoning behind many of the steps and observations made during the analysis of the experimental sample, follows: 
Table 6. Chemical fractions containing signature nuclides, to be isolated from a 1 -gram sample of weapons-grade plutonium.

\begin{tabular}{|c|c|c|c|c|}
\hline Fraction & $\begin{array}{l}\text { Nuclide (s) } \\
\text { of interest }\end{array}$ & Purpose* & $\begin{array}{l}\text { Chem. yield } \\
\text { indicator }\end{array}$ & $\underline{\text { method }}^{\mathfrak{a}}$ \\
\hline$\overline{\mathrm{Kr}(\mathrm{Xe})}$ & ${ }^{85} \mathrm{Kr}$ & $\mathrm{M}$ & none & $\overline{\mathrm{ms}}$ \\
\hline $\mathrm{Sr}$ & ${ }^{90} \mathrm{Sr}$ & $\mathrm{C}$ & ${ }^{89} \mathrm{Sr}$ & $\mathrm{b}$ \\
\hline $\mathrm{Zr}$ & ${ }^{93} \mathrm{Zr}$ & C & ${ }^{95} \mathrm{Zr}$ & $b, g$ \\
\hline $\mathrm{TC}$ & ${ }^{99} \mathrm{TC}$ & C & ${ }^{99 \mathrm{~m}} \mathrm{TC}$ & $b, g$ \\
\hline $\mathrm{Ru}$ & ${ }^{106} \mathrm{Ru}$ & C & ${ }^{103} \mathrm{Ru}$ & $g$ \\
\hline $\mathrm{Sb}$ & ${ }^{125} \mathrm{Sb}$ & C & $126,127 \mathrm{Sb}$ & $\mathrm{g}$ \\
\hline$I$ & ${ }^{129} \mathrm{I}$ & $\mathrm{C}$ & ${ }^{131,133} \mathrm{I}$ & $b, g$ \\
\hline $\mathrm{Cs}$ & ${ }^{135,137} \mathrm{Cs}$ & $C, D$ & ${ }^{136} \mathrm{Cs}$ & $b, g$ \\
\hline $\mathrm{Ce}$ & ${ }^{144} \mathrm{Ce}$ & $\mathrm{C}$ & ${ }^{141} \mathrm{Ce}$ & $g$ \\
\hline $\mathrm{Nd}$ & ${ }^{\mathrm{mix}} \mathrm{Nd}$ & C & ${ }^{147} \mathrm{Nd}$ & $\mathrm{ms}$ \\
\hline $\mathrm{Eu}$ & ${ }^{155} \mathrm{Eu}$ & C & ${ }^{156} \mathrm{Eu}$ & g \\
\hline Th & ${ }^{m i x} \mathrm{Th}$ & $C, D$ & ${ }^{231} \mathrm{Th}$ & $\mathrm{a}, \mathrm{g}, 2 \mathrm{p}$ \\
\hline $\mathrm{Pa}$ & ${ }^{231} \mathrm{~Pa}$ & $C, D$ & ${ }^{233} \mathrm{~Pa}$ & $a, g, 2 p$ \\
\hline $\mathrm{U}$ & ${ }^{\operatorname{mix}} U$ & $C, D, I$ & ${ }^{237} \mathrm{U}$ & $a, g, m s, 2 p$ \\
\hline $\mathrm{Np}$ & ${ }^{237} \mathrm{~Np}$ & $\mathrm{C}, \mathrm{D}$ & ${ }^{239} \mathrm{~Np}^{*}$ & $a, g, 2 p$ \\
\hline $\mathrm{Pu}$ & ${ }^{\operatorname{mix}} \mathrm{Pu}$ & $\mathrm{D}, \mathrm{I}, \mathrm{R}$ & none & $\mathrm{a}, \mathrm{Ig}, \mathrm{milk}, \mathrm{ms}, \mathrm{ndg}$ \\
\hline Am & ${ }^{\mathrm{mix}} \mathrm{Am}$ & $C, D, F$ & ${ }^{241} \mathrm{Am},{ }^{243} \mathrm{Am}^{*}$ & $\mathrm{a}, \mathrm{g}, \mathrm{milk}$, ms, ndg \\
\hline $\mathrm{Cm}$ & $242,244 \mathrm{Cm}$ & $C, F, R$ & ${ }^{246} \mathrm{Cm}^{*}$ & a \\
\hline
\end{tabular}

* Purpose codes:

$\mathrm{C}=$ chemical-process signature

$\mathrm{D}$ = date of chemical separation

${ }^{\mathrm{a}}$ Method codes:

$F=$ reactor flux parameter

$I=$ reactor type and integrated flux

$M=$ metal casting time

$\mathrm{R}=$ reactor discharge time

* non-radiogenic tracer, aliquot added
$a=$ alpha spectroscopy
$\mathrm{b}=$ beta counting
$\mathrm{g}=$ gamma spectroscopy
Ig= low geometry alpha $\mathrm{milk}=$ radiochemical $\mathrm{milk}$ $\mathrm{ms}=$ mass spectrometry $\mathrm{ndg}=$ non-destructive gamma $2 \mathrm{p}=$ gross alpha count

The sample was received and the packing materials were removed down to the last uncontaminated container. prior to the radiochemical analysis we counted the sample for gamma rays with a germanium detector. The 90-minute pulse-height spectrum was analyzed with the MGA code, which uses pairs of gamma rays with similar energies to measure the plutonium isotopics and the relative ${ }^{241} \mathrm{Am}$ content of a sample.

After the non-destructive gamma-ray analysis, the container was passed into a glove box and opened, and the plutonium sample was transfered to a reaction vessel containing $\mathrm{Ru}, \mathrm{I}$, and ${ }^{142} \mathrm{Nd}$ carriers and the necessary heavy-element radiotracers. The transfer was as close to quantitative as possible without using 
solvents; some residual grit was transfered using a fine camelhair brush and a pair of forceps. After the transfer, the empty container, the brush, and the forceps were passed out of the glove box and counted for gamma rays; they were found to be contaminated with less than $0.001 \%$ of the sample, and were discarded.

The calibrated ${ }^{142} \mathrm{Nd}$ carrier provides for a determination of the absolute concentration of neodymium in the plutonium material and ensures that there is sufficient mass in the Nd fraction for a mass-spectrometric analysis. This carrier was calibrated (via mass spectrometry) against a standard ${ }^{\text {nat }} \mathrm{Nd}$ solution, obtained by dissolving a gravimetric standard of $\mathrm{Nd}_{2} \mathrm{O}_{3}$ in $\mathrm{HCl}$ and diluting to a known volume. Since the carriex complicates the deconvolution of the radiogenic and natural components of the isotopic distribution of the neodymium in the plutonium sample, it should be of high isotopic purity. Our carrier aliquot contained $120 \mathrm{ng}$ of $988^{142} \mathrm{Nd}$.

Except for curium, the plutonium sample is self-tracing. Short-lived progeny nuclides in equilibrium with the plutonium isotopes or heavy-element contaminants act as radiotracers for most fractions; plutonium and americium do not need to be traced, since their activities can be determined through the non-destructive gamma-ray analysis and low-geometry alpha counting. However, there may not be a sufficient amount of contaminant ${ }^{243} \mathrm{Am}$ in the sample to permit the observation of the $2.4-$ day ${ }^{239} \mathrm{~Np}$ daughter, which traces the neptunium fraction. We added a small aliquot of ${ }^{243} \mathrm{Am}$ tracer to the sample to ensure adequate tracing of neptunium; at a later time we determined the relative amounts of ${ }^{241} \mathrm{Am}$ and ${ }^{243} \mathrm{Am}$ in the americium fraction (through a radiochemical milking) and subtracted the tracer component to obtain the ${ }^{243} \mathrm{Am}$ activity in the original sample. We added tracer aliquots of $1.8 \times 10^{4} \mathrm{dpm}{ }^{243} \mathrm{Am}$ and $1.7 \times 10^{3}$ dpm ${ }^{246} \mathrm{Cm}$ (mass separated), which yielded good results.

The plutonium sample was dissolved in an apparatus that provided for the collection of volatile fractions, including the noble gases. The reaction vessel containing the sample was placed beneath a reservoir for the addition of reagents, and was connected to a trap containing $\mathrm{NaOH}$, and thence to a liquid-nitrogen trap containing activated carbon (baked-out before use). The apparatus and the reagents were thoroughly purged with helium (precleaned by passing it through a separate liquid-nitrogen trap) before the sample was dissolved with the dropwise addition of HCl from the reservoir. As the sample dissolved, the helium gas carried noblegas fission products out of the reaction vessel, through the $\mathrm{NaOH}$ trap, and into the liquid-nitrogen trap, where $\mathrm{Xe}$ and $\mathrm{Kr}$ were adsorbed on the carbon. When dissolution was complete, the trap was valved off and bypassed by the helium. Because of the noble gas content of ambient atmosphere (see above), it was important that air be rigorously excluded from the apparatus during this step of the procedure; we were not completely successful in this (see Section IV). 
Under helium flow, the reaction vessel was heated until the sample was almost dry, then $\mathrm{HNO}_{3}$ was added to the system, the heat was increased, and $\mathrm{Ru}, \mathrm{I}$, and (maybe) Tc were distilled from the reaction vessel into the $\mathrm{NaOH}$ trap. The entire dissolution system had to be kept warm so that the volatile products wouldn't condense on the apparatus before reaching the trap. The ${ }^{99 \mathrm{~m}} \mathrm{Tc}$ and ${ }^{133} \mathrm{I}$ chemical-yield indicators are short-lived (half-lives of 6 hours and 21 hours, respectively), so these fractions had to be processed immediately, as outlined in Appendix A. Subsequent chemical steps are fairly straight-forward; we had substantial yield losses in the distillation step, caused by an inadequate temperature profile between the reaction vessel and the trap, an insufficient distillation interval, or both.

At this point the sample was mostly in solution, but some oxides of plutonium remained. A couple of drops of fluoroboric acid were necessary to complete the dissolution. The action of $\mathrm{BF}_{4}{ }^{-}$ ions on $\mathrm{PuO}_{2}$ is semicatalytic, and proceeds more quickly with heat. This step is recommended even if no visible deposit is present upon addition of $\mathrm{HCl}$, since $\left(\mathrm{PuO}_{2}\right)_{\mathbf{x}}$ can be colloidal.

The sample was dissolved in $\mathrm{HCl}$ (with $\mathrm{BF}_{4}{ }^{-}$) and quantitatively transfered to a $25-\mathrm{ml}$ volumetric flask. This required a large number of small-volume washes of the entire dissolving apparatus from the reagent reservoir entrance to the end of the distillation column where it entered the trap. The acid concentration had to stay fairly high to avoid loss of protactinium and polymerization of plutonium. After the transfer was complete, the dissolving apparatus was passed out of the glove box and counted for gamma rays; only 0.0098 of the plutonium and 0.0048 of the americium in the original sample remained on the glassware. During the transfer of the activity, the volumetric flask had to be heated gently to complete the dissolution process and reduce gas evolution in the volumetric steps; subsequent volumetric measurements had to be performed at the temperature at which the glassware was standardized.

After the solution in the flask was cooled, made up to the mark, and thoroughly mixed, a volumetric 20-ul aliquot was taken and added to a second $25-\mathrm{ml}$ volumetric flask. This primary dilution sample was made up to the mark with $2 \mathrm{M} \mathrm{HCl}$ and mixed, and quantitative 20-ul aliquots were stippled and dried onto platinum counting disks, which were then heated to a low red in a Bunsenburner flame. The steps in this paragraph must be performed with care; the results of the low-geometry alpha counts and alpha spectroscopy of these samples are what give the absolute americium and plutonium contents of the sample. Most of the primary dilution is unused, and would be of an appropriate concentration for analysis by ICP mass spectrometry (see section VI).

The original sample solution was transfered to the top of a large anion-exchange column (Saran-wool plug), and the first group separation was performed. The eluant from the load solution and 
several $\mathrm{HCl}$ washes of the sample container were combined to form fraction "X", containing $\mathrm{Cs}, \mathrm{Sr}, \mathrm{Ce}, \mathrm{Nd}, \mathrm{Eu}, \mathrm{Th}, \mathrm{Am}$, and $\mathrm{Cm}$, among others. Americium is the source of most of the gamma-ray dose in the original sample; fraction " $\mathrm{X}$ " must be handled with some caution from the standpoint of radiation protection. After fraction " $X$ " was collected, the column was converted to $8 \mathrm{M} \mathrm{HNO}$, and the eluant comprised sample "Y", containing $\mathrm{Zr}, \mathrm{Sb}, \mathrm{Pa}, \mathrm{U}$, and $\mathrm{Np}$, among others. The values of $\mathrm{K}_{\mathrm{d}}$ for these elements in nitric acid are not negligible, and a large volume of eluant must be collected to recover them. We suffered significant yield losses of all the fraction "Y" nuclides because we ran out of time on the evening of the second day of the chemistry and cut the elution short. The collection times for fractions "X" and " $Y$ " must be noted during the chemistry; they define the separation times for the short-lived chemical-yield indicators (fission products, ${ }^{231} \mathrm{Th},{ }^{237} \mathrm{U}$, and ${ }^{239} \mathrm{~Np}$ ); ${ }^{233} \mathrm{~Pa}$ can be considered to remain in equilibrium with ${ }^{237} \mathrm{~Np}$ after this step, since they have not yet been separated from one another. After the elution of fraction "Y", plutonium was eluted with dilute HCl. Some conc HCl was added to the eluant to help prevent the polymerization of the plutonium.

$T h$ was removed from fraction " $X$ " with a nitric acid anionexchange column; the half-life of ${ }^{231} \mathrm{Th}$ is only 25 hours, so this fraction had to be processed immediately, as described in Appendix $A$. Cs and Sr were then recovered from fraction " $X$ " with a cationexchange procedure. The subsequent production of $\mathrm{Cs}$ and $\mathrm{Sr}$ fractions was straightforward, though care had to be taken to remove ${ }^{140} \mathrm{Ba}$ from the $\mathrm{Sr}$ fraction. Through the early steps of $\mathrm{Sr}$ recovery, the fraction contained a substantial amount of white precipitate of low solubility. This could only be $\mathrm{Ca}^{2+}$ or $\mathrm{Mg}^{2+}$ salts, residues from the metallurgical or pyrochemical processes; in future experiments it would be interesting to characterize this residue. The separation of the remainder of fraction " $\mathrm{X}$ " into actinide and rare-earth fractions was accomplished with a saturated-HCl cation-exchange column.

Fraction " $\mathrm{Y}$ " was divided into $\mathrm{Zr} / \mathrm{Pa} / \mathrm{Np}$ and $\mathrm{U} / \mathrm{Sb}$ fractions with an anion-exchange procedure; it is important that the column be housed in plastic rather than in glass to reduce the loss of $\mathrm{Pa}$ in this fluoride-free step. The $\mathrm{Zr} / \mathrm{Pa} / \mathrm{Np}$ fraction was subdivided into its three component elements with another anion-exchange procedure using low-fluoride HCl solutions. Since the half-life of ${ }^{239} \mathrm{~Np}$ is only 2.4 days, the Np fraction was processed first, as described in Appendix $\mathrm{A}$. The $\mathrm{U} / \mathrm{Sb}$ fraction was separated with a solvent extraction. The 3.8-day half-life of ${ }^{127} \mathrm{Sb}$ and its 10 equilibrium concentration control the order in which the fractions are processed. Gallium (an alloying element with weapons implications) follows $\mathrm{Sb}$ through much of the procedure and a separate Ga fraction could be taken without too much additional effort. Most of the plutonium that breaks-through the first anion column in the initial group separation ends up in the uranium fraction, which must be 
handled with caution and scrupulously decontaminated.

The trivalent actinide fraction (recovered from fraction " $\mathrm{X}$ ") was separated into $\mathrm{Am}$ and $\mathrm{Cm}$ fractions on an anion-exchange column using a methanolic- $\mathrm{HNO}_{3}$ eluant. The procedure had to be repeated several times on the $\mathrm{Cm}$ fraction to reduce the ${ }^{241} \mathrm{Am}\left(\mathrm{E}_{\mathrm{a}}=5.486 \mathrm{MeV}\right.$ ) contaminant to the point where the ${ }^{246} \mathrm{Cm}\left(\mathrm{E}_{\mathrm{a}}=5.386 \mathrm{MeV}\right)$ tracer activity could be resolved unequivocably. The time that the main Am fraction was eluted from the column was recorded; this is the reference time for the ingrowth of $\mathrm{Np}$ in the milking procedure (see below). Small aliquots of the Am fraction were taken for analysis.

The rare-earth sample (also recovered from fraction "X") was divided into three fractions: $\mathrm{Ce}, \mathrm{Nd}$, and $\mathrm{Eu}$. This was accomplished by differential elution of the elements from a cationexchange column with solutions of alpha-hydroxyisobutyric acid. The elution positions are very dependent on the eluant concentrations, as seen in Table 7 . The rare-earth activities were too weak to allow efficient on-line monitoring of column performance; the elution position of the easily-observable ${ }^{241} \mathrm{Am}$ contaminant provided the benchmark by which the fractions could be separated.

The plutonium fraction was purified of other actinides with a thenoyltrifluoroacetone (TTA/xylene) solvent extraction. The phase separation time of the last extraction was recorded as the reference time for the ingrowth of $U$ in the milking procedure (see below). Small aliquots of the Pu fraction were taken for analysis.

After about three weeks, the $\mathrm{Am}$ and $\mathrm{Pu}$ fractions were milked of their daughters. This is the best technique for measuring the ${ }^{243} \mathrm{Am}$ and ${ }^{236} \mathrm{Pu}$ contents of the original sample. In twenty days, the decay of the americium isotopes had grown in $60 \mathrm{dpm}$ (alpha) of ${ }^{237} \mathrm{~Np}$ and $2.2 \times 10^{4} \mathrm{dpm}$ (beta) of ${ }^{239} \mathrm{~Np}$ (equilibrium). The relative decay rates of these nuclides in a $\mathrm{Np}$ sample separated from the Am fraction, corrected for decay of $2.4-\mathrm{day}{ }^{239} \mathrm{~Np}$ since separation, define the concentration of ${ }^{243} \mathrm{Am}$ relative to ${ }^{241} \mathrm{Am}$. Since the amount of ${ }^{241} \mathrm{Am}$ in the original sample was known from other measurements, total ${ }^{243} \mathrm{Am}$ in the reaction vessel could be calculated; subtraction of the amount of added ${ }^{243} \mathrm{Am}$ tracer gave the ${ }^{243} \mathrm{Am}$ concentration in the $\mathrm{Pu}$ sample. Separation of $\mathrm{Np}$ from the Am fraction was accomplished with an anion-exchange procedure.

In twenty days, the decays of the plutonium isotopes in the $\mathrm{Pu}$ fraction had grown in $70 \mathrm{dpm}$ (alpha) of ${ }^{234} \mathrm{U}, 1.0 \times 10^{6} \mathrm{dpm}$ (beta) of ${ }^{237} \mathrm{U}$ (near-equilibrium), $4 \times 10^{6} \mathrm{dpm}$ (alpha) of ${ }^{241} \mathrm{Am}$, and much smaller amounts of the other uranium isotopes. A uranium fraction was milked from the main $\mathrm{Pu}$ fraction with a TTA/Xylene solvent extraction, followed by an anion-exchange procedure. This final uranium fraction contained the equivalent of $1.7 \mathrm{dpm}$ of ${ }^{232} \mathrm{U}$, which could only arise from the decay of ${ }^{236} \mathrm{Pu}$. The concentration of ${ }^{232} \mathrm{U}$ relative to that of ${ }^{234} \mathrm{U}$, and the half-lives of the plutonium parents, could be used to calculate the concentration of ${ }^{236} \mathrm{Pu}$ relative to that of ${ }^{238} \mathrm{Pu}$ in the original sample. 
Table 7. Elution positions (in free-column volumes) of selected rare-earth elements and americium, eluted from an $80^{\circ} \mathrm{C}$ Dowex-50 cation-exchange column with alpha-hydroxyisobutyric acid, as a function of concentration.

\begin{tabular}{|c|c|c|c|c|c|}
\hline Element & \multicolumn{5}{|c|}{ Concentration (molar) } \\
\hline & 0.05 & 0.15 & 0.23 & 0.32 & 0.98 \\
\hline $\mathrm{Eu}$ & $>\overline{1000}$ & 30 & 5.4 & $\overline{1.4}$ & - \\
\hline Am & " & 120 & 20 & 5.2 & - \\
\hline $\mathrm{Nd}$ & $"$ & 170 & 32 & 8 & - \\
\hline $\mathrm{Ce}$ & $"$ & $\sim 400$ & 70 & 18 & -0.2 \\
\hline $\mathrm{La}$ & " & $\sim 1000$ & 150 & 37 & 0.4 \\
\hline
\end{tabular}

Alpha spectroscopic measurements were performed either with surface-barrier detectors (samples mounted in vacuum) or with Frisch-grid gas-proportional detectors (samples mounted in argon counting gas). Data were accumulated between 2.5 and $9.5 \mathrm{MeV}$ in 1000-channel spectra. Long-term background spectra were scaled to the appropriate counting intervals and subtracted from each spectrum prior to data reduction. Frisch-grid counters were used to count low-level ( $\leq 100 \mathrm{dpm}$ ) samples because of their high counting efficiencies. High-level (up to $10^{6} \mathrm{dpm}$ ) samples and samples that emitted $R n$ (e.g., the Th fraction) were counted at lower counting efficiencies (backed-off) with surface-barrier detectors.

Absolute alpha-decay rates of samples containing more than $10^{4}$ dpm were measured with a low-geometry counter. Samples were mounted in vacuum with the deposit of activity a known distance from a collimator with a well-defined diameter. The geometrical efficiency $(0.08191 \%)$ was used to correct the gross count rate of decays depositing more than $2 \mathrm{MeV}$ in the active area of a surfacebarrier detector, less the background rate of 6 per minute. Absolute alpha-decay rates of lower-level samples were determined with "two-pi" windowless gas-filled counters, with a nominal efficiency of $52 \%$ for the decay of ${ }^{241} \mathrm{Am}$ deposited on Pt; this efficiency was checked periodically with a calibration standard. Background count rates were on the order of 0.6 per minute.

Beta-decay rates were measured with thin-window methanefilled counters, operated in the plateau region. Counting efficiencies as a function of beta-endpoint energy were determined with a set of calibration standards, mounted in the same configuration as the experimental samples.

Gamma spectroscopic measurements were performed with largevolume germanium detectors, except for that used in the nondestructive analysis of the original sample. Data were accumulated between 50 and $2000 \mathrm{keV}$ in $4000-$ channel spectra. Efficiencies and 
peak shapes were determined with standard sources, and were used by the GAMANAL code to calculate absolute photons per minute emitted by the experimental samples.

Activities measured by radiation counting were converted into atoms in the original sample using the chemical-yield indicators and the latest spectroscopic information available in Nuclear Data sheets.

The isotopics of the $\mathrm{Kr}(\mathrm{Xe})$ sample were determined with noblegas mass spectrometry. The noble gases were pumped from the activated-carbon trap at room temperature, and were purified before being introduced into the source of the mass spectrometer. Blanks were run to ensure a minimal contribution from instrument background. The isotopics of the $\mathrm{U}, \mathrm{Pu}, \mathrm{Am}$, and Nd fractions were measured with thermal-ionization mass spectrometry. Relative intensities of singly-charged actinide ions were measured; neodymium was measured through relative $\mathrm{NdO}^{+}$intensities.

IV. Results.

The $\mathrm{Kr}(\mathrm{Xe})$ sample was contaminated with natural krypton, equivalent to the amount to be found in about $1 \mathrm{~cm}^{3}$ of air at STP. The stable isotopes in the sample made it impossible to determine the relative concentration of fission-product ${ }^{85} \mathrm{Kr}$ (not a natural isotope) with mass spectrometry because of the necessary dynamic range of the measurement. A reduction in the incorporation of air by as little as two orders of magnitude would make the measurement possible; this should not be difficult to accomplish.

Table 8 lists the chemical yields we achieved for the fissionproduct fractions. The procedure was intended to result in yields of more than $30 \%$ in each of these fractions. In the previous section we discussed the yield losses in the distillation step and in the collection of fraction " $Y$ " in the initial anion-exchange group separation. The yield loss of cerium relative to the other rare earths is probably caused by the oxidation of $\mathrm{Ce}^{3+}$ to $\mathrm{Ce}^{4+}$ (potential $=-1.6 \mathrm{~V}$ in acid solution) prior to the group separation. The addition of $\mathrm{H}_{2} \mathrm{O}_{2}$ during the distillation of the volatile fractions should have prevented this from happening, and we have no explanation for the result. Yield loss in the Sr fraction was due to an error in following the procedure, caused by fatigue. 
Table 8. Chemical yields of fission products in chemical fractions, and contaminant levels.

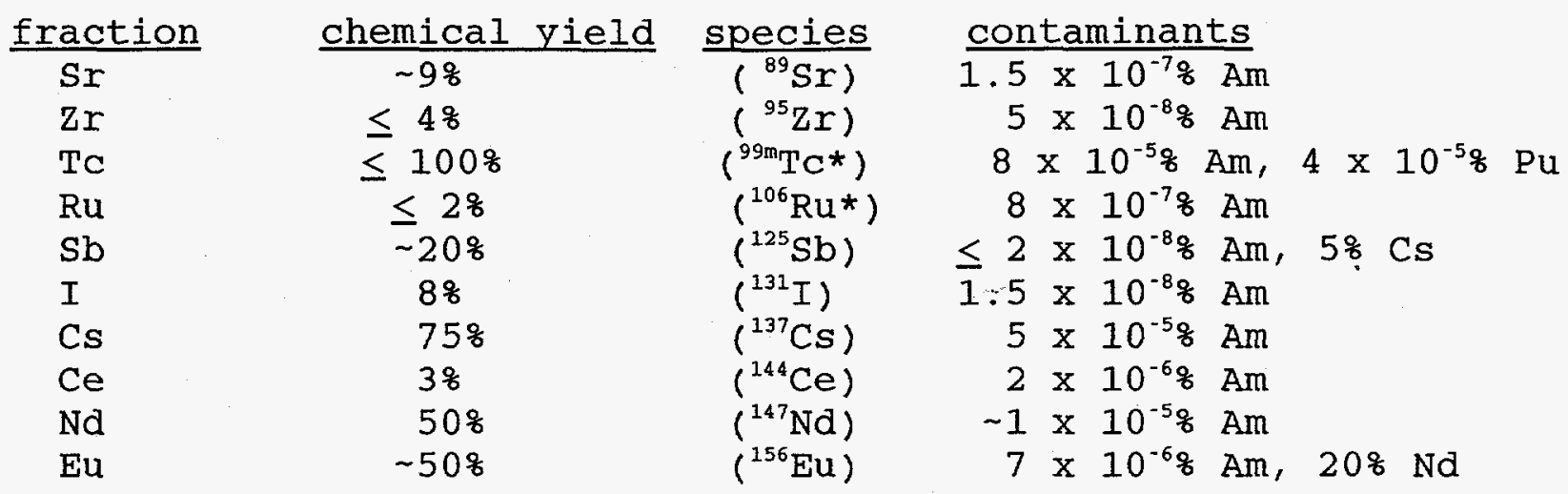

*Activity not observed.

Table 8 also lists observable contaminant levels in the final fractions. These amounts are of negligible importance except in the cases of $\mathrm{Sr}, \mathrm{Zr}, \mathrm{Tc}$, and $\mathrm{I}$, where the activity of the longlived contaminant-indicating nuclide has to be measured with beta counting. Contaminant levels of less than $10^{-5} \%$ could not be measured in chemical test runs, in which we used less than $10^{6} \mathrm{dpm}$ of the heavy element nuclides. The experimental sample contained $1.5 \mathrm{mCi}$ of ${ }^{241} \mathrm{Am}$ at the separation time, so a seemingly trivial contaminant yield of $10^{-7} \%$ translates to more than $3 \mathrm{dpm}$ (alpha) of ${ }^{241} \mathrm{Am}$ in the final sample. Secondary electrons emitted with the decay of ${ }^{241} \mathrm{Am}$ raise the effective background rate in the beta counter, particularly at low energies.

The combination of low or indeterminate chemical yields for the fission products and the contamination of most of the fractions with ${ }^{241} \mathrm{Am}$ made it impossible to establish meaningful limits on many of the potential contaminant indicators. Table 9 lists the observed concentrations (and limits) of four contaminant species in our experimental sample. The "reprocessing decontamination factor" is that fraction of the original fuel composition associated with the plutonium in the sample (from Table 5) that was not successfully separated from the plutonium. The amounts of ${ }^{137} \mathrm{Cs}$ and ${ }^{155} \mathrm{Eu}$ observed in the sample are consistent with radiogenic production from the spontaneous fission of ${ }^{240} \mathrm{Pu}$, accumulated for $(3.3 \pm 0.9)$ years. The reprocessing chemistry was successful in removing all four of these contaminant-indicating species down to our detection limits. 
Table 9. Signature nuclides of incomplete fuel reprocessing in plutonium recovery. Contaminant activities present in $850-\mathrm{mg}$ sample BG-522-3.

$\begin{array}{lc}\text { Nuclide } & \begin{array}{c}\text { Observed } \\ \text { activity (dpm) }\end{array} \\ \frac{{ }^{90} \mathrm{Sr}}{{ }^{129} \mathrm{I}} & \leq 36 \\ { }^{137} \mathrm{Cs} & \leq 19 \\ { }^{155} \mathrm{Eu} & (8 \pm 2) \\ & \sim 0.5\end{array}$

Reprocessing
decon. factor
$\leq 1.3 \times 10^{-11}$
$\leq 1.8 \times 10^{-5}$
$\leq \quad 2 \times 10^{-12}$
$\leq \quad 3 \times 10^{-12}$

The results of the mass spectrometric analysis of the Nd fraction and the ${ }^{142} \mathrm{Nd}$ carrier material are listed in Table 10 , along with literature values for the isotopic distribution in ${ }^{\text {nat }} \mathrm{Nd}$ and the expected isotopics of fission-product Nd from the ORIGEN2 calculation for a "natural-uranium-fueled BWR", as described in Section II.

From Table 10, it is clear that we under-spiked the original sample with ${ }^{142} \mathrm{Nd}$; the isotopic distribution of the experimental sample is scarcely different from what is expected from a sample of natural neodymium. Since the fission-product component of the mixture is small, we make the assumption that the fission contribution at mass 142 is negligible, and using the carrier aliquot of $0.1230 \mathrm{ug}$ total $\mathrm{Nd}$, we can determine that the naturalneodymium component in the $\mathrm{Nd}$ fraction corresponds to $(50 \pm 40) \mathrm{ug}$. Using the relative concentrations at the other masses, we can deconvolute the fission-product component of the mixture, which turns out to be $\leq 30 \mathrm{ug}$. This means that less than $4 \mathrm{x} 10^{-4}$ of the original fission-product neodymium was left in the sample after fuel reprocessing.

Table 10. Mass spectrometric determination of the isotopic composition (in atom $\%$ ) of the experimental fraction and the carrier. The compositions of natural Nd and reactor-produced fission-product Nd (ORIGEN2 calculation) are listed for comparison.

\begin{tabular}{|c|c|c|c|c|c|c|}
\hline ucl & Nd & & Ta & & natural No & Eiss \\
\hline${ }^{142} \mathrm{Nd}$ & $2 7 \longdiv { 3 0 7 }$ & \pm 0.144 & 97.77 & \pm 0.02 & 27.13 & 0.014 \\
\hline${ }^{143} \mathrm{Nd}$ & 12.121 & \pm 0.038 & 0.755 & \pm 0.001 & 12.18 & 27.250 \\
\hline${ }^{144} \mathrm{Nd}$ & 23.650 & \pm 0.040 & 0.697 & 0.007 & 23.80 & 25.734 \\
\hline${ }^{145} \mathrm{Nd}$ & 8.223 & \pm 0.027 & 0.151 & 0.001 & 8.30 & 18.732 \\
\hline${ }^{146} \mathrm{Nd}$ & 17.038 & \pm 0.051 & 0.304 & 0.001 & 17.19 & 15.135 \\
\hline${ }^{148} \mathrm{Nd}$ & 5.920 & \pm 0.132 & 0.187 & 0.017 & 5.76 & 9.005 \\
\hline${ }^{150} \mathrm{Nd}$ & 5.740 & \pm 0.085 & 0.138 & \pm 0.014 & 5.64 & 4.131 \\
\hline
\end{tabular}


As discussed in section II, reagent-grade solvents usually contain on the order of $100 \mathrm{ppb}$ neodymium. Thus, the naturalneodymium component of the experimental sample corresponds to the Nd content expected in a reagent volume of about $500 \mathrm{ml}$. Assuming an efficient reprocessing method for the removal of Nd from the plutonium, after the last separation approximately $500 \mathrm{ml}$ of reagents were used to manipulate the sample into its final form. Unfortunately, this volume includes the solvents used in our separation procedure, which were of normal reagent grade; approximately $160 \mathrm{ml}$ of reagents were required to produce the final Nd fraction, from dissolution of the plutonium sample through the final ion-exchange step. Because of the errors involved, it is possible that the entire natural-neodymium component of the Nd fraction had its source in our analytical reagents.

In future work, it is clear we should use ultra-pure reagents, particularly in steps involving the addition of large solvent volumes. It is also clear that we should process a radiochemical blank, in which the same reagent aliquots used in the analytical procedure are also used to process the contents of an "empty" reaction vessel. In this case, the final Nd fraction will only contain ${ }^{142} \mathrm{Nd}$-carrier and ${ }^{\text {nat }} \mathrm{Nd}$-contamination components; the contaminant concentration in the blank can be used to correct the data in the experimental fraction for the contribution from the analytical reagents. A radiochemical blank run in parallel with the main experiment is also valuable in determining whether contamination from an external source has occurred (see secton $V$ ). However, processing a simultaneous blank almost doubles the chemical effort, requiring at least one additional chemist during the analytical procedure.

Turning our attention to the heavy elements, the results of the non-destructive gamma-ray analysis of the sample, performed several months before the radiochemical analysis, are given in Table 11. The analysis with the MGA code gives fairly precise values for the relative amounts of the plutonium isotopes and ${ }^{241} \mathrm{Am}$; the gamma-rays arising in the decays of long-lived ${ }^{242} \mathrm{Pu}$ could not be measured, and its relative concentration was estimated from the other plutonium isotopes. A careful examination of the raw gammaray spectrum gave no evidence for the presence of other radionuclides (e.g. fission products) in the sample. The MGA code output gives the age of the material (from the relative concentrations of ${ }^{241} \mathrm{Am}$ and ${ }^{241} \mathrm{Pu}$ ) at the reference time (day 238 , $1992)$ as $(3.48 \pm 0.24)$ years. 
Table 11. Sample BG-522-3, non-destructive gamma-spectroscopic determination of the plutonium isotopics and relative ${ }^{241} \mathrm{Am}$ content. Counted for 93-minute live time interval, at 5\% dead time. From the MGA output, reference time for decay calculations is day 238, 1992. $\mathrm{Pu}$ isotopes sum to $100 \%$, exclusive of ${ }^{241} \mathrm{Am}$.

$\begin{array}{lcc}\text { Nuclide } & \text { weight percent } & \text { relative error } \\ { }^{238} \mathrm{Pu} & 0.01471 & 3.258 \\ { }^{239} \mathrm{Pu} & 93.71488 & 0.048 \\ { }^{240} \mathrm{Pu} & 5.99197 & 0.688 \\ { }^{241} \mathrm{Pu} & 0.23843 & 0.458 \\ { }^{242} \mathrm{Pu} * & 0.040 & \\ { }^{241} \mathrm{Am} & 0.04370 & 1.478\end{array}$

*Estimated, not measured.

The results of the non-destructive gamma-ray analysis of the sample can be compared with the relative isotopics of the sample, determined with mass-spectrometric and alpha-spectroscopic measurements of purified chemical fractions, given in Table 12 . These data were corrected for radioactive decay since the reference time of the non-destructive analysis. The radiochemical results are in good agreement with the data in Table 11, and are of higher precision. Note that the ${ }^{242} \mathrm{Pu}$ concentration assumed by MGA was about $25 \%$ different than the measurement, but ${ }^{242} \mathrm{Pu}$ is such a minor component that this had little effect on the rest of the data.

Table 12. Sample BG-522-3, radiochemical determination of the plutonium isotopics and relative ${ }^{241} \mathrm{Am}$ content. From a combination of mass-spectrometric and alpha-spectroscopic measurements. Data are decay-corrected to day 238, 1992. Pu isotopes sum to 100\%, exclusive of ${ }^{241} \mathrm{Am}$.

$\begin{array}{lcc}\text { Nuclide } & \text { weight percent } & \text { relative error } \\ \frac{{ }^{238} \mathrm{Pu}}{{ }^{239} \mathrm{Pu}} & 0.0144 & 0.638 \\ { }^{240} \mathrm{Pu} & 53.7066 & 0.0108 \\ { }^{241} \mathrm{Pu} & 5.9847 & 0.0538 \\ { }^{242} \mathrm{Pu} & 0.2410 & 0.138 \\ { }^{241} \mathrm{Am} & 0.0534 & 0.378 \\ { }^{24} & 0.0452 & 1.078\end{array}$


In the measurement of the heavy-element nuclides we achieved considerably greater success than we did with the fission products, even though the chemical yields of some of the fractions could have been better. The power of the radiochemical technique lies not only in the increased precision demonstrated in the comparison of Tables 11 and 12, but also in the ability to measure very small concentrations of radionuclides in the presence of a high concentration of radioactive background species. The results of the radiochemical analysis of sample BG-522-3 are given in Table 13. All concentrations were corrected for radioactive decay since the reference time of the group separation (day 67, 1993); in cases where the concentration of a given nuclide was determined with more than one measurement, the value in Table 13 is a weighted average. The increased error bars on the plutonium isotopes compared with those given for the same nuclides in Table 12 are from propagation of the uncertainty in the absolute decay rate with the errors on the relative isotopic composition.

We would like to point out that the concentrations given in Table 13 span sixteen orders of magnitude. The relative amounts of the members of several decay chains are listed, providing the means of determining the age of the sample. We were also able to measure the ${ }^{243} \mathrm{Am},{ }^{242} \mathrm{Cm}$, and ${ }^{244} \mathrm{Cm}$ contaminant species; along with the plutonium isotopics, they provide clues to the performance of the production reactor (see below).

Table 13. Heavy element content, sample BG-522-3, nominal $850 \mathrm{mg}$ $\mathrm{Pu}$ metal (weapons-grade). Data decay-corrected to day 67, 1993.

$\begin{array}{ll}\frac{\text { Nuclide }}{{ }^{227} \mathrm{AC}} & (1.21 \pm 0.18) \times 10^{8} \\ { }^{228} \mathrm{Th} & (5.02 \pm 0.68) \times 10^{8} \\ { }^{229} \mathrm{Th} & (3.51 \pm 2.12) \times 10^{9} \\ { }^{230} \mathrm{Th} & (3.38 \pm 0.51) \times 10^{11} \\ { }^{232} \mathrm{Th} & (2.70 \pm 2.50) \times 10^{15} \\ { }^{231} \mathrm{~Pa} & (3.80 \pm 0.35) \times 10^{13} \\ { }^{232} \mathrm{U} & (3.96 \pm 0.41) \times 10^{10} \\ { }^{233} \mathrm{U} & \leq 1.6 \times 10^{13} \\ { }^{234} \mathrm{U} & (9.16 \pm 0.37) \times 10^{15} \\ { }^{235} \mathrm{U} & (2.22 \pm 0.09) \times 10^{17} \\ { }^{236} \mathrm{U} & (4.99 \pm 0.20) \times 10^{16} \\ { }^{238} \mathrm{U} & (4.64 \pm 0.20) \times 10^{16} \\ { }^{237} \mathrm{~Np} & (5.75 \pm 0.39) \times 10^{15}\end{array}$

Nuclide
${ }^{236} \mathrm{Pu}$
${ }^{238} \mathrm{Pu}$
${ }^{239} \mathrm{Pu}$
${ }^{240} \mathrm{Pu}$
${ }^{241} \mathrm{Pu}$
${ }^{242} \mathrm{Pu}$
${ }^{244} \mathrm{Pu}$
${ }^{241} \mathrm{Am}$
${ }^{24} \mathrm{~mm}$
${ }^{243} \mathrm{Am}$
${ }^{242} \mathrm{Cm}$
${ }^{244} \mathrm{Cm}$

$\left(2.64 \pm \frac{\text { atoms }}{0.22) \times 10^{10}}\right.$
$(3.09 \pm 0.05) \times 10^{17}$
$(2.01 \pm 0.03) \times 10^{21}$
$(1.28 \pm 0.02) \times 10^{20}$
$(4.97 \pm 0.07) \times 10^{18}$
$(1.13 \pm 0.02) \times 10^{18}$
$\leq 9 \times 10^{15}$
$(1.09 \pm 0.02) \times 10^{18}$
$\leq 1 \times 10^{8}$
$(2.54 \pm 0.42) \times 10^{13}$
$(2.10 \pm 0.27) \times 10^{5}$
$(3.71 \pm 0.08) \times 10^{10}$


V. Interpretation of Heavy-Element Data.

The data in Table 13 can be used to calculate the plutonium observables plotted in figure 1; $\left({ }^{238} \mathrm{Pu} /\left({ }^{239} \mathrm{Pu}+{ }^{240} \mathrm{Pu}\right)\right)$ activity $=0.0342 \pm$ 0.0009 , and $\left({ }^{240} \mathrm{Pu} /{ }^{239} \mathrm{Pu}\right)=0.0640 \pm 0.0014$. These values define $\mathrm{a}$ point on the plot that is just below the 3.28 -enrichment- ${ }^{235} U$ BWR curve. ${ }^{238} \mathrm{Pu}$ is a fairly short-lived nuclide $\left(t_{1 / 2}=88\right.$ years); since the plutonium in the sample was discharged from the reactor approximately 10 years before the analysis (see below), allowance for radioactive decay occurring since the material was discharged would lead to a higher corrected value for ${ }^{238} \mathrm{Pu} /\left({ }^{239} \mathrm{Pu}+{ }^{240} \mathrm{Pu}\right)$, falling even closer to the BWR curve. This eliminates the possibility that the material was produced in a heavy-water-moderated reactor, or in a target external to the reactor core (blanket).

Figure 3 shows the production of other plutonium isotopes relative to ${ }^{239} \mathrm{Pu}$, in a 37.5 MW 3.28 -enrichment- ${ }^{235} \mathrm{U}$ BWR, as a function of irradiation interval, calculated with the ORIGEN2 code. The value of ${ }^{240} \mathrm{Pu} /{ }^{239} \mathrm{Pu}$, compared with the calculated curve, defines a reactor irradiation interval of 88 days; the experimental values of ${ }^{241} \mathrm{Pu} /{ }^{239} \mathrm{Pu}$ and ${ }^{242} \mathrm{Pu} /{ }^{239} \mathrm{Pu}$ are also plotted at this interval time. We can see that the observed value of ${ }^{242} \mathrm{Pu} /{ }^{239} \mathrm{Pu}$ is a factor of three larger than the code prediction. The comparison of the observed ${ }^{241} \mathrm{Pu} /{ }^{239} \mathrm{Pu}$ with the calculation is more difficult to make, since ${ }^{241} \mathrm{Pu}$ has a half-life of only 14.4 years. A decay correction of 28 years would bring the value of ${ }^{241} \mathrm{Pu} /{ }^{239} \mathrm{Pu}$ up to the curve. This decay period, requiring reactor discharge of the starting material in the mid-1960's, seems too long; weapons-grade materials dating from that time could only have been produced by one of the major nuclear powers, and are unlikely to have been chemically purified in the recent past (see below).

So, even though the ${ }^{238} \mathrm{Pu}$ content of the material suggests an enriched-fuel BWR as the production reactor, the ORIGEN2 calculation of the heavier plutonium isotopes in the reactor fuel predicts too much ${ }^{241} \mathrm{Pu}$ and too 1 ittle ${ }^{242} \mathrm{Pu}$ at the fixed value of ${ }^{240} \mathrm{Pu} /{ }^{239} \mathrm{Pu}$ to account for our experimental results.

Production of plutonium for weapons purposes is likely to take place in reactors using fuel with little more than the natural enrichment in ${ }^{235} \mathrm{U}$. This is partly because of the more favorable production of plutonium relative to the fission products with a reduction of the concentration of ${ }^{235} \mathrm{U}$ in the starting materials, and partly because of the effort involved in enriching uranium and the subsequent increased scrutiny by International safeguards. Furthermore, we know that both the U.S. and the U.K. have produced weapons-grade plutonium through the irradiation of uranium of nearnatural isotopic composition.

It would be naive to conclude that production of the plutonium represented by our sample occurred in BW or PW Reactors with lower fuel enrichments; a light-water-moderated natural-uranium-fueled reactor will not sustain a chain reaction. However, ORIGEN2 can 
be forced to calculate plutonium production in non-viable reactor types. An ORIGEN2 calculation for a hypothetical natural-uraniumfueled BWR resulted in the curve given in figure 4 , compared with the same calculation depicted in figure 1 for a 3.28-enrichment${ }^{235} \mathrm{U}$ BWR. The experimental data point is also indicated in the figure. Some of the difference between the calculations results from the fact that much of the production of ${ }^{238} \mathrm{Pu}$ is from capture of a neutron by ${ }^{237} \mathrm{~Np}$; at medium-to-long irradiation times, ${ }^{237} \mathrm{~Np}$ arises largely from sequential capture of two neutrons by ${ }^{235} \mathrm{U}$ followed by beta decay of 6.7 -day ${ }^{237} \mathrm{U}$. An enrichment in the ${ }^{235} \mathrm{U}$ content of the starting material thereby results in an increase in production of ${ }^{238} \mathrm{Pu}$.

Figure 5 shows the production of other plutonium isotopes relative to ${ }^{239} \mathrm{Pu}$ in a hypothetical $37.5 \mathrm{MW}$ natural-uranium-fueled BWR, as a function of irradiation interval, calculated with ORIGEN2. The value of ${ }^{240} \mathrm{Pu} /{ }^{239} \mathrm{Pu}$, compared with the calculated curve, defines a reactor irradiation interval of 33 days; the experimental values of ${ }^{241} \mathrm{Pu} /{ }^{239} \mathrm{Pu}$ and ${ }^{242} \mathrm{Pu} /{ }^{239} \mathrm{Pu}$ are also plotted at this interval time. The reason that the time required to produce weapons-grade plutonium at a constant power level is less with natural fuel than with enriched fuel is because, at low burn-ups, reactor power is derived almost exclusively from the fission of ${ }^{235} \mathrm{U}$; with natural fuel, the number of ${ }^{238} \mathrm{U}$ target atoms per ${ }^{235} \mathrm{U}$ fission is higher, resulting in more plutonium production and a larger target for subsequent capture reactions.

In figure 5, the observed value of ${ }^{242} \mathrm{Pu} /{ }^{239} \mathrm{Pu}$ is still larger than the ORIGEN2 prediction of natural-uranium-fueled BWR production by a factor of 2.2, and a 28-year decay correction is still required to bring the measured value of ${ }^{241} \mathrm{Pu} /{ }^{239} \mathrm{Pu}$ up to the calculated curve. As with the enriched-fuel BWR, the code still predicts too much ${ }^{241} \mathrm{Pu}$ and too little ${ }^{242} \mathrm{Pu}$. With natural-uranium fuel, the code also predicts too little ${ }^{238} \mathrm{Pu}$ (figure 4).

Another path to ${ }^{238} \mathrm{Pu}$ is through the interaction of highenergy neutrons with ${ }^{239} \mathrm{Pu}$ via the ${ }^{239} \mathrm{Pu}(n, 2 \mathrm{n})$ reaction. Production of the isotopic mix of light plutonium nuclides in the sample from natural uranium would require a harder neutron spectrum than that generated by the reactors in the calculations, implying a less efficient (higher-z) moderator than either light or heavy water. A harder neutron spectrum can also be used to explain the concentrations of the heavier plutonium isotopes relative to ${ }^{239} \mathrm{Pu}$ : other than local resonance effects, the $(n, f)$ fission cross sections of ${ }^{239} \mathrm{Pu}$ and ${ }^{241} \mathrm{Pu}$ are roughly constant with energy ("Neutron Cross Sections", vol. 2; V. Mclane, C. L. Dunford, and P. F. Rose; Academic Press, Boston, 1988); the (n,gamma) capture cross sections of ${ }^{239} \mathrm{Pu},{ }^{240} \mathrm{Pu}$, and ${ }^{239} \mathrm{Pu}$ all decrease with increasing energy. The figure-5 calculations would better match the data if the effective ( $n$,gamma) cross section were decreased slightly relative to the $(n, f)$ cross section. This requires neutrons of higher average energy than those used in the ORIGEN2 run. 
The only moderators that allow reactor operations with nearnatural-enrichment uranium fuel are $\mathrm{D}_{2} \mathrm{O}$ (eliminated by figure 1), beryllium (unlikely), and graphite. Elastic collisions with highmass carbon nuclei provide an inefficient mechanism for slowing down neutrons, resulting in a harder spectrum in the fuel. This means that our sample of weapons-grade $\mathrm{Pu}$ was probably produced in a graphite-moderated reactor. Unfortunately, the oRIGEN2 libraries available at LLNL do not contain a graphite-moderated "Production Reactor" data set.

In a search of the literature, we were able to find information on the isotopic composition of plutonium produced in gas-cooled, graphite-moderated Calder Hall-type reactors ( $L$. Barbieri, J. Webster, and K. Chow, Nucl. Sci. and Eng. $\underline{5}, 105$ (1959)). At irradiation intervals defined by the ${ }^{240} \mathrm{Pu} /{ }^{239} \mathrm{Pu}$ value, our observed value of ${ }^{242} \mathrm{Pu} /{ }^{239} \mathrm{Pu}$ was within $20 \%$ of that expected from the reference, and a decay correction of only 11 years was required to bring our value of ${ }^{241} \mathrm{Pu} /{ }^{239} \mathrm{Pu}$ to Calder Hall composition. The plutonium in sample BG-522-3 is the product of a graphite-moderated reactor.

Since we don't have the appropriate cross section library, we do not have the means to calculate the isotopic composition of fuel irradiated in a graphite-moderated reactor using the ORIGEN2, code. However, the production of most of the fission products and heavy element isotopes are through neutron-capture reactions that are relatively spectrum insensitive; the hypothetical natural-uraniumfueled BWR calculation can be used to estimate the composition of the fuel at discharge, within a factor of two in most cases. This is the justification for using the results of this calculation in the tables and discussion in section II.

While the reactor flux has a very minor effect on the relative isotopics of the plutonium product, it has a strong effect on the efficiency with which the fuel can be converted to plutonium. Figure 6 shows the results of an ORIGEN2 calculation of the integrated flux required to produce plutonium that is $68{ }^{240} \mathrm{Pu}$ by mass, as a function of the power level of a natural-uranium-fueled BWR. At low reactor power, production of weapons-grade $\mathrm{Pu}$ is a function of integrated flux only. At higher reactor power levels, a greater integrated $f l u x$ is required to achieve the same isotopic composition; this is largely due to the fact that during a shorter irradiation period, a more significant fraction of the mass-239 product yield exists as short-lived precursors ${ }^{239} \mathrm{U}$ and ${ }^{239} \mathrm{~Np}$, resulting in fewer $(n, f)$ reactions on ${ }^{239} \mathrm{Pu}$. The higher integrated flux required at higher power levels to achieve the desired isotopic composition of the plutonium product results in a more efficient use of the uranium fuel. Therefore, efficiencies of both time and materials favor high reactor powers in Pu production.

Figure 7 shows the results of an ORIGEN2 calculation of the two plutonium parameters that are most sensitive to changes at high reactor flux, for fixed weapons-grade ${ }^{240} \mathrm{Pu}$ content, as a function 
of reactor power in a natural-uranium-fueled BWR. Note that the $\mathrm{Pu}$ observables are plotted on a linear scale in the figure; at the high-flux extreme of reactor performance there is a small power dependence of these parameters. It is not strong enough to preclude the use of (logarithmic) figure 1 to determine production reactor type, but may affect the use of figures 3 and 5 , where disagreements between the measured and calculated mass ratios are more subtle. Reactor flux can significantly affect the isotopic fingerprint of the plutonium nuclides in a given sample.

As we discussed in section II, the relative concentrations of ${ }^{242 \mathrm{~m}} \mathrm{Am},{ }^{243} \mathrm{Am},{ }^{242} \mathrm{Cm}$, and ${ }^{244} \mathrm{Cm}$ are strongly dependent on flux and are the most sensitive means of determining production reactor power. Unfortunately, the cross sections of the reactions that create and destroy ${ }^{242 \mathrm{~m} A m}$ are also very sensitive to small changes in the neutron-energy spectrum, so the use of an improper ORIGEN2 Iibrary precludes the use our calculations for flux diagnostics. Our limit on ${ }^{242 \mathrm{Am}} /{ }^{243} \mathrm{Am} \leq 4 \times 10^{-6}$ is three orders of magnitude less than the results of the ORIGEN2 calculation for a 100 MW (thermal) naturaluranium-fueled BWR (figure 2).

The reactions that produce the curium isotopes are not terribly sensitive to small changes in the reactor neutron spectrum; however, the half life of ${ }^{242} \mathrm{Cm}$ is so short $\left(t_{1 / 2}=163\right.$ days) that substantial decay corrections have to be made before figure 2 can be used. The observed value of ${ }^{244} \mathrm{Cm} /{ }^{242} \mathrm{Cm}=1.8 \times 10^{5}$; if we assume that the reactor ran at a power level between 10 and 150 MW (thermal), then the correction for decay requires discharge of the fuel from the reactor between 8 and 10 years prior to the reference time of the radiochemical analysis. This is in reasonable agreement with the 11-year decay correction required by comparing the observed ${ }^{241} \mathrm{Pu} /{ }^{239} \mathrm{Pu}$ with the value expected from a Calder Hall-type reactor.

The measured value of ${ }^{244} \mathrm{Cm} /{ }^{243} \mathrm{Am}$ is $1: 5 \times 10^{-3}$. This is an order of magnitude lower than expected from figure 2, and implies that the sample was more effectively decontaminated from curium than from americium. Separation schemes based on complex nitrate species (e.g. TBP extraction of neutral nitrates, or ion exchange of anionic nitrates) provide for a better separation of Pu from $\mathrm{cm}$ than from Am. From Table 3, 0.308 of the ${ }^{243} \mathrm{Am}$ in the discharged reactor fuel and 0.0238 of the ${ }^{244} \mathrm{Cm}$ remained with the plutonium.

The decontamination factors obtained from the ${ }^{243} \mathrm{Am}$ and ${ }^{244} \mathrm{Cm}$ concentrations indicate that the reprocessors did a very poor job of cleaning these elements out of the plutonium in the sample. Even though we obtain interpretable values of ${ }^{244} \mathrm{Cm} /{ }^{242} \mathrm{Cm}$ and ${ }^{244} \mathrm{Cm} /{ }^{243} \mathrm{Am}$, it made us question whether there might be a mechanism by which these nuclides could be produced in the sample after chemical separation, short of a contamination process. It occurred to us that in the time since separation (see below) the ${ }^{240} \mathrm{Pu}$ in the sample had undergone enough spontaneous-fission decay to have emitted a total of $7 \times 10^{9}$ neutrons. However, even if one assumes 
that all of the neutrons are stopped in the sample, and are selectively captured by ${ }^{242} \mathrm{Pu}$ in preference to all other nuclides, there would still be three orders of magnitude too little ${ }^{243} \mathrm{Am}$ production to explain the experimental data.

As discussed in section II, samples can be age-dated using pairs of radionuclides that are linked by radioactive decay. It must be assumed that there existed a time in the past when the sample contained only parent activities, meaning that a chemical separation was performed to remove daughters. At some later time, the determination of the relative concentrations of any two longlived members of a decay chain can be used to determine the time at which the separation occurred.

From nuclide concentrations in experimental sample BG-522-3, given in Table 13, we can calculate the age of the sample from several genetically-related pairs of nuclides. These age determinations are listed in Table 14, associated with the nuclides from which they arise. All of these ages are relative to the Table 13 reference time of day $67,1993$.

The ingrowth of ${ }^{234} \mathrm{U},{ }^{235} \mathrm{U}$, and ${ }^{236} \mathrm{U}$ from the decays of ${ }^{238} \mathrm{Pu},{ }^{239} \mathrm{Pu}$, and ${ }^{240} \mathrm{Pu}$, respectively, all define the same age. Since the isotopic compositions of natural uranium and the uranium constituting probable reactor fuels are all considerably different from the mixture given in Table 13, contamination from incomplete fuel reprocessing can make only a trivial contribution to the concentrations of these uranium nuclides. The weighted average $\mathrm{U} / \mathrm{Pu}$ age of $(3.743 \pm 0.094)$ years before the measurement time (or June $12,1989 \pm 34$ days) is the best value for the time at which the plutonium was last separated from its progeny.

The age derived from the relative concentrations of ${ }^{238} \mathrm{U}$ and its parent ${ }^{242} \mathrm{Pu}$ is approximately 22000 years; however, the combination of the long half-life and low isotopic abundance of ${ }^{242} \mathrm{Pu}$ and the prevalence of ${ }^{238} \mathrm{U}$ in uranium of near-natural composition makes the ${ }^{238} \mathrm{U} /{ }^{242} \mathrm{Pu}$ age a factor of $4 \times 10^{6}$ more sensitive to the effects of contamination than is the ${ }^{235} \mathrm{U} /{ }^{239} \mathrm{Pu}$ age. The addition of a few micrograms of natural uranium to the sample would have a negligible effect on ${ }^{235} \mathrm{U} /{ }^{239} \mathrm{Pu}$ ages of more than one year, while completely compromising the ${ }^{238} \mathrm{U} /{ }^{242} \mathrm{Pu}$ age; see the relative ingrowth amounts given in Table 4 . In terms of mass, the amount of ${ }^{238} \mathrm{U}$ in the experimental sample, as given in Table 13, is 18 micrograms; this is more uranium than we would expect to have introduced from contaminants in our reagents (see discussion of Table 10, section III), but not comfortably so. This is another argument for using ultra-pure reagents in the early parts of the chemical procedure, and running a simultaneous solvent blank. From the reference value given in Table 3 , we can state that the reprocessors left no more than $4 \times 10^{-8}$ of the uranium present in the discharged reactor fuel with the final plutonium product. 
Table 14. Time of last chemical separation of sample BG-522-3, in years before day 67, 1993. U/Pu ages are consistent with a separation date of June 12,1989 ( \pm 34 days).

$\frac{\text { Nuclide pair }}{{ }^{241} \mathrm{Am}}{ }^{241} \mathrm{Pu}$
${ }^{237} \mathrm{~Np} /{ }^{241} \mathrm{Am}$
${ }^{234} \mathrm{U} /{ }^{238} \mathrm{Pu}$
${ }^{235} \mathrm{U} /{ }^{239} \mathrm{Pu}$
${ }^{236} \mathrm{U} /{ }^{240} \mathrm{Pu}$
${ }^{238} \mathrm{U} /{ }^{242} \mathrm{Pu}$
${ }^{230} \mathrm{Th} /{ }^{232} \mathrm{U}$
${ }^{231} \mathrm{~Pa}$
${ }^{227} \mathrm{AC} /{ }^{235} \mathrm{U}$
${ }^{231} \mathrm{~Pa}$

$\frac{\text { time of separation }}{(4.12 \pm 0.09)}$
$(4.02 \pm 0.24) \quad$ (from gamma-spec NDA)
$(6.22 \pm 0.42)$
$(3.70 \pm 0.16)$
$(3.85 \pm 0.17)$
$(3.69 \pm 0.16)$
22000
$(3.30 \pm 0.75)$
infinite
$(0.155 \pm 0.035)$

Table 14 also gives two values for the ${ }^{241} \mathrm{Am} /{ }^{241} \mathrm{Pu}$ age, from the radiochemical results in Table 13 and from the MGA output obtained from the non-destructive analysis of the sample. The two values are in good agreement with one another; however, the more precise radiochemistry age is significantly older than the average $U / \mathrm{Pu}$ age. This means that, at the time the uranium was removed from the sample, some americium remained. We already know this from the presence of non-progeny ${ }^{243} \mathrm{Am}$ in the sample. An initial non-zero ${ }^{241} \mathrm{Am}$ concentration, added to the amount resulting from ingrowth, makes it appear that the chemical separation took place at an earlier time than it actually did.

The amount of ${ }^{241} \mathrm{Am}$ left in the sample at the uranium separation time was $(1.1 \pm 0.3) \times 10^{17}$ atoms. If we assume that the purification process was performed all at one time, over a time interval that was short compared to the ${ }^{241} \mathrm{Pu}$ half-life, then the yield of ${ }^{243} \mathrm{Am}\left(0.308\right.$, see above) can be applied to the residual ${ }^{241} \mathrm{Am}$ concentration to obtain a ${ }^{241} \mathrm{Am} /{ }^{241} \mathrm{Pu}$ age prior to the separation; this is potentially a measure of how long the sample existed prior to reprocessing. We obtain a value of approximately 40 years (reactor discharge in 1949!), which is inconsistent with the ${ }^{241} \mathrm{Pu} /{ }^{239} \mathrm{Pu}$ and ${ }^{244} \mathrm{Cm} /{ }^{242} \mathrm{Cm}$ ages of approximately 6 years (10 years before the Table-13 analysis time). What this means is that the reprocessing chemistry was performed in at least two distinct phases, each providing a partial decontamination from americium, with a substantial time interval for ingrowth of ${ }^{241} \mathrm{Am}$ between the phases. The difference between the $\mathrm{U} / \mathrm{Pu}$ and ${ }^{241} \mathrm{Am} /{ }^{241} \mathrm{Pu}$ ages precludes a single-step mechanism by which freshly-cleaned plutonium was contaminated with aged plutonium in the final reprocessing steps. 
The ${ }^{237} \mathrm{~Np}$ age given in Table 14 was calculated assuming that the sample was originally purified from both ${ }^{241} \mathrm{Am}$ and ${ }^{237} \mathrm{~Np}$; the $0.0024 \%$ alpha-decay branch of ${ }^{241} \mathrm{Pu}$ (producing ${ }^{237} \mathrm{~Np}$ through the beta decay of the short-lived ${ }^{237} \mathrm{U}$ daughter) was also taken into account in the calculation. As before, the sample age is evidence that ${ }^{237} \mathrm{~Np}$ was incompletely removed from the sample during reprocessing. Since the ingrowth of ${ }^{237} \mathrm{~Np}$ from decays of ${ }^{241} \mathrm{Pu}$ and ${ }^{241} \mathrm{Am}$ in the spent fuel is insignificant compared with its production during reactor operations, the non-progenic component of the ${ }^{237} \mathrm{~Np}$ concentration can be used to estimate the decontamination factor for neptunium: The reprocessors left approximately $1 \times 10^{-4}$ of the original neptunium content in the final plutonium sample.

The ${ }^{230} \mathrm{Th} /{ }^{234} \mathrm{U}$ age is consistent with a very poor decontamination of the plutonium from thorium. However, the ${ }^{228} \mathrm{Th} /{ }^{232} \mathrm{U}$ age is consistent with complete removal of thorium in the reprocessing. The explanation for these two conflicting interpretations lies in the half-lives of ${ }^{228} \mathrm{Th}$ ( 1.9 years) and ${ }^{230} \mathrm{Th}$ ( 75000 years) and in the two-step chemical reprocessing procedure that is also required by the americium isotopes (see above). Shortly after reactor discharge, the plutonium was cleaned of thorium, though not very efficiently. The amounts of thorium left in the sample were small compared with the original uranium-fuel content, but large relative to plutonium ingrowth amounts. During the years intervening between the first and second phases of the reprocessing, the ${ }^{228} \mathrm{Th}$ in the sample decayed to a small fraction of its initial concentration, while the ${ }^{230}$ Th concentration remained essentially constant; this requires a time interval equivalent to several ${ }^{228} \mathrm{Th}$ half-lives between the first and second phases of the operation. The second phase of the reprocessing chemistry was also not very efficient for the removal of thorium, leaving the ${ }^{230} \mathrm{Th}$ content significantly larger than ingrowth values, but knocking the decayed ${ }^{228}$ Th content down well below the saturation activity. The uranium isotopics in the reactor fuel and the relatively short half-lives of the nuclides in the ${ }^{236} \mathrm{Pu}$ decay chain combine to result in a ${ }^{228} \mathrm{Th} /{ }^{232} \mathrm{U}$ age that is approximately correct, even though the overall separation from thorium was not complete.

The ages determined from the lower members of the ${ }^{239} \mathrm{Pu}$ decay chain $\left({ }^{231} \mathrm{~Pa}\right.$ and $\left.{ }^{227} \mathrm{AC}\right)$ are nonsensical. There was more ${ }^{231} \mathrm{~Pa}$ in the sample than could be accounted for by complete saturation with the current amount of ${ }^{235} \mathrm{U}$. One could argue that this was due to a remarkably poor decontamination from protactinium in the reprocessing chemistry if it weren't for the impossibly short ${ }^{227} \mathrm{AC} /{ }^{231} \mathrm{~Pa}$ age. We were in possession of the sample for several months before we performed the analysis, in clear contradiction with the 2-month ingrowth period defined by ${ }^{227} \mathrm{Ac} /{ }^{231} \mathrm{~Pa}$. The sample must have been contaminated with freshly-separated ${ }^{231} \mathrm{~Pa}$ at some point during the radiochemical procedure. The ${ }^{246} \mathrm{Cm} /{ }^{243} \mathrm{Am}$ tracer solution was cleaned of its daughters at an appropriate time, but this would have concentrated ${ }^{227} \mathrm{Ac}$ rather than its parent. The ${ }^{231} \mathrm{~Pa}$ 
decay rate of $1500 \mathrm{dpm}$ is far more than we would expect from contamination in our reagents or apparatus. The most likely source of contamination is the ambient glove-box background; it had been used two years previously in the preparation of ${ }^{231} \mathrm{~Pa}$ accelerator targets. The mechanism by which ${ }^{231} \mathrm{~Pa}$ was selectively removed from its ${ }^{227} \mathrm{Ac}$ daughter prior to its introduction into the sample is unknown. Along with the ${ }^{\text {nat }} \mathrm{Nd}$ and ${ }^{238} \mathrm{U}$ contaminants, this is a strong argument for processing a simultaneous radiochemical blank in future experiments.

VI. Future developments/needs for improvement.

The chemical procedure given in Appendix $A$ needs to be improved to give better decontamination factors and higher chemical yields. Some of this can be accomplished with the existing procedure if more chemists were available. There were times during the experiment that the chemist was performing as many as five different separation procedures simultaneously, distributed between the glove box and two fume hoods in separate rooms. This is not the best way to ensure optimum chemical performance. Additional purification steps are necessary to remove ${ }^{241} \mathrm{Am}$ from TC, I, Sr, and Zr fractions.

In redesigning the chemical procedure, there are several issues to be addressed. We have been asked several times if the procedure could be made portable; if a plutonium sample is intercepted in a foreign country, they might not want to relinquish control of the material. While most of the chemistry could be transported without too much dificulty, the radiation-counting and mass-spectrometry facilities cannot, so the analysis will never be truly portable. However, we would propose the following as a compromise:

After the initial sample dissolution and the collection of volatile noble gases and the I/Ru/Tc fraction, plutonium can be extracted from $1 \mathrm{M} \mathrm{HNO}_{3}$ into an immiscible TTA/xylene solution. This leaves Sr, Cs, the rare earths (except $\mathrm{Ce}^{4+}$ ), $U$, and the trivalent actinides behind in the aqueous phase. Plutonium can be reduced to $\mathrm{Pu}^{3+}$ and back-extracted from the organic phase with an aqueous ferrous sulfamate solution, leaving $\mathrm{Zr}$, $\mathrm{Th}, \mathrm{Pa}$, and $\mathrm{Np}$ behind in the organic phase. The four chemical fractions (noble gas, volatiles, aqueous, and organic) can then be transported to a domestic laboratory, leaving the plutonium fraction in the custody of the original agency. Following this prescription, we lose only the possibility of measuring ${ }^{236} \mathrm{Pu}$ through milking and nuclides too short-lived to survive transportation.

This solvent extraction step takes the place of the anionexchange group separation on day 2 of the procedure. With the exception of $\mathrm{Th}$ and (possibly) Sb, the aqueous phase contains the nuclides found in fraction " $X$ " and the organic phase contains the 
fraction "Y" nuclides. This eliminates the need to collect several hundred milliliters of column eluant in fraction "Y", which was one of the primary sources of yield loss in our procedure. Most of the

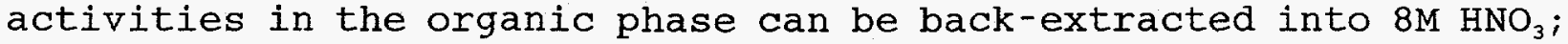
Zr remains, but can be recovered through evaporation and volatilization of the organic medium.

Another issue affecting portability of the first phases of the separation procedure is the collection of the noble-gas fraction. The use of liquid nitrogen to cool the traps is unavoidable, as is the need for a small vacuum pump to check the system for leaks (a step we should have included in our original experiment). A large cylinder of pure helium carrier gas is probably the bulkiest part of the apparatus; however, helium could be replaced by hydrogen in the procedure with no effect on performance. Hydrogen can be generated electrolytically from a very dilute solution of sulfuric acid using with a very compact apparatus. Water and residual oxygen can be removed from the hydrogen stream with a combination of a cold trap and a deoxygenating getter. If the electrolysis unit is properly degassed, the carrier gas will probably contain less $\mathrm{Xe}$ and $\mathrm{Kr}$ than will the helium carrier from a bottle. With $\mathrm{H}_{2}$, the system exhaust must be handled with appropriate caution. One might consider techniques for analyzing the ${ }^{4} \mathrm{He}$ (accumulated from alpha decay) in the $\mathrm{H}_{2}$ exhaust to give another measure of the metal casting time.

We have been asked whether our procedure could be modified to analyze samples of plutonium oxide for forensic signatures. $\mathrm{PuO}_{2}$, particularly if high-fired, can be difficult to dissolve, usually requiring the use of $\mathrm{HF}$, which may cause fractionation of many of the signature nuclides from the plutonium and certainly affects the down-stream chemistry. We propose that CEPOD (Catalyzed Electrolytic Plutonium Oxide Dissolution) be used to dissolve these samples, and also any $\mathrm{PuO}_{2}$ inclusions left over after dissolution of metal samples. In CEPOD, a short-lived catalytic species $\left(\mathrm{Ag}^{2+}\right)$ is generated in situ by application of a potential to the solution in which the $\mathrm{PuO}_{2}$ sample is dispersed. The $4 \mathrm{M} \mathrm{HNO}_{3}$ solution should be chloride free; this may require repeated evaporations to dryness with addition of $\mathrm{HNO}_{3}$. The $\mathrm{PuO}_{2}$ is spread over the surface of a large-area Pt anode, a few drops of $10 \mathrm{mg} / \mathrm{ml} \mathrm{Ag}^{+}$carrier is added to the solution, a Pt-wire cathode is immersed in the liquid near the top of the reaction vessel, and a potential of approximately $2 \mathrm{~V}$ is applied to the solution. The power supply used to generate $\mathrm{H}_{2}$ can also serve for this purpose. An intense brown color is imparted to the solution near the anode; this is due to $\mathrm{Ag}^{2+}$, which catalyzes the oxidation of $\mathrm{PuO}_{2}$ to $\mathrm{PuO}_{2}{ }^{2+}$. The dissolution proceeds more rapidly at higher temperatures. We have tried this technique on samples of calcined ${ }^{242} \mathrm{PuO}_{2}$ and reactor-grade ${ }^{239} \mathrm{PuO}_{2}$, and find that we can completely dissolve a l-gram sample in a few hours. The presence of a few milligrams of $\mathrm{Ag}^{+}$in the final solution does not affect the down-stream chemistry. It would be wise to continue to 
include the $\mathrm{BF}_{4}^{-}$step (day 1) to avoid interference from residual colloidal $\left(\mathrm{PuO}_{2}\right)_{\mathrm{x}}$ polymer. For more information on CEPOD, see $L$. A. Bray and J. L. Ryan, Radioactive Waste Management 6 , 129 (1982).

The procedure given in Appendix A could be improved in many ways; it will require a large amount of lab work to accomplish this. The biggest problem is the separation of Tc. The distillation apparatus must be improved so that there are no losses due to condensation (e.g., on the gas-delivery tube and the exit from the reagent reservoir) or chemical reactions (e.g., on the grease used to seal ground-glass joints). "The ${ }^{99 m} \mathrm{Tc}$ chemical-yield indicator, with a half-life of only 6 hours and a saturation activity of only $87 \mathrm{dpm} / \mathrm{gram} \mathrm{Pu}$, is probably observable under only the most optimum conditions. We would propose to add a few dpm of ${ }^{97} \mathrm{TC}$ tracer activity $\left(t_{1 / 2}=2.6 \times 10^{6}\right.$ years $)$ to the reaction flask before the dissolution, and try to develop a mass-spectrometric procedure for determining the relative concentrations of the Tc isotopes in the final fraction.

The ${ }^{231} \mathrm{~Pa},{ }^{238} \mathrm{U}$, and ${ }^{\text {nat }} \mathrm{Nd}$ contaminations in our experimental samples point out the need for using higher-grade reagents and running simultaneous blanks with each plutonium sample. The use of standard reagent-grade chemicals made it impossible to determine what fraction of the observed concentrations of $\mathrm{Nd}$ and ${ }^{238} \mathrm{U}$ to attribute to fuel reprocessing. The presence of impossibly-young ${ }^{231} \mathrm{~Pa}$ in the process solutions would be less confusing if it had also showed up in the $\mathrm{Pa}$ fraction from a radiochemical blank.

In section III, we alluded to the use of the major part of the primary dilution of the quantitative plutonium solution (Appendix A, day 2) for other measurements. The non-radioactive contaminants in a plutonium sample also give information as to its origin. In this work we have measured natural neodymium isotopes, and have observed a significant amount of a light alkaline earth ( $\mathrm{Mg}$ or $\mathrm{Ca}$ ) in the early steps of the Sr procedure; the alkaline earth is probably a residue from a metallurgical process. We could have taken a gallium fraction, whose presence would be a strong indication of the weaponization of the material. The primary dilution is of an appropriate concentration for use in the source of an inductively-coupled-plasma (ICP) mass spectrometer. The heavy-element laboratory at Karlsruhe used an ICP measurement to attribute the origins of samples of SNM seized in the Frankfurt airport. We believe that this is an important capability to develop at LLNL. Alternatively, a small aliquot of the original solution could be analyzed for contaminants by X-ray Fluorescence; this is less sensitive than ICP-mass spectrometry, but the Isotope Sciences Division already has the capability in place.

The accuracy with which the chemical yields of the fission products can be determined is limited by the accuracy with which the spontaneous-fission yield of each short-lived indicator nuclide is known. Laidler and Brown (J.Inorg.Nucl.Chem 24, 1485 (1962)) measured the cumulative yields of fifteen nuclides arising in the 
spontaneous fission of ${ }^{240} \mathrm{Pu}$; information on the yields of a few other nuclides is also available (A. Prindle, unpublished data, 1976). However, most of the fission yields given in Table 5, particularly for long-lived and stable species, were estimated from the known ${ }^{240} \mathrm{Pu}$ yields, and yields from the spontaneous fission of ${ }^{252} \mathrm{Cf}$, corrected for differences in $\mathrm{Z}, \mathrm{A}, \mathrm{Z}_{\mathrm{p}}$, and $\mathrm{A}_{\mathrm{p}}$. The Table-5 yields are probably accurate to better than $\pm 25 \%$. Clearly, the determination of the chemical yields of the fission products could be improved with a better determination of the mass distribution arising in the spontaneous fission of ${ }^{240} \mathrm{Pu}$. Also, we have completely ignored the yields of products of the decays of ${ }^{238} \mathrm{Pu}$ and ${ }^{242} \mathrm{Pu}$, which contribute $0.7 \%$ and $1.7 \%$, respectively, to the total spontaneous-fission rate in a sample of weapons-grade plutonium.

In the absence of a data base of plutonium isotopic signatures, our interpretations of the analytical data in terms production reactor parameters are very dependent upon ORIGEN2 calculations. Obtaining a cross-section library for graphite production reactors is of highest priority. It would be useful to put together a set of cross-section libraries organized by the reactor types that are present in each country. In fact, since reactor irradiation lengths and fluxes are variable, it makes far more sense to produce an ORIGEN2 library for every interesting reactor in the world than it does to put together a library of isotopic fingerprints; different batches of plutonium from the same reactor may have different isotopics. Creation of this "library of libraries" would be a large undertaking, and would require the cooperation of intelligence agencies.

VII. Summary.

Forensic signatures are present in any sample of plutonium metal that provide the means to determine the origin of the sample. These signatures include the isotopic distribution of the plutonium nuclides themselves, progeny species that grow into the sample as the result of radioactive decay, and contaminant species that are left over from the incomplete purification of the plutonium in fuel reprocessing. The plutonium isotopes and certain heavy-element contaminants provide information about the reactor type, irradiation length, and power level used in the fuel irradiation resulting in the sample. The concentrations of progeny nuclides delineate the time table over which the material was produced, purified, and cast. The presence of contaminant species in excess of ingrowth concentrations provide clues as to the chemical techniques employed in the purification process. In the context of intelligence information, this suite of signatures can result in the attribution of responsibility for the product of clandestine proliferant operations or material smuggled from existing stockpiles. 
We have developed a list of signature elements and have defined what will eventually be possible to determine from them. A considerable amount of work remains to be done in converting concentrations of signature species into a quantitative forensic analysis, particularly in regards to reactor performance; however, we believe that the information given in this report proves that this can be accomplished with a small effort. We developed a radiochemical analysis scheme for measuring these nuclides; more work is needed to improve this "zeroth order" procedure (particularly for the determination of fission product concentrations), and we include suggestions for the future development of the method.

We have analyzed a sample of plutonium metal and determined several interesting parameters that are strong indicators of its point of origin. The isotopic distribution of the plutonium nuclides indicates that the production reactor was moderated with graphite rather than with $\mathrm{H}_{2} \mathrm{O}$ or $\mathrm{D}_{2} \mathrm{O}$, and that the fuel charge was uranium of near-natural composition. The deviation of ${ }^{241} \mathrm{Pu}$ and relative ${ }^{242} \mathrm{Cm}$ concentrations from calculated concentrations are consistent with approximately 10 years of decay, requiring that the reactor irradiation of the starting materials ended in 1983 (approximately). From the ingrowth of heavy-element progeny nuclides, we determined that the chemical purification of the sample took place at two distinct times (at least), the first occurring shortly (ca. one year) after the fuel was discharged from the reactor, and the last occurring on June $12,1989 \pm 34$ days. The reporcessors did a good job of removing $\mathrm{Cs}, \mathrm{Sr}, \mathrm{I}, \mathrm{Eu}$, and $\mathrm{U}$ from the final sample, but were less successful in removing $\mathrm{Am}, \mathrm{Cm}$, $\mathrm{Np}$, and (particularly) Th. This implies a separation method based on the formation of complex nitrate species, which includes both anion exchange and solvent extraction with TBP.

\section{Acknowledgements.}

Bryant Hudson and Wayne Culham participated in the collection of the noble-gas fraction and performed the mass-spectrometric measurement on it. Brian Ruiz and Joan Beiriger performed the thermal-ionization mass-spectrometric measurements on the Nd, $U$, $\mathrm{Pu}$, and $\mathrm{Am}$ fractions; Carol Velsko helped in the interpretation of the data. Richard Nagle, Ruth Nuckolls, and Fernando Bazan performed the gamma-spectroscopic measurements and did the beta counting. Austin Prindle obtained sample BG-522-3 for us, and provided his unpublished fission-product data. Wayne Ruhter performed the non-destructive gamma-ray measurement and the MGA analysis. Robert wikkerink and Lester Cronk provided assistance with the set-up of the chemical separation and with facility issues. Joseph Carlson provided assistance with the ORIGEN2 calculations. Judith Kammeraad, Ronald Lougheed, and Sidney 
Niemeyer have worked unflaggingly to ensure the continuation of this work in the future.

Funding for the later parts of this program was provided by LLNL's LDRD offices; their support is gratefully acknowledged. 
Figure captions.

1. Results of ORIGEN2 calculations for several reactor types, correlation between plutonium observables: ${ }^{238} \mathrm{Pu} /\left({ }^{239} \mathrm{Pu}+{ }^{240} \mathrm{Pu}\right)$ activity vs. ${ }^{240} \mathrm{Pu} /{ }^{239} \mathrm{Pu}$ mass. Reactor power level $37.5 \mathrm{MW}$ (thermal).

2. Effect of reactor flux on the production of heavy elements in irradiations tailored to produce $6 \frac{{ }^{\circ}}{{ }^{240} \mathrm{Pu}}$ by mass. ORIGEN2 calculation, "natural-uranium" BWR.

3. ORIGEN2 calculation of the relative production of the indicated plutonium isotopes as a function of irradiation time at a power level of $37.5 \mathrm{MW}$ (thermal) in a BWR burning 3.28 -enrichment- ${ }^{235} \mathrm{U}$ fuel. Data points defined by our analysis of sample BG-522-3 are plotted at an irradiation length of 88 days.

4. Results of ORIGEN2 calculations for Boiling Water reactors, and the effect of variable fuel enrichment on $\mathrm{Pu}$ observables. The data point was derived from our analysis of sample BG-522-3.

5. ORIGEN2 calculation of the relative production of the indicated plutonium isotopes as a function of irradiation time at a power level of 37.5 MW (thermal) in a hypothetical natural-uraniumfueled BWR. Data points defined by our analysis of sample BG-5223 are plotted at an irradiation length of 33 days.

6. Reactor-power dependence of the integrated flux needed to produce plutonium that is $68{ }^{240} \mathrm{Pu}$ by mass in a natural-uraniumfueled BWR. ORIGEN2 calculation.

7. Reactor-power dependence of two plutonium observables, $\left({ }^{242} \mathrm{Pu} /{ }^{239} \mathrm{Pu}\right)_{\text {mass }}$ and $\left({ }^{238} \mathrm{Pu} /\left({ }^{239} \mathrm{Pu}+{ }^{240} \mathrm{Pu}\right)\right)$ activity, for product containing $6 \%$ ${ }^{240} \mathrm{Pu}$ by mass, in a natural-uranium-fueled BWR. ORIGEN2 calculation. 


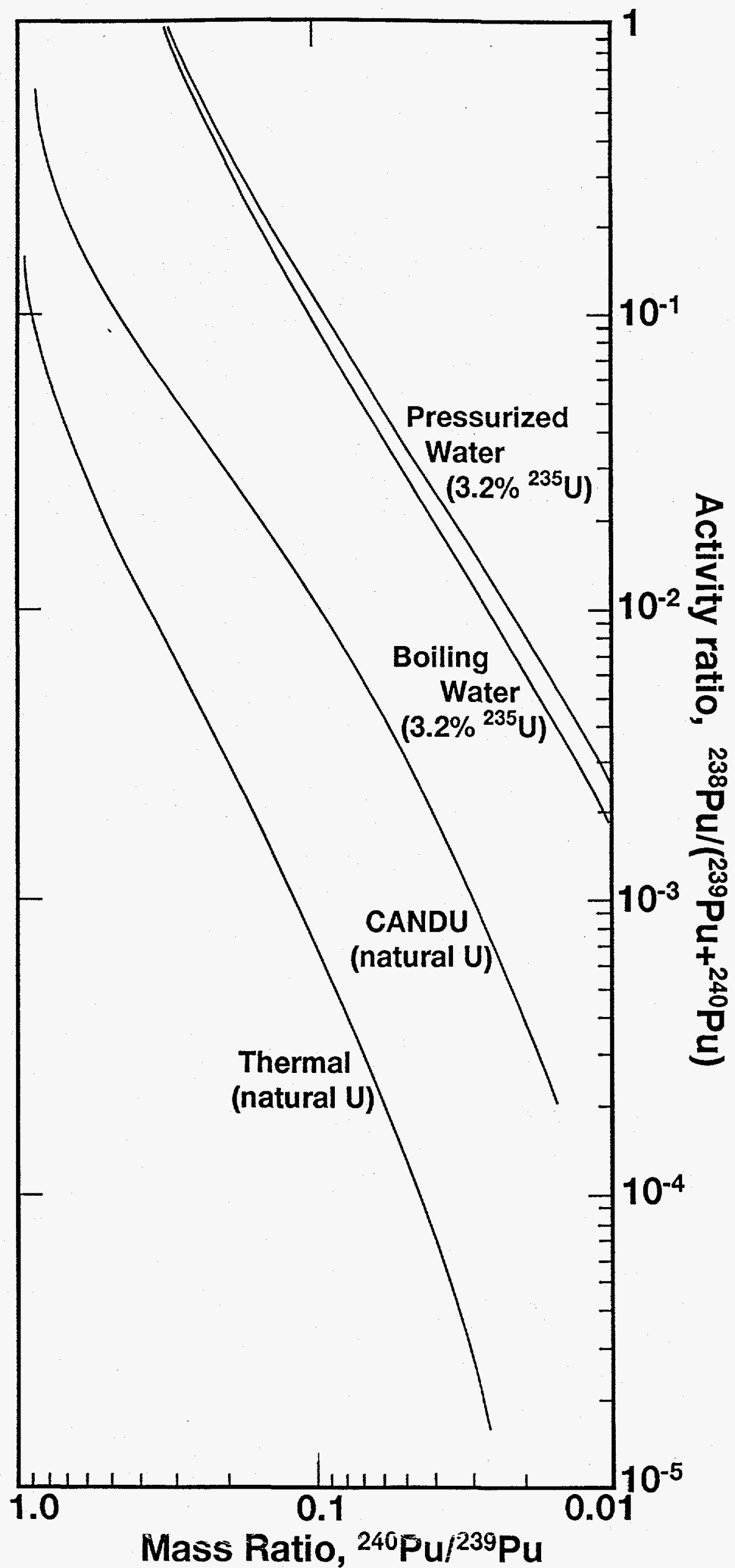




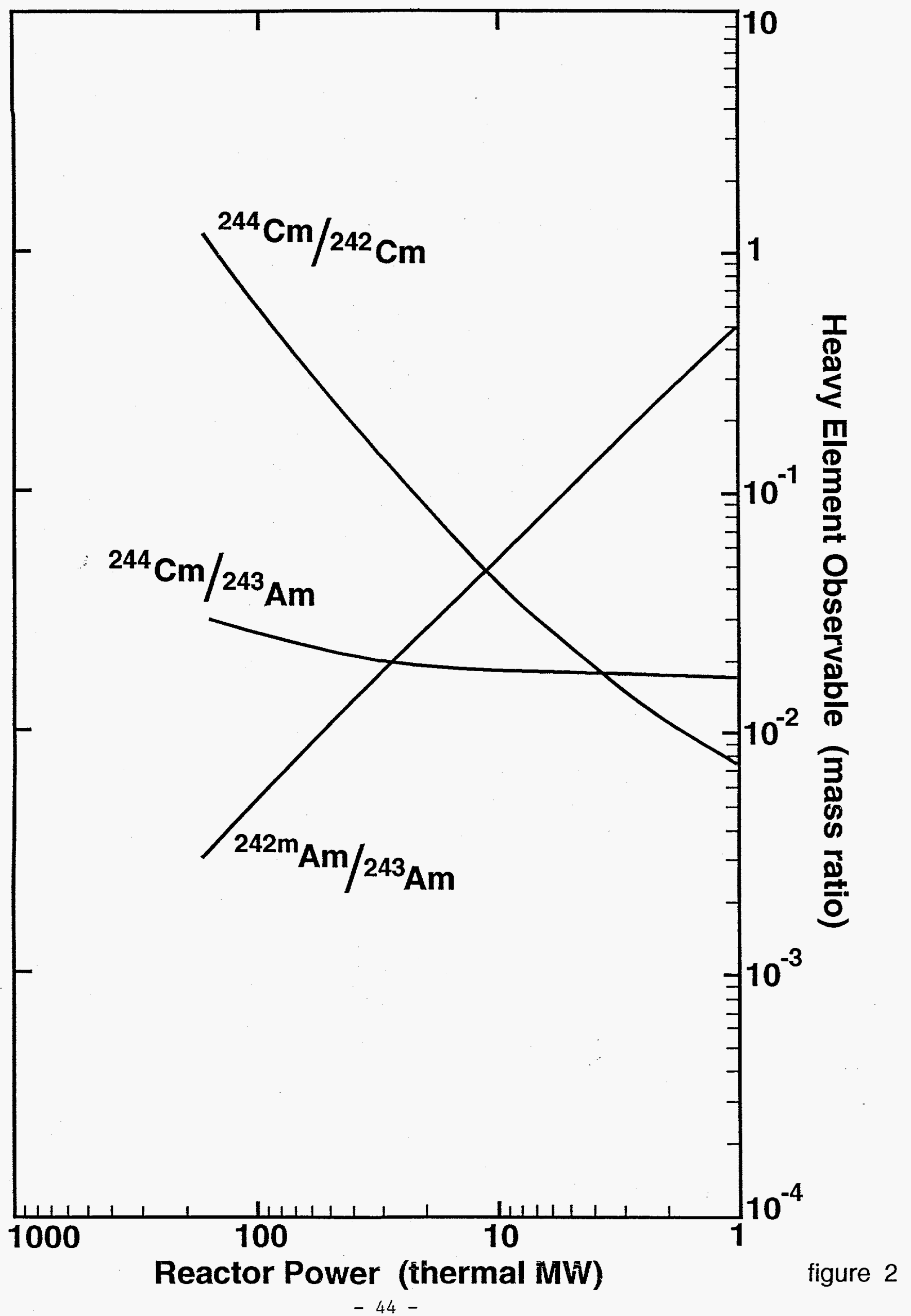




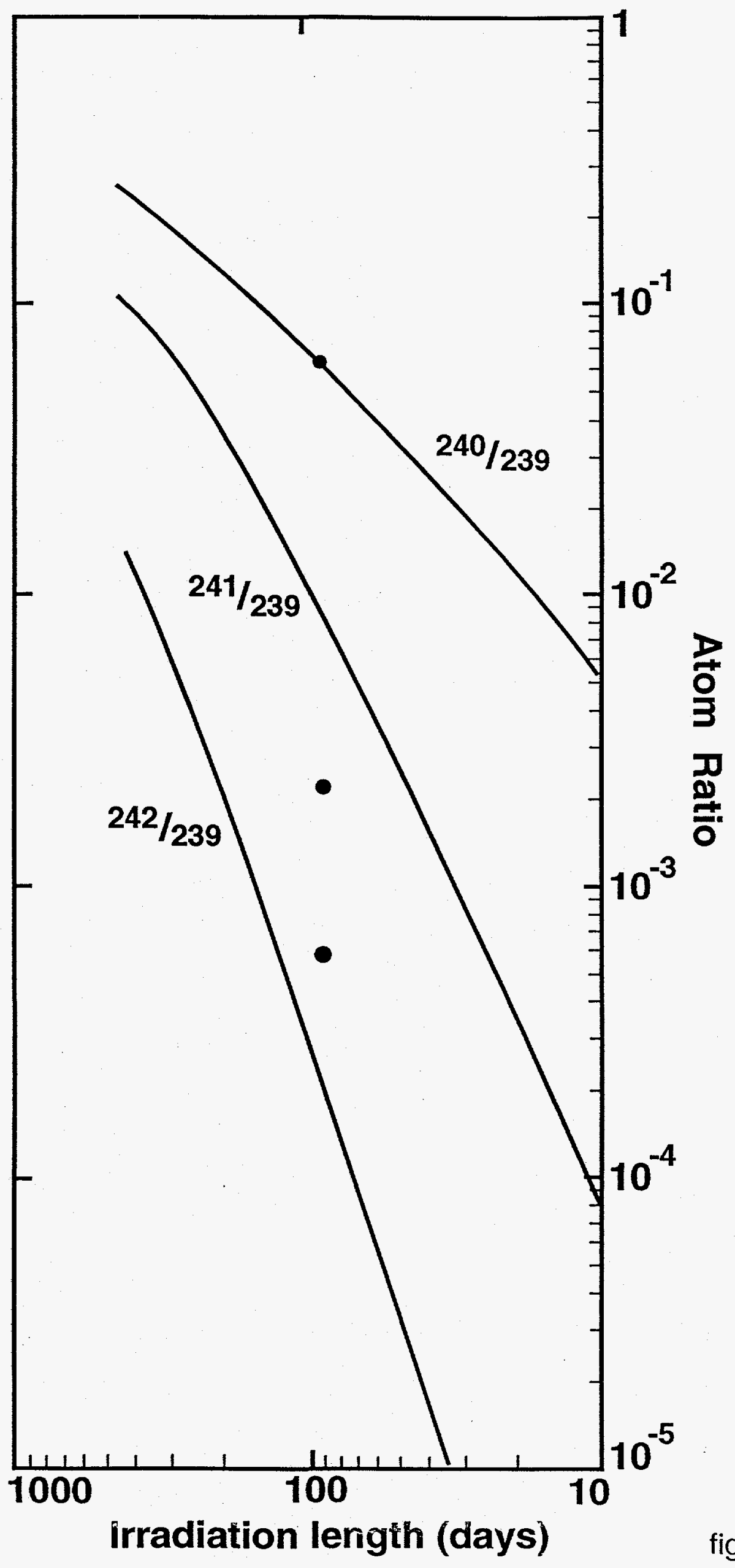

-45 -

figure 3 


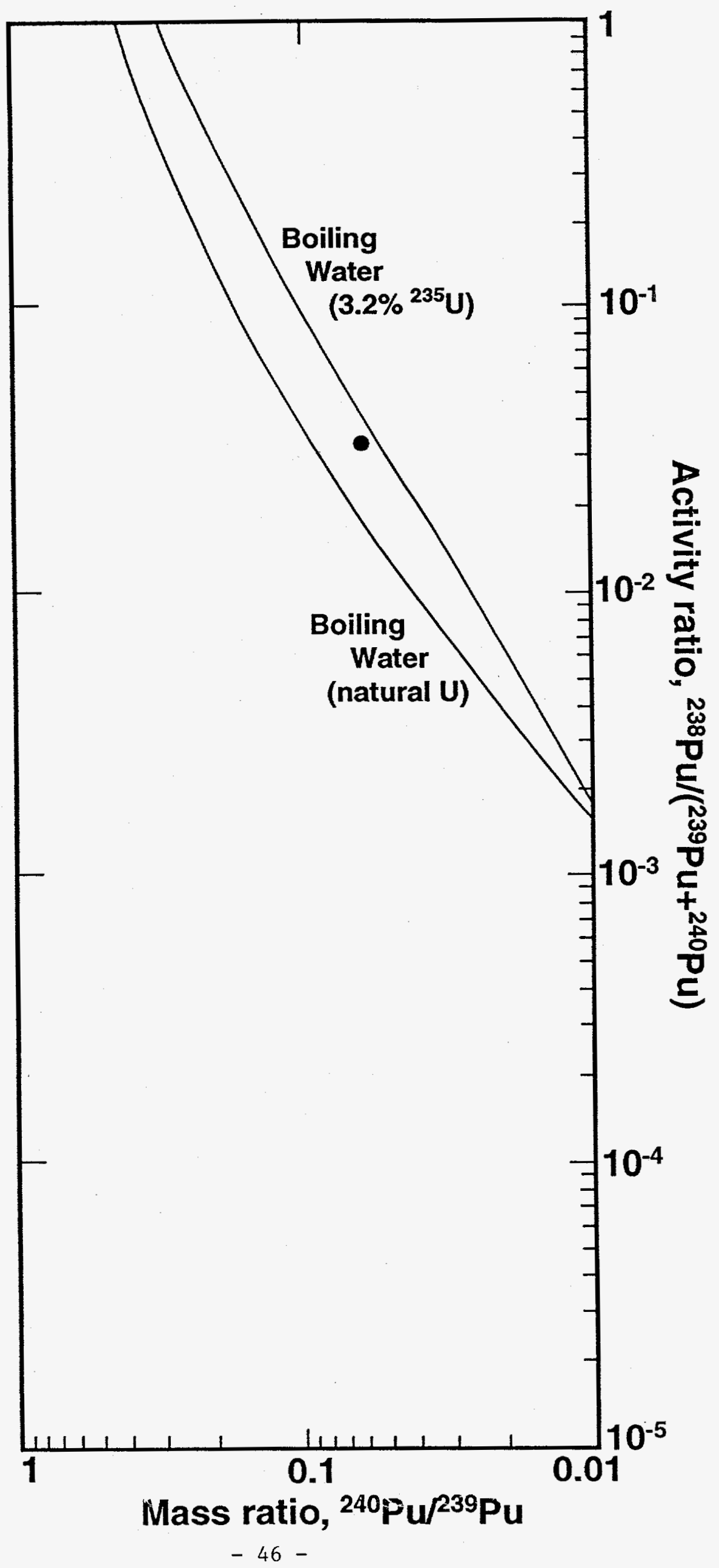




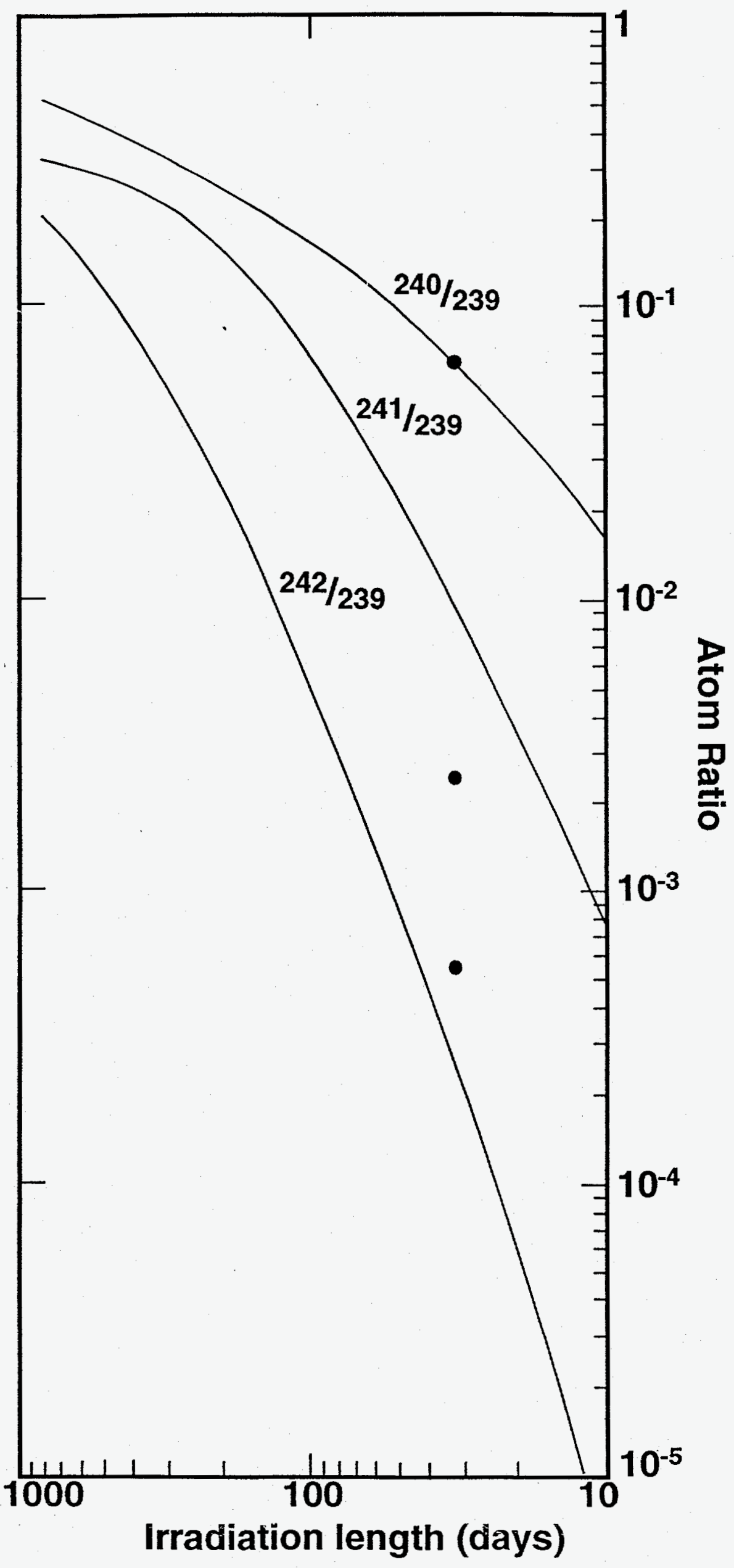

-47 -

figure 5 


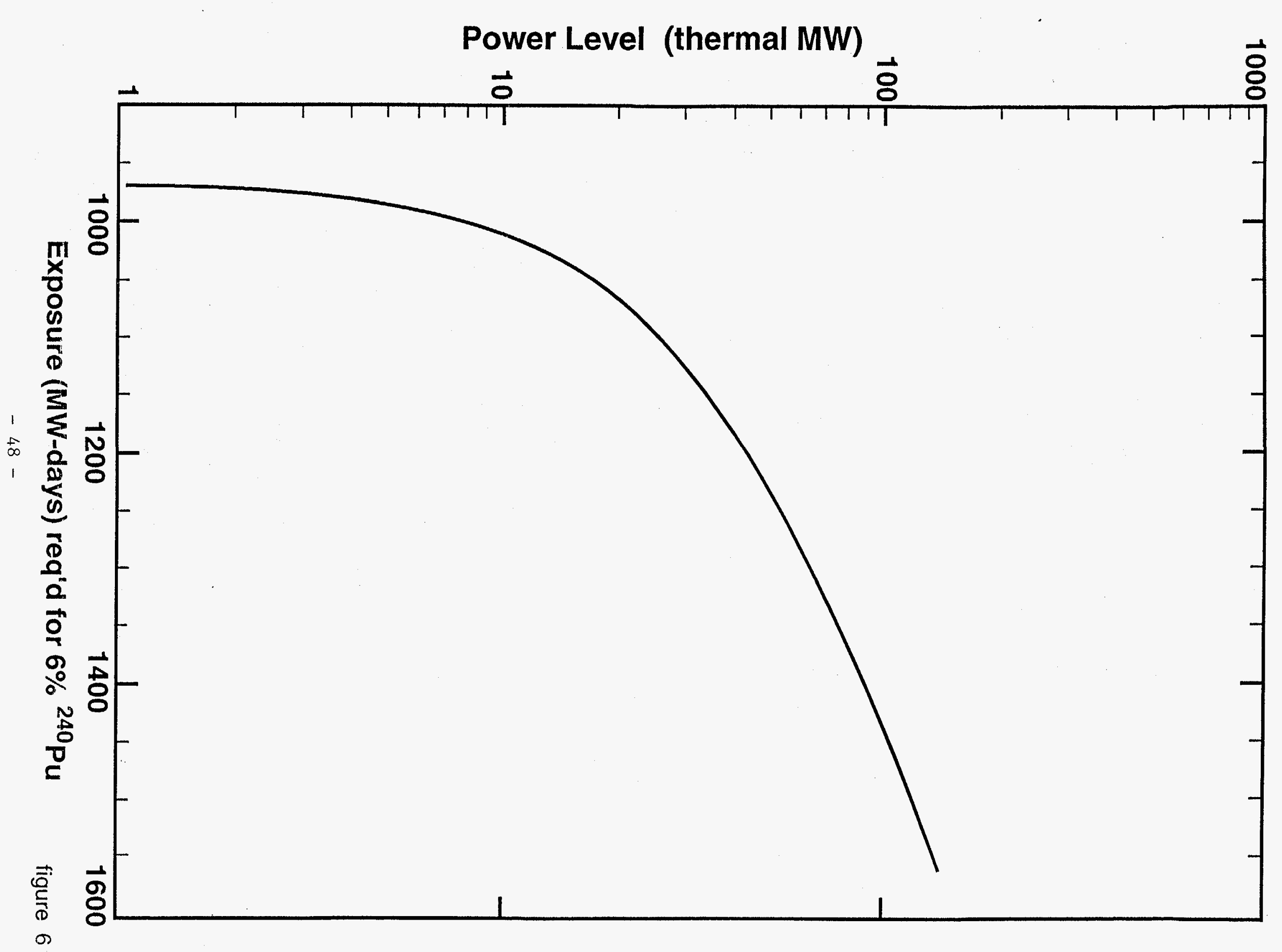




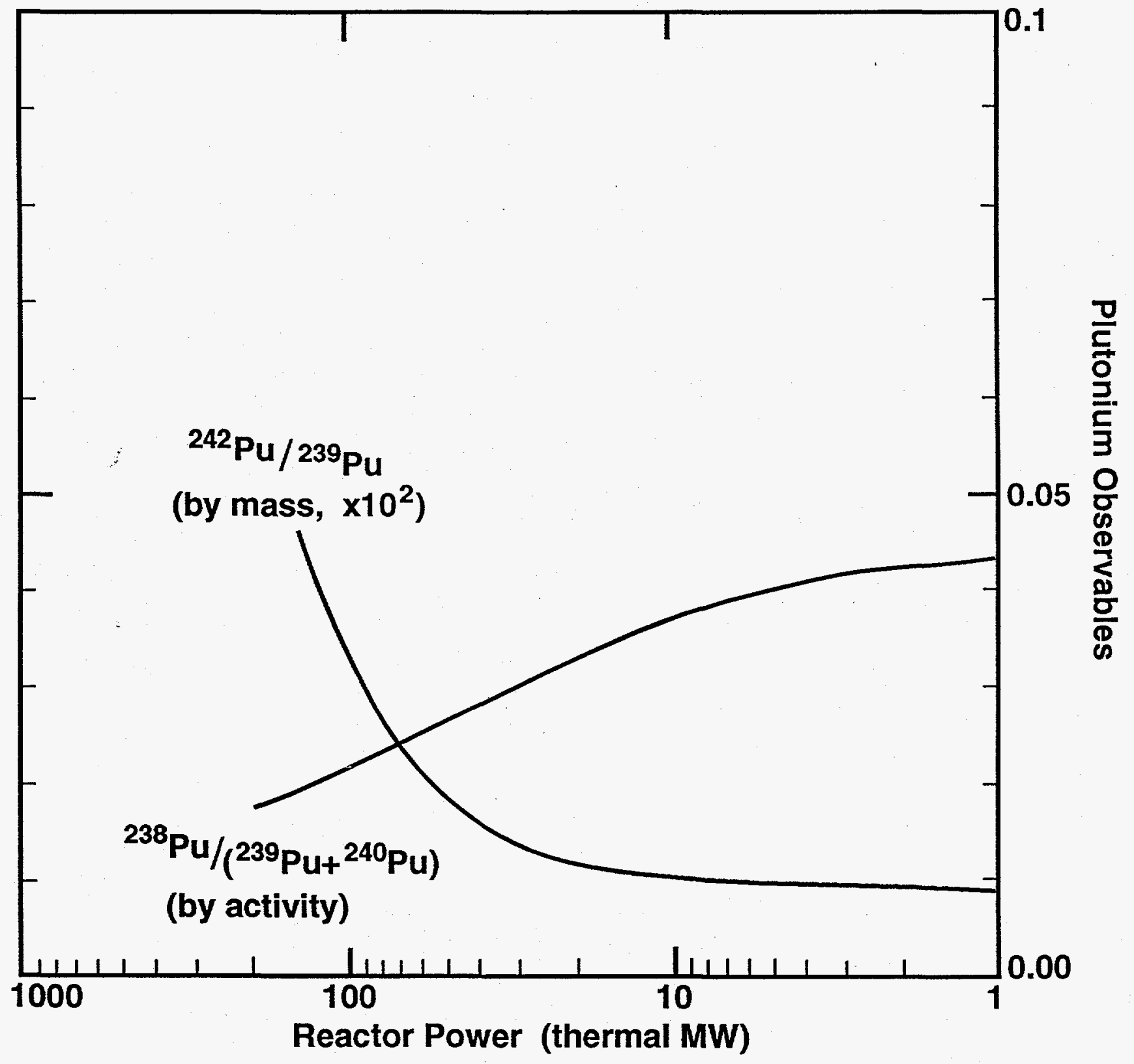

figure 7 
Appendix A. Chemical procedure used in the analysis of sample BG$522-3,850 \mathrm{mg}$ weapons-grade plutonium.

\section{Introduction}

Impurities in bulk samples of $\mathrm{Pu}$ metal can be used to determine information about the origin of the material. The following radiochemical procedure is intended to result in very pure chemical fractions of the heavy elements ( $T h, \mathrm{~Pa}, \mathrm{U}, \mathrm{Np}, \mathrm{Am}$, $\mathrm{Cm}$ ) and several long-lived or stable fission products (Kr, Sr, Zr, $\mathrm{Tc}, \mathrm{Ru}, \mathrm{Sb}, \mathrm{I}, \mathrm{Cs}, \mathrm{Ce}, \mathrm{Nd}, \mathrm{Eu}$ ) which can be analyzed by radiation counting and/or mass spectrometry to address this problem.

The procedure is designed to start with approximately 1 gram of $\mathrm{Pu}$ metal. The work has been broken down into days, assuming one chemist working 12 hours/day; the order in which steps are performed is designed to complete fractions containing short-lived chemical-yield indicators as rapidly as possible.

\section{Apparatus}

The handling of samples and chemical intermediates containing more than 200 uCi of alpha radioactivity must be performed in a glove box; lower-level samples may be handled in a standard radiochemical fume hood.

The Pu sample must be dissolved under a gas flow in a system that is gas tight so that ambient $\mathrm{Kr}$ is not introduced into the sample. He gas is run through a liquid nitrogen cold trap containing activated carbon before being passed through the wall of the glove box and introduced into the dissolving apparatus. The He is used both to purge the reagents used in the dissolution of the sample and to carry the volatile sample impurities of interest. The dissolver consists of glassware that connects together through ground-glass joints, including a 50-ml reaction flask in a heating mantle, a reagent reservoir, a 50-ml trap containing $20 \mathrm{ml} 6 \mathrm{M} \mathrm{NaOH}$, and an inline filter. Between the reaction flask and the trap, the dissolver is wrapped with heating tape. $\mathrm{Kr}$ is condensed in a second liquid nitrogen cold trap containing activated carbon. The $\mathrm{Kr}$ trap must be thoroughly baked out and purged prior to use. The line to the $\mathrm{Kr}$ trap must have a shunt to allow the trap to be bypassed during purging operations.

Other apparatus in glove box:

hot plate

$60 \mathrm{ml}$ separatory funnels ( $3 \mathrm{ea}$ )

$25 \mathrm{ml}$ volumetric flasks (2 ea)

20 ul micropipet, calibrated

5 ul micropipet

$250 \mathrm{ml}$ Erlenmeyer flasks ( 3 ea)

$40 \mathrm{ml}$ centrifuge cones (12 ea) poly waste container compressed air (regulated) mineral-oil bath hot-water bath thermometer

beta-gamma survey instrument $40 \mathrm{ml}$ polycarbonate cone 
$12 \mathrm{ml}$ centrifuge cones (20 ea)

transfer pipets

glass planchets (15 ea)

Dowex-1x8 anion-exchange column, 100-140 mesh, $1.4-\mathrm{cm}$ dia $\mathrm{x}$

20-cm long, Saran-wool plug at column tip

Dowex-1x8 anion-exchange column, 100-140 mesh, 6-mm dia $x$

8- cm long, Saran-wool plug at column tip, plastic body ( 2 ea)

Dowex 1x8 anion-exchange column, 100-140 mesh, 4-mm dia $\mathrm{x}$

8-cm long, glass-wool plug

Dowex 1x8 anion-exchange column, 100-140 mesh, 2.5-mm dia $x$

5-cm long, glass-wool plug

Dowex $50 \times 4$ cation-exchange column, 4-mm dia $x$ 8-cm long

AG MP-50 cation-exchange column, $4-\mathrm{mm}$ dia $\times 6-\mathrm{cm}$ long

AG MP-1 anion-exchange column, 2.5-mm dia $x$ 5- $\mathrm{cm}$ long

Apparatus in fume hood:

drying oven, $110^{\circ} \mathrm{C}$

hot plate

heat lamp

Bunsen burner

centrifuge

ice bath

mineral-oil bath

transfer pipets

10 ul micropipets ( 2 ea)

alpha survey instrument

column heater
Millipore frit and chimney, vacuum 1" dia nitrocellulose filters ( 5 ea)

1" dia Whatman 542 filters ( 5 ea) mixer

parafilm

hot-water bath

thermometer

$250 \mathrm{ml}$ separatory funnel

20 ul micropipet, calibrated

beta-gamma survey instrument

electroplating cells ( 2 ea)

glass planchets (sample collection) (100 ea)

1" dia Pt counting disks (12 ea)

1" dia stainless-steel counting disks ( 2 ea)

$12 \mathrm{ml}$ centrifuge cones ( $35 \mathrm{ea)}$

$40 \mathrm{ml}$ centrifuge cones ( 10 ea)

$12 \mathrm{ml}$ polycarbonate cones (10 ea)

$40 \mathrm{ml}$ polycarbonate cone

Dowex $1 \times 8$ anion-exchange columns, 100-140 mesh, 4-mm dia $x$

8-cm long, glass-wool plug ( 3 ea)

Dowex 1x8 anion-exchange column, 100-140 mesh, 4-mm dia $\mathrm{x}$

8-cm long, Saran-wool plug, plastic column body

Dowex $1 x 8$ anion-exchange columns, 100-140 mesh, 2.5-mm dia $x$

5-cm long, glass-wool plug (15 ea)

Dowex 1x8 anion-exchange columns, 100-140 mesh, 2.5-mm dia $x$

5-cm long, Saran-wool plug ( 2 ea)

Dowex 50x4 cation-exchange columns, $2.5-\mathrm{mm}$ dia $\mathrm{x} 5$-cm long ( 3 ea)

AG MP-50 cation-exchange columns, 4 -mm dia x 6-cm long ( 2 ea)

AG MP-50 cation-exchange columns, $2.5-\mathrm{mm}$ dia $\mathrm{x} 5-\mathrm{cm}$ long ( 2 ea)

AG MP-1 anion-exchange column, 2.5-mm dia x 5-cm long ( 2 ea)

Dowex-50x12 cation-exchange column, colloidal, 2.5-mm dia x 5$\mathrm{cm}$ long, pt capillary tip 
Reagents

in glove box

$20 \mathrm{mg} \mathrm{KI}$

$5 \mathrm{mg} \mathrm{RuCl} 1_{4}$

$120 \mathrm{ng} / \mathrm{ml}^{142} \mathrm{Nd}$

${ }^{246} \mathrm{Cm} /{ }^{243} \mathrm{Am}$ tracer

$1 \mathrm{mg} \mathrm{CsCl}$

$30 \mathrm{mg} \mathrm{KNO}_{2}$

He gas purge

$1 \mathrm{ml}$ fluoroboric acid

$10 \mathrm{ml}$ sat'd HCl, 108 in ethanol

$20 \mathrm{ml}$ methylisobutylketone (hexone)

$30 \mathrm{ml} 2 \mathrm{M} \mathrm{HCl}$

$60 \mathrm{ml} 0.2 \mathrm{M}$ thenoyltrifluoroacetone

$5 \mathrm{ml} 908$ methanol/108 conc $\mathrm{HNO}_{3}$

$10 \mathrm{mI} 30 \%$ methanol/5M $\mathrm{HNO}_{3}$

$10 \mathrm{ml} 1: 12$ conc $\mathrm{HI} / \mathrm{COnC} \mathrm{HCl}$ (fresh, $\mathrm{PO}_{4}{ }^{3-}$-free)

in fume hood

$20 \mathrm{ml}$ fuming $\mathrm{HNO}_{3}$

$2 \mathrm{ml}$ conc $\mathrm{HNO}_{3}$

$50 \mathrm{ml} 8 \mathrm{M} \mathrm{HNO}_{3}$

$1 \mathrm{ml} \quad 6 \mathrm{M} \mathrm{HNO}_{3}$

$60 \mathrm{ml}$ Conc $\mathrm{HCl}$

$30 \mathrm{ml} 9 \mathrm{M} \mathrm{HCl}$

$50 \mathrm{mI} 6 \mathrm{M} \mathrm{HCl}$

$20 \mathrm{ml} 3 \mathrm{M} \mathrm{HCl}$

$20 \mathrm{mI} 1 \mathrm{M} \mathrm{HCl}$

$20 \mathrm{mI} 0.5 \mathrm{M} \mathrm{HCl}$

$2 \mathrm{ml}$ conc $\mathrm{HClO}_{4}$

$1 \mathrm{ml} 1 \mathrm{M} \mathrm{HNO}$

$50 \mathrm{ml}$ sat'd HCl, $10 \%$ in ethanol

$20 \mathrm{ml} 9 \mathrm{M} \mathrm{HCl} / 0.02 \mathrm{M} \mathrm{HF}$

$10 \mathrm{ml} 4 \mathrm{M} \mathrm{HCl} / 0.1 \mathrm{M} \mathrm{HF}$

$2 \mathrm{ml} 100 \mathrm{mg} / \mathrm{ml} \mathrm{SnCl}_{2}$ in $9 \mathrm{M} \mathrm{HCl}$ (fresh)

$1 \mathrm{ml}$ thymolphthalein in $0.1 \%$ ethanol

$15 \mathrm{ml}$ sat'd mandelic acid

$10 \mathrm{ml} 5 \%$ mandelic acid in $2 \% \mathrm{HCl}$

$10 \mathrm{ml}$ diisopropyl ether

$10 \mathrm{ml} 90 \%$ methanol/10\% conc $\mathrm{HNO}_{3}$

$30 \mathrm{ml} 308$ methanol $/ 5 \mathrm{M} \mathrm{HNO}_{3}$

$10 \mathrm{mg}$ tetraphenylarsonium chloride

$200 \mathrm{mg} \mathrm{KClO}_{3}$

$2 \mathrm{ml} 0.05 \mathrm{M}$ alpha-hydroxyisobutyric acid

$2 \mathrm{ml} 0.15 \mathrm{M}$ alpha-hydroxyisobutyric acid
$300 \mathrm{ml} 8 \mathrm{M} \mathrm{HNO}_{3}$

$20 \mathrm{ml} 6 \mathrm{M} \mathrm{HNO}_{3}$

$5 \mathrm{ml}$ conc $\mathrm{H}_{2} \mathrm{SO}_{4}$

$20 \mathrm{ml} 508 \mathrm{NaOH}$

$40 \mathrm{ml} 6 \mathrm{M} \mathrm{NaOH}$

$3 \mathrm{ml} 30 \% \quad \mathrm{H}_{2} \mathrm{O}_{2}$

$1 \mathrm{ml}$ Conc $\mathrm{HClO}_{4}$

$10 \mathrm{ml}$ xylene

$1 \mathrm{ml}$ sat'd $\mathrm{NH}_{4} \mathrm{NO}_{2}$

$10 \mathrm{ml} \mathrm{CCl}_{4}$

$60 \mathrm{ml} 1 \mathrm{M} \mathrm{HNO}_{3}$

(TTA) in xylene
$1 \mathrm{ml} 1 \mathrm{M} \mathrm{NaHSO}_{3}$

$1 \mathrm{M} \mathrm{KNO}$

$2 \mathrm{ml} 10 \mathrm{mg} / \mathrm{ml} \mathrm{Pd}\left(\mathrm{NO}_{3}\right)_{2}$

$2 \mathrm{ml} 10 \mathrm{mg} / \mathrm{ml} \operatorname{Sr}\left(\mathrm{NO}_{3}\right)_{2}$

$3 \mathrm{ml} 10 \mathrm{mg} / \mathrm{ml} \mathrm{La}\left(\mathrm{NO}_{3}\right)_{3}$

$1 \mathrm{ml} \mathrm{Br}_{2}$

$10 \mathrm{ml}$ isopropanol

$1 \mathrm{ml} 20 \mathrm{mg} / \mathrm{ml} \mathrm{CsNO}_{3}$

$1 \mathrm{ml} 10 \mathrm{mg} / \mathrm{ml} \mathrm{FeCl}_{3}$

$10 \mathrm{ml}$ conc $\mathrm{HF}$

$1 \mathrm{ml} 5 \mathrm{mg} / \mathrm{ml} \mathrm{GaCl}{ }_{3}$

$1 \mathrm{ml} 10 \mathrm{mg} / \mathrm{ml} \mathrm{SbCl}_{3}$

$1 \mathrm{ml} 10 \mathrm{mg} / \mathrm{ml} \mathrm{SnCl}_{4}$

$20 \mathrm{ml} 5 \mathrm{M} \mathrm{NaOH}$

$10 \mathrm{ml}$ conc $\mathrm{NH}_{4} \mathrm{OH}$

$2 \mathrm{ml} \mathrm{gl}$. acetic acid

$5 \mathrm{ml} 1 \mathrm{M} \mathrm{NaOH}$

$4 \mathrm{ml}$ sat'd $\mathrm{H}_{3} \mathrm{BO}_{3}$

$\mathrm{H}_{2} \mathrm{~S}$ gas

pHydrion indicator

$20 \mathrm{ml}$ sat'd $\left(\mathrm{NH}_{4}\right)_{2} \mathrm{C}_{2} \mathrm{O}_{4}$

$20 \mathrm{ml}$ sat'd $\mathrm{Na}_{2} \mathrm{CO}_{3}$

$5 \mathrm{ml}$ sat'd $\mathrm{NH}_{4} \mathrm{NO}_{2}$

$2 \mathrm{ml} 5 \% \mathrm{H}_{2} \mathrm{PtCl}_{6}$

$1 \mathrm{ml}$ conc HI ( $\mathrm{PO}_{4}{ }^{3-}$-free)

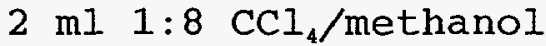

$1 \mathrm{ml} 308 \quad \mathrm{H}_{2} \mathrm{O}_{2}$

$20 \mathrm{ml} \mathrm{CCl}_{4}$

$20 \mathrm{ml}$ ethanol

$15 \mathrm{ml}$ methanol

$20 \mathrm{ml} \mathrm{CHCl}_{3}$ 
$2 \mathrm{ml} 0.23 \mathrm{M}$ alpha-hydroxyisobutyric acid

$2 \mathrm{ml} 0.32 \mathrm{M}$ alpha-hydroxyisobutyric acid

$2 \mathrm{ml} 0.98 \mathrm{M}$ alpha-hydroxyisobutyric acid

$30 \mathrm{ml} 1: 12$ conc $\mathrm{HI} / \mathrm{Conc} \mathrm{HCl}$ (fresh, $\mathrm{PO}_{4}{ }^{3-}$-free)

Procedure

Day 1:

To the reaction vessel add $0.1 \mathrm{ug}{ }^{142} \mathrm{Nd}$ (in dil $\mathrm{HCl}$ ), $10^{4}$ alpha disintegrations/minute of the ${ }^{246} \mathrm{Cm} /{ }^{243} \mathrm{Am}$ tracer, and $2 \mathrm{mg} \mathrm{RuCl}_{4}$. Gently evaporate to dryness. Add $20 \mathrm{mg} \mathrm{KI}$ and the plutonium metal sample, then seal the reaction vessel to the gas system, purge the system and the aqueous reagents with He gas, and assemble the heating system. $10 \mathrm{ml} 6 \mathrm{M} \mathrm{HCl}$ from the reservoir is added dropwise to the sample in the reaction vessel (which can be heated to facilitate dissolution, if required). During dissolution, the He gas carries fission-product $\mathrm{Kr}$ from the reaction vessel through the $6 \mathrm{M} \mathrm{NaOH}$ trap and a dry in-line filter (room temperature), and back through the wall of the glove box to where it is condensed in an activated-carbon trap in liquid nitrogen. Dissolution should take about 20 minutes, after which the $\mathrm{Kr}$ trap is valved off and sent for gas analysis.

At this point the reaction vessel should contain an intensely blue solution $\left(\mathrm{Pu}^{3+}\right)$ and some black grit $\left(\mathrm{PuO}_{2}\right)$. Under a reduced gas flow (the He effluent is now exhausted into the glove box), the reaction vessel is heated until only a moist residue remains. The solution in the trap is then replaced with a new aliquot of $20 \mathrm{ml}$ $6 \mathrm{M} \mathrm{NaOH}$, and $10 \mathrm{mI} 6 \mathrm{M} \mathrm{HNO}_{3}$ (containing a few drops of $308 \mathrm{H}_{2} \mathrm{O}_{2}$ ) is added to the reaction vessel through the reservoir. Distillation is started immediately, still under a reduced flow of He gas, and continues until the evolution of $\mathrm{NO}_{\mathrm{x}}$ becomes vigorous (about an hour). Both the heating mantle and the heating tape must be used to keep the entire system warm during the distillation.

The $\mathrm{NaOH}$ trap collects fission-product $\mathrm{I}, \mathrm{Ru}$, and (to a lesser degree) Tc. The solution is acidified with conc $\mathrm{H}_{2} \mathrm{SO}_{4}$ (cautiously) until it turns an orange-brown color, and then is transfered to a 60-ml separatory funnel. $30 \mathrm{mg} \mathrm{KNO}_{2}$ is added to the solution, and $\mathrm{I}$ and $\mathrm{Ru}$ are extracted into $\mathrm{CCl}_{4}$ twice (total $10 \mathrm{ml}$ ). The purple organic phase is transfered out of the glove box to the fume hood. The aqueous phase is made basic with the addition of $50 \% \mathrm{NaOH}$. The base is added carefully until the solution starts to salt out, then $\mathrm{H}_{2} \mathrm{O}$ is added until the salt redissolves; this should result in a solution that is about $5 \mathrm{M}$ in $\mathrm{OH}^{-}$. Tc is extracted into hexone (methylisobutylketone) twice, with a total volume of $20 \mathrm{ml}$. The organic phase is transfered out of the glove box to the fume hood.

Iodine is back-extracted from the $\mathrm{CCl}_{4}$ fraction twice with 10 $\mathrm{ml} \mathrm{H}_{2} \mathrm{O}$ containing 3 drops $1 \mathrm{M} \mathrm{NaHSO}$, leaving $\mathrm{Ru}$ in the organic phase. $1 \mathrm{ml} 6 \mathrm{M} \quad \mathrm{HNO}_{3}$ and 5 drops $1 \mathrm{M} \mathrm{KNO}_{2}$ are added to the aqueous phase, and $\mathrm{I}$ is re-extracted into $\mathrm{CCl}_{4}$ twice, in a total volume of 
$5 \mathrm{ml}$. Iodine is again back-extracted into $\mathrm{H}_{2} \mathrm{O}$ containing 2 drops $1 \mathrm{M} \mathrm{NaHSO}$, and the aqueous fraction is heated in a hot-water bath under an air stream for about 30 minutes to drive off any residual $\mathrm{CCl}_{4}$. $2 \mathrm{ml} \mathrm{Pd}^{2+}$ carrier is added to this fraction, which is then returned to the hot-water bath for several minutes. The fraction is then filtered through a nitrocellulose filter, and the $\mathrm{PdI}_{2}$ precipitate is washed twice with water and three times with ethanol before being dried (gently) under the heat lamp.

Methanol is added to the ruthenium fraction in $\mathrm{CCl}_{4}$ until $\mathrm{RuO}_{2}$ precipitates. After centrifuging, the supernatant liquid is decanted, and the precipitate is washed with a mixture of 8 parts methanol to 1 part $\mathrm{CCl}_{4}$. After centrifuging, the precipitate is dissolved/slurried in a minimum volume of $\mathrm{CCl}_{4}$, and the mixture is stippled onto a stainless-steel counting disk under the heat lamp.

The hexone solution of $\mathrm{TC}$ is washed with a fresh solution of $5 \mathrm{M} \mathrm{NaOH} .10 \mathrm{ml} \mathrm{CHCl}{ }_{3}$ is added to the organic phase, and TC is back-extracted into $\mathrm{H}_{2} \mathrm{O}$ twice, a total of $15 \mathrm{ml}$. Tetraphenylarsonium cloride (about $1 \mathrm{mg}$ ) is added to the aqueous phase, and Tc is extracted twice into $\mathrm{CHCl}_{3}$. The combined organic phase (about $7 \mathrm{ml} \mathrm{CHCl}_{3}$ total) is evaporated to a small volume in a hotwater bath under an air stream, and is then stippled onto a stainless-steel counting disk under the heat lamp.

The reaction vessel in the glove box is kept warm overnight under a flow of He gas to result in a dry $\mathrm{Pu}$ deposit.

\section{Day 2:}

The distillation apparatus is broken down into component parts, all of which are washed into the reaction vessel with conc $\mathrm{HCl}$ (total volume approximately $10 \mathrm{ml}$ ). The reaction flask is reinserted into the heating mantle, and the temperature is slowly increased until the evolution of $\mathrm{NO}_{\mathrm{x}}$ is complete and the solvent refluxes, but short of the boiling point. After about an hour of refluxing, the contents of the reaction vessel are allowed to cool and settle, and the dark-brown supernatant liquid is transfered to a 25-ml volumetric flask. Once again, the distillation glassware is rinsed into the reaction vessel (with approximately $5 \mathrm{ml} 9 \mathrm{M}$ $\mathrm{HCl}$ ). After 30 minutes of refluxing, the contents of the reaction vessel are allowed to cool and settle, and the supernatant liquid is pooled with the previous supernate in the $25-\mathrm{ml}$ volumetric flask. The volumetric flask is placed on a hot plate and maintained at a temperature of approximately $70^{\circ} \mathrm{C}$ to complete $\mathrm{NO}_{\mathbf{x}}$ evolution.

The reaction vessel probably contains black and gray flakes of $\mathrm{PuO}_{2}$ from surface oxidation of the original sample. The distillation glassware is washed into the reaction vessel with a solution of $6 \mathrm{M} \mathrm{HCl}$ containing 2 drops of fluoroboric acid. The vessel is maintained at a temperature of $70^{\circ} \mathrm{C}$ for two hours, until sample dissolution is complete. In the dissolution, the action of the fluoroboric acid is semi-catalytic; avoid adding more if at all 
possible. When the dissolution is complete, pool the solution to the 25-ml volumetric flask containing the rest of the sample, then wash the reaction vessel into the volumetric flask using a minimum volume of $9 \mathrm{M} \mathrm{HCl}$. At this point the quantitative transfer of the sample to the volumetric flask has been accomplished.

The volumetric flask is kept on the hotplate for another hour to ensure that the dissolution of fine particles is complete. The flask is then allowed to cool, and conc $\mathrm{HCl}$ is added to bring the sample volume up to a quantitative $25 \mathrm{ml}$. After the sample is thoroughly mixed, a quantitative 20 ul aliquot is taken to a new volumetric flask which is diluted to $25 \mathrm{ml}$ with $2 \mathrm{M} \mathrm{HCl}$. This primary dilution is passed out of the glove box to the fume hood.

In the glove box, a 1.4-cm-diameter Dowex-1x8 anion-exchange column is preconditioned with conc $\mathrm{HCl}$. The solution from the 25$\mathrm{ml}$ volumetric flask is loaded onto the column, the first $5 \mathrm{ml}$ of eluant are discarded, then fraction $\mathrm{X}$ is collected in a $40-\mathrm{ml}$ centrifuge cone containing one crystal of CsCl. The column is washed four times with $10 \mathrm{ml}$ conc $\mathrm{HCl}$, collecting the first wash eluant with the load solution and the next three aliquots in a second 40-ml centrifuge cone, also containing a crystal of $\mathrm{CsCl}$. The $\mathrm{X}$ solutions are colorless; a brown $\mathrm{Pu}$ deposit takes up the top quarter of the column resin bed. The two $X$ solutions are placed in a hot-water bath and evaporated to small volumes under an air stream. The solution from the second cone is then transfered to the first cone using a small amount of $6 \mathrm{M} \mathrm{HCl}$ as a wash solution, then the pooled $x$ solution is evaporated to dryness.

Fraction $\mathrm{Y}$ is eluted from the column with $200 \mathrm{ml} 8 \mathrm{M} \mathrm{HNO}_{3}$, collected in a 250-ml Erlenmeyer flask. During this process, the $\mathrm{Pu}$ adsorbed on the column changes to an intense green color. The $Y$ solution is evaporated to a small volume under an air stream and is transfered to a $40 \mathrm{ml}$ centrifuge cone with washes of $8 \mathrm{M} \mathrm{HNO}_{3}$, and is then placed in a hot-water bath and evaporated to a moist deposit (not dry).

$\mathrm{Pu}$ is eluted from the column with $120 \mathrm{ml}$ of $1 \mathrm{M} \mathrm{HCl}$, collected in a 250-ml Erlenmeyer flask. Upon completion of this step, $20 \mathrm{ml}$ conc $\mathrm{HCl}$ are added to the flask to guard against formation of plutonium polymer. The flask is sealed with Parafilm and stored.

In the fume hood, quantitative 20-ul aliquots of the solution in the 25-ml volumetric flask containing the primary dilution of the original stock solution are stippled onto Pt counting disks and evaporated to dryness under a heat lamp. These samples are heated briefly in a Bunsen-burner flame. Each source contains about $10^{5}$ alpha disintegrations/minute, which is an appropriate size for counting at low geometry.

Day 3:

The $\mathrm{X}$ fraction contains the trivalent actinides, the rare earths, Cs, Sr, and Th. $0.5 \mathrm{ml} 8 \mathrm{M} \mathrm{HNO}_{3}$ is added to dry fraction $\mathrm{X}$, which is again evaporated to dryness. $2 \mathrm{ml} 8 \mathrm{M} \mathrm{HNO}_{3}$ and 1 drop 
saturated $\mathrm{NH}_{4} \mathrm{NO}_{2}$ are added to the sample, which is heated briefly, then loaded onto a 4-mm-diameter Dowex-1x8 anion-exchange column, preconditioned with $8 \mathrm{M} \mathrm{HNO}_{3}$. The load solution and $10 \mathrm{ml} 8 \mathrm{M} \mathrm{HNO}_{3}$ wash eluant are collected in a 40-ml centrifuge cone; this is the new fraction $X$. 5 drops $30 \% \mathrm{H}_{2} \mathrm{O}_{2}$ are added to the new $X$ solution, which is evaporated to dryness under an air stream in a hot-water bath. From this point until the rare-earth separation (day 5) the light should remain on in the glove box to ensure that cerium is not oxidized.

The Th fraction is eluted from the column with $8 \mathrm{ml} 9 \mathrm{M} \mathrm{HCl}$, collected in a 12-ml centrifuge cone. This solution is passed from the glove box to the fume hood, where it is evaporated to dryness in a hot-water bath.

$2 \mathrm{ml} 2 \mathrm{M} \mathrm{HCl}$ is added to the dry fraction $\mathrm{X}$, which is again evaporated to dryness. The sample is then dissolved in $2 \mathrm{ml} 1 \mathrm{M}$ $\mathrm{HCl}$, heated briefly, and loaded onto a 4-mm-diameter Dowex-50x4 cation-exchange column, preconditioned by cycling it up through conc $\mathrm{HCl}$ and back down to $1 \mathrm{M} \mathrm{HCl}$. The eluants from the load solution and $2 \mathrm{ml} 2 \mathrm{M} \mathrm{HCl}$ column washes are collected as the Cs/Sr fraction in a 12-ml centrifuge cone. The column is then washed with approximately $4 \mathrm{ml} 2.5 \mathrm{M} \mathrm{HCl}$. Each eluant drop is checked with a radiation survey instrument before being added to the Cs/Sr fraction; at the first indication of ${ }^{241} \mathrm{Am}$ gamma activity, collection is stopped. The $A n / R E$ fraction is then eluted with 8 $\mathrm{ml} 6 \mathrm{M} \mathrm{HCl}$, collected in a $12-\mathrm{ml}$ centrifuge cone. Both the Cs/Sr and $A n / R E$ fractions are evaporated to dryness under an air stream in a hot-water bath. The dry Cs/Sr fraction is passed out of the glove box to the fume hood.

In the fume hood, the dry Th fraction is dissolved in $1 \mathrm{ml} 8 \mathrm{M}$ $\mathrm{HNO}_{3}$ and 1 drop saturated $\mathrm{NH}_{4} \mathrm{NO}_{2}$, warmed slightly, and loaded onto a preconditioned 2.5-mm-diameter Dowex-1x8 anion-exchange column. The eluants from the load solution and $2 \mathrm{ml} 8 \mathrm{M} \mathrm{HNO}_{3}$ column washes are disposed of to waste. Th is then eluted from the column with $3 \mathrm{ml} 9 \mathrm{M} \mathrm{HCl}$, collected in a $12-\mathrm{ml}$ centrifuge cone, and evaporated to dryness. The dry sample is dissolved in $1 \mathrm{ml} 8 \mathrm{M} \mathrm{HNO}$ and 1 drop saturated $\mathrm{NH}_{4} \mathrm{NO}_{2}$, and the last ion-exchange step is repeated with a new 2.5-mm-diameter Dowex-1x8 column. The Th fraction is again evaporated to dryness.

Day 4 :

The dry $\mathrm{Th}$ fraction is dissolved in $1 \mathrm{ml} 8 \mathrm{M} \mathrm{HNO}_{3}$ and 1 drop saturated $\mathrm{NH}_{4} \mathrm{NO}_{2}$, warmed slightly, and loaded onto a preconditioned 2.5-mm-diameter Dowex-1x8 anion-exchange column. The eluants from the load solution and $2 \mathrm{ml} 8 \mathrm{M} \mathrm{HNO}_{3}$ column washes are disposed of to waste. Th is then eluted from the column with $3 \mathrm{ml} 9 \mathrm{M} \mathrm{HCl,}$ collected in a $12-\mathrm{ml}$ centrifuge cone, and again evaporated to dryness. The dry sample is dissolved in $1 \mathrm{ml} 9 \mathrm{M} \mathrm{HCl}$ and evaporated to dryness. The sample is then transfered to a tungsten filament with $6 \mathrm{M} \mathrm{HCl}$ and volatilized onto a Pt counting disk. 
The dry Cs/Sr fraction is dissolved in $1 \mathrm{mI} \mathrm{H}_{2} \mathrm{O}$. If significant $\mathrm{Ca}$ from metallurgy is present, there may be a persistent flocculent white precipitate that should be ignored. $2 \mathrm{ml} \mathrm{Sr}$ carrier is added, the solution is thoroughly mixed, and 20 $\mathrm{ml}$ iced fuming $\mathrm{HNO}_{3}$ is added. The sample is placed in an ice bath for 15 minutes, then is centrifuged while still cold. After decanting the supernatant liquid to a 40-ml centrifuge cone (the Cs fraction), the $\mathrm{Sr}\left(\mathrm{NO}_{3}\right)_{2}$ precipitate is dissolved in $10 \mathrm{ml} \mathrm{H}_{2} \mathrm{O}$, and conc $\mathrm{NH}_{4} \mathrm{OH}$ is added dropwise until the solution is just basic, then 10 drops more conc $\mathrm{NH}_{4} \mathrm{OH}$ are added. $2 \mathrm{ml}$ glacial acetic acid, $2 \mathrm{ml} \cdot \mathrm{Ba}^{2+}$ carrier, and $2 \mathrm{ml} 108 \mathrm{Na}_{2} \mathrm{CrO}_{4}$ are added to the sample which is then digested for 15 minutes and centrifuged. The supernatant liquid is transfered to a clean 40-ml centrifuge cone, and the $\mathrm{BaCrO}_{4}$ precipitate is discarded to waste. $5 \mathrm{ml}$ saturated $\left(\mathrm{NH}_{4}\right)_{2} \mathrm{C}_{2} \mathrm{O}_{4}$ is added to the solution, which is then digested for 10 minutes and centrifuged. The supernatant liquid is decanted to waste, and 2 $\mathrm{ml}$ conc $\mathrm{HNO}_{3}$ and $200 \mathrm{mg} \mathrm{KClO}_{3}$ are added to the $\mathrm{SrC}_{2} \mathrm{O}_{4}$ precipitate, which is then boiled in a Bunsen burner flame for 2 minutes to destroy the oxalate. The sample is diluted to $15 \mathrm{ml}$ with $\mathrm{H}_{2} \mathrm{O}$, conc $\mathrm{NH}_{4} \mathrm{OH}$ is added dropwise until the solution is just basic, then $5 \mathrm{ml}$ saturated $\mathrm{Na}_{2} \mathrm{CO}_{3}$ is added to the sample, which is digested briefly, iced, and centrifuged. The $\mathrm{SrCO}_{3}$ precipitate is washed with $10 \mathrm{ml}$ $\mathrm{H}_{2} \mathrm{O}$ and $2 \mathrm{ml}$ saturated $\mathrm{Na}_{2} \mathrm{CO}_{3} ;$ after which it is cautiously dissolved in a minimum volume of $9 \mathrm{M} \mathrm{HCl}$. To this solution is added 1 drop conc $\mathrm{HI}$ and 5 drops $\mathrm{La}^{3+}$ carrier; it is then transfered to a 12-ml polycarbonate cone with enough $\mathrm{H}_{2} \mathrm{O}$ to make a total volume of $3 \mathrm{ml}$. $1.5 \mathrm{ml}$ conc $\mathrm{HF}$ is added to the sample, which is then digested and centrifuged. The supernate is transfered to another polycarbonate cone where it is evaporated to dryness. The dry deposit is dissolved in 1 drop conc HI, 5 drops $\mathrm{La}^{3+}$ carrier, and $3 \mathrm{ml} \mathrm{H}_{2} \mathrm{O}$. $1.5 \mathrm{ml}$ conc $\mathrm{HF}$ is added to the sample, which is then digested and centrifuged. The supernate is transfered to another polycarbonate cone where it is evaporated to dryness. The sample is then dissolved in $5 \mathrm{ml} 1 \mathrm{M} \mathrm{HCl}$ and $3 \mathrm{ml}$ saturated $\mathrm{H}_{3} \mathrm{BO}_{3}$. Conc $\mathrm{NH}_{4} \mathrm{OH}$ is added dropwise until $\mathrm{Sr}(\mathrm{OH})_{2}$ precipitates. The sample is digested and centrifuged, the supernate is discarded, and the precipitate is dissolved in $1 \mathrm{M} \mathrm{HCl}$. Conc $\mathrm{NH}_{4} \mathrm{OH}$ is added dropwise until the sample is just basic, then $5 \mathrm{ml}$ saturated $\mathrm{Na}_{2} \mathrm{CO}_{3}$ is added, the solution is digested briefly and centrifuged, and the supernatant liquid is decanted to waste. The precipitate is transfered to the Millipore apparatus with $8 \mathrm{ml} \quad \mathrm{H}_{2} \mathrm{O}$ and $2 \mathrm{ml}$ saturated $\mathrm{Na}_{2} \mathrm{CO}_{3}$, where it is filtered onto whatman 542 paper. The final sample is washed once with $\mathrm{H}_{2} \mathrm{O}$ and twice with ethanol before being dried in an oven at $110^{\circ} \mathrm{C}$.

The Cs fraction is evaporated to dryness, and is then dissolved in $1 \mathrm{ml} \mathrm{Cs}$ carrier, 5 drops $\mathrm{Fe}^{3+}$ carrier, and 1 drop each of $\mathrm{Ru}^{4+}, \mathrm{Zr}^{4+}$, and $\mathrm{La}^{3+}$ carriers. 3 drops thymolphthalein indicator is added to the sample, and $1 \mathrm{M} \mathrm{NaOH}$ is added dropwise until the indicator endpoint (solution turns gray). The sample is 
centrifuged for 20 minutes, and the supernatant liquid is transfered to a $12-\mathrm{ml}$ centrifuge cone; the precipitate is discarded to waste. 3 drops $\mathrm{La}^{3+}$ carrier are added to the basic solution which is then mixed, digested for 10 minutes, and centrifuged. The supernatant 1 iquid is transfered to another $12-\mathrm{ml}$ centrifuge cone, where it is mixed with $2 \mathrm{ml} 5 \% \mathrm{H}_{2} \mathrm{PtCl}_{6}$, digested, and centrifuged. The supernate is decanted to waste, and the precipitate is slurried with $\mathrm{H}_{2} \mathrm{O}$ and transfered to the Millipore apparatus where it is filtered onto nitrocellulose. This sample is washed with $\mathrm{H}_{2} \mathrm{O}$ and dried under the heat lamp; the final sample should be mounted immediately for radiation counting, since it tends to be deliquescent.

The $Y$ fraction (in the glove box) consists of a moist deposit containing $\mathrm{Zr}, \mathrm{Sb}, \mathrm{Pa}, \mathrm{U}$, and $\mathrm{Np}$. It is dissolved in $3 \mathrm{mil} 4 \mathrm{M} \mathrm{HCl}$, heated briefly, and loaded onto a 6-mm-diameter Dowex-1x8 anionexchange column with a plastic column body and a saran-wool plug (no glass). The eluant from the load solution and $17 \mathrm{ml}$ of $4 \mathrm{M} \mathrm{HCl}$ column washes is the $\mathrm{Zr} / \mathrm{Pa} / \mathrm{Np}$ fraction, and is collected in a $40-$ $\mathrm{ml}$ polycarbonate cone. The column is then washed with $25 \mathrm{ml} 1 \mathrm{M}$ $\mathrm{HCl}$, which is the U/Sb fraction, and is collected in a 40-ml centrifuge cone. Both fractions are passed out of the glove box to the fume hood, where they are evaporated to dryness.

The dry $\mathrm{Zr} / \mathrm{Pa} / \mathrm{Np}$ fraction is dissolved in $1 \mathrm{ml} 8 \mathrm{M} \mathrm{HNO}_{3}$ and 1 drop saturated $\mathrm{NH}_{4} \mathrm{NO}_{2}$, warmed slightly, and loaded onto a $2.5-\mathrm{mm}$ diameter Dowex-1x8 anion-exchange column. The eluant from the load solution and from $2 \mathrm{ml} 8 \mathrm{M} \mathrm{HNO}$ column washes is the $\mathrm{Zr}$ fraction, and is collected in a $12-\mathrm{ml}$ polycarbonate cone. The column is then washed with conc $\mathrm{HCl}$, still collecting eluant in the $\mathrm{zr}$ fraction until $\mathrm{HCl}$ starts to come through. Pa is eluted from the column with $3 \mathrm{ml}$ of a solution that is $9 \mathrm{M}$ in $\mathrm{HCl}$ and $0.02 \mathrm{M}$ in $\mathrm{HF}$. $\mathrm{Np}$ is then eluted from the column with $3 \mathrm{ml}$ of a solution that is $4 \mathrm{M}$ in $\mathrm{HCl}$ and $0.1 \mathrm{M}$ in $\mathrm{HF}$. Both the $\mathrm{Pa}$ and $\mathrm{Np}$ fractions are collected in 12-ml polycarbonate cones, and are then evaporated to dryness.

To the $\mathrm{Zr}$ fraction is added $0.5 \mathrm{ml} \mathrm{Zr}^{4+}$ carrier, 3 drops $\mathrm{La}^{3+}$ carrier, and $2 \mathrm{ml}$ conc HF. The sample is mixed, digested, and centrifuged, and the supernatant liquid is transfered to a new 12 $\mathrm{ml}$ polycarbonate cone. Another 3-drop aliquot of $\mathrm{La}^{3+}$ carrier is added to the solution, which is then mixed, digested, and centrifuged. The supernatant liquid is transfered to a new $12-\mathrm{ml}$ polycarbonate cone, and $1 \mathrm{ml}$ conc $\mathrm{HF}$ and $1 \mathrm{ml} \mathrm{Ba}^{2+}$ carrier are added. The sample is digested and centrifuged, and the supernatant liquid is decanted to waste. The barium fluorozirconate precipitate is dissolved in $2 \mathrm{ml} \mathrm{H}_{2} \mathrm{O}, 1 \mathrm{ml}$ saturated $\mathrm{H}_{3} \mathrm{BO}_{3}$, and $2 \mathrm{ml}$ $6 \mathrm{M} \mathrm{HCl}$, using the hot-water bath. $5 \mathrm{M} \mathrm{NaOH}$ is added to the solution until precipitation is complete, the sample is digested and centrifuged, and the supernatant liquid is decanted to waste. The precipitate is dissolved in $6 \mathrm{ml} 6 \mathrm{M} \mathrm{HCl}$, and transfered to a 40$\mathrm{ml}$ centrifuge cone with $2 \mathrm{ml} \mathrm{H}_{2} \mathrm{O}$ washes. $10 \mathrm{ml}$ saturated mandelic acid is added to the sample, which is heated to more than $80^{\circ} \mathrm{C}$ for 
20 minutes in a hot-water bath. Using the Millipore apparatus, the sample is filtered while still warm onto whatman 542 paper, and then washed with $10 \mathrm{ml}$ of a warm solution that is 58 in mandelic acid and $2 \%$ in $\mathrm{HCl}$. After washing with a few $\mathrm{ml}$ of ethanol, the sample is dismounted and placed in a drying oven at $110^{\circ} \mathrm{C}$.

\section{Day 5 :}

The U/Sb fraction is transfered to a 250-ml separatory funnel. $1 \mathrm{ml} \mathrm{Ga}{ }^{3+}$ carrier and $1 \mathrm{ml} \mathrm{Sb}^{3+}$ carrier are added, and the solution volume is doubled with addition of conc $\mathrm{HCl}$. Several drops of $\mathrm{Br}_{2}$ are added to the sample, then $\mathrm{Sb}$ is extracted for 5 minutes into $10 \mathrm{ml}$ disopropyl ether. The aqueous fraction, containing $\mathrm{U}$, is transfered to two 40-ml centrifuge cones and reduced in volume by evaporation in a hot-water bath under an air stream; this requires care, since there is enough organic phase dissolved in the aqueous phase to cause bumping if heated too fast. When the volumes have been reduced to a few $\mathrm{ml}$ each, the $\mathrm{U}$ fraction is pooled to a single cone with $6 \mathrm{M} \mathrm{HCl}$ and evaporated to dryness.

A solution of $5 \mathrm{ml} 3 \mathrm{M} \mathrm{HCl}$ and $1 \mathrm{ml}$ fresh $\mathrm{Sn}^{2+}$ carrier in $9 \mathrm{M} \mathrm{HCl}$ is added to the organic phase in the separatory funnel, and $\mathrm{Sb}$ is back-extracted for several minutes. This step is repeated, and the aqueous phases are pooled to a 40-ml centrifuge cone. The sample is heated gently in a hot-water bath for about an hour to reduce the amount of dissolved organic phase. $1 \mathrm{ml} \mathrm{Sn}^{4+}$ hold-back carrier is added to the sample, which is heated to near-boiling; $\mathrm{H}_{2} \mathrm{~S}$ gas is bubbled through the sample while hot, until the formation of orange $\mathrm{Sb}$ sulfide precipitate is complete. The sample is centrifuged while still hot, and the supernatant liquid is decanted to waste. The precipitate is slurried with $\mathrm{H}_{2} \mathrm{O}$ and transfered to the Millipore apparatus, where it is filtered onto whatman 542 paper. After another $\mathrm{H}_{2} \mathrm{O}$ wash, the sample is dried at $110^{\circ} \mathrm{C}$ in the drying oven.

The dry $\mathrm{Np}$ fraction is dissolved in $1 \mathrm{ml}$ of a solution consisting of 1 part conc $\mathrm{HI}$ to 12 parts conc $\mathrm{HCl}$, by volume. The solution is warmed, and loaded onto a $2.5-\mathrm{mm}$-diameter Dowex-1x8 anion-exchange column, preconditioned with conc HCl. The eluant from the load solution is discarded to waste, as is the eluant from column washes with $2 \mathrm{ml}$ warm $1: 12 \mathrm{HI} / \mathrm{HCl}$ followed by $1 \mathrm{ml}$ conc $\mathrm{HCl}$ and $1 \mathrm{ml}$ of a solution that is $9 \mathrm{M}$ in $\mathrm{HCl}$ and $0.02 \mathrm{M}$ in $\mathrm{HF}$. The $\mathrm{Np}$ fraction is eluted from the column with $2 \mathrm{ml}$ of a solution that is $4 \mathrm{M}$ in $\mathrm{HCl}$ and $0.1 \mathrm{M}$ in $\mathrm{HF}$, collected in a $12-\mathrm{ml}$ polycarbonate cone, and is then evaporated to dryness. The dry Np fraction is then dissolved in $1 \mathrm{ml} 1: 12 \mathrm{HI} / \mathrm{HCl}$, warmed briefly, and loaded on a new 2.5-mm-diameter Dowex-1x8 column, preconditioned with conc $\mathrm{HCl}$. The eluant from the load solution is discarded to waste, as is the eluant from column washes with $2 \mathrm{ml}$ warm 1:12 $\mathrm{HI} / \mathrm{HCl}$ followed by $1 \mathrm{ml}$ conc $\mathrm{HCl}$. The $\mathrm{Np}$ fraction is eluted from the column with 3 $\mathrm{ml} 1 \mathrm{M} \mathrm{HCl}$, collected in a $12-\mathrm{ml}$ centrifuge cone. The sample is evaporated to dryness, transfered to a tungsten filament with $6 \mathrm{M}$ 
$\mathrm{HCl}$, and volatilized onto a pt counting disk.

The dry $\mathrm{Pa}$ fraction is dissolved in $1 \mathrm{ml}$ of a solution consisting of 1 part conc HI to 12 parts conc HCl, by volume. The solution is warmed, and loaded onto a 4-mm-diameter Dowex-1x8 anion-exchange column in a plastic column body with a Saran-wool plug, preconditioned with conc $\mathrm{HCl}$. The eluant from the load solution is discarded to waste, as is the eluant from column washes with $3 \mathrm{ml}$ warm $1: 12 \mathrm{HI} / \mathrm{HCl}$ followed by $1 \mathrm{ml}$ conc $\mathrm{HCl}$. The $\mathrm{Pa}$ fraction is eluted from the column with $4 \mathrm{ml}$ of a solution that is $9 \mathrm{M}$ in $\mathrm{HCl}$ and $0.02 \mathrm{M}$ in $\mathrm{HF}$, collected in a $12-\mathrm{ml}$ polycarbonate cone. The Pa fraction is then evaporated to dryness in a hot-water bath.

In the glove box, the dry $\mathrm{An} / \mathrm{RE}$ fraction is dissolved in 3 drops of a solution that is composed of $90 \%$ conc $\mathrm{HCl}$ and $10 \%$ ethanol, by volume, saturated with $\mathrm{HCl}$ by bubbling the gas through the solution. The sample is loaded on a 4-mm-diameter AG MP-50 cation-exchange column, preconditioned with conc $\mathrm{HCl}$. After the load is complete, the empty sample cone is washed onto the column several times with 2-drop aliquots of saturated alcoholic $\mathrm{HCl}$; the purpose is to effect an efficient loading in a minimum load volume. After several small-volume aliquots, $10 \mathrm{ml}$ of the saturated alcoholic $\mathrm{HCl}$ solution is loaded on the column. The column eluant is collected in glass planchets, 8 drops per planchet. Approximately 12 planchets are required. After receiving its eluant aliquot, each planchet is heated to dryness on a hot plate, and the contents are counted with a beta-gamma survey instrument inserted into the box glove. Essentially all of the observable activity in the samples is due to the decay of ${ }^{241} \mathrm{Am}$. Fractions from just prior to the onset of observable activity through the third fraction following the sample with the highest activity are recovered from the planchets with $6 \mathrm{M} \mathrm{HCl}$ and are pooled to a 12$\mathrm{ml}$ centrifuge cone; this is the An fraction. The last planchets are similarly pooled to another $12-\mathrm{ml}$ centrifuge cone, into which the column is stripped with $6 \mathrm{ml} 6 \mathrm{M} \mathrm{HCl}$; this is the RE fraction. The RE fraction is passed out of the glove box to the fume hood, where it is evaporated to dryness in a hot-water bath. In the glove box, the An fraction is evaporated to dryness in a hot-water bath, 2 drops conc $\mathrm{HClO}_{4}$ are added, and the sample is evaporated to dryness in a mineral-oil bath.

Day 6:

The dry $\mathrm{U}$ fraction is dissolved in $2 \mathrm{ml} 9 \mathrm{M} \mathrm{HCl}$ and loaded onto a 4-mm-diameter Dowex- $1 \times 8$ anion-exchange column, preconditioned with $9 \mathrm{M} \mathrm{HCl}$. The eluants from the load solution and a column wash with $2 \mathrm{ml} 9 \mathrm{M} \mathrm{HCl}$ are discarded to waste. The uranium fraction is eluted with $8 \mathrm{M}^{\mathrm{HNO}_{3}}$; the first $0.5 \mathrm{ml}$ of eluant is discarded to waste, and the next $10 \mathrm{ml}$ is collected in a $12-\mathrm{ml}$ centrifuge cone as the $\mathrm{U}$ fraction. This sample is evaporated to dryness, dissolved in $1 \mathrm{ml}$ conc $\mathrm{HCl}$, and evaporated to dryness again. The dry $U$ fraction is dissolved in $1 \mathrm{ml}$ of a solution consisting of 1 part 
conc HI to 12 parts conc $\mathrm{HCl}$, by volume, which is heated briefly and loaded onto a 2.5-mm-diameter Dowex-1x8 anion-exchange column, preconditioned with conc $\mathrm{HCl}$. The eluant from the load solution and that from column washes with $1 \mathrm{ml} 1: 12 \mathrm{HI} / \mathrm{HCl}$ followed by $1 \mathrm{ml}$ conc HCl are discarded to waste. The U fraction is eluted to a 12$\mathrm{ml}$ centrifuge cone with $3 \mathrm{ml} 0.5 \mathrm{M} \mathrm{HCl}$ and evaporated to dryness. The dry $U$ fraction is then dissolved in $1 \mathrm{ml} 1: 12 \mathrm{HI} / \mathrm{HCl}$, and the last anion-exchange step is repeated with a fresh $2.5-\mathrm{mm}$-diameter column. The final $\mathrm{U}$ eluant is collected in a $12-\mathrm{ml}$ centrifuge cone and evaporated to dryness. The dry $U$ fraction is dissolved in $6 \mathrm{M}$ $\mathrm{HCl}$, and is subdivided into several equal-sized fractions in clean 12-ml centrifuge cones. Some of these are evaporated to dryness and are submitted for mass-spectrometric analysis; others are transfered to tungsten filaments and volatilized onto pt counting disks.

The dry $\mathrm{Pa}$ fraction is dissolved in $1 \mathrm{ml}$ of a solution consisting of 1 part conc HI to 12 parts conc HCl, by volume, which is heated briefly and loaded onto a 2.5-mm-diameter Dowex-1x8 anion-exchange column, preconditioned with conc $\mathrm{HCl}$. The eluant from the load solution and that from column washes with $1 \mathrm{ml} 1: 12$ $\mathrm{HI} / \mathrm{HCl}$ followed by $1 \mathrm{ml}$ conc $\mathrm{HCl}$ are discarded to waste. $\mathrm{Pa}$ is eluted to a 12-ml centrifuge cone with $2 \mathrm{ml}$ of a solution that is $9 \mathrm{M}$ in $\mathrm{HCl}$ and $0.02 \mathrm{M}$ in $\mathrm{HF}$. The $\mathrm{Pa}$ fraction is evaporated to dryness, dissolved in a minimum volume of $9 \mathrm{M} \mathrm{HCl} / 0.02 \mathrm{M} \mathrm{HF}$, transfered to a tungsten filament and volatilized onto a $\mathrm{Pt}$ counting disk.

In the glove box, the dry $A n$ fraction is dissolved in approximately 100 ul of a fresh solution consisting of 1 part conc $\mathrm{HNO}_{3}$ to 9 parts methanol, by volume. This pink (Am nitrate) solution is loaded onto a 2.5-mm-diameter AG MP-1 anion-exchange column, preconditioned with both $8 \mathrm{M} \mathrm{HNO}_{3}$ and 10:90 $\mathrm{HNO}_{3} / \mathrm{methanol}$. The load cone is rinsed onto the column several times with small aliquots of the 10:90 mixture to effect an efficient transfer of the sample to the column. The 10:90 column eluant is discarded to waste. The trivalent actinides are eluted from the column with a fresh solution that is $5 \mathrm{M}$ in $\mathrm{HNO}_{3}$ and $30 \%$ methanol, by volume ( 30 $\mathrm{ml}$ methanol $+31 \mathrm{ml}$ conc $\left.\mathrm{HNO}_{3}+39 \mathrm{ml} \mathrm{H}_{2} \mathrm{O}\right)$. The eluant is collected in 5-drop fractions in 12-ml centrifuge cones. Each sample is assayed with a beta-gamma survey instrument inserted into a box glove. Fraction collection continues until the first fraction that has a significant dose rate over background. The first fraction is discarded to waste; all others (approximately five) are transfered to a $12-\mathrm{ml}$ centrifuge cone with $8 \mathrm{M} \mathrm{HNO}$ washes. This $\mathrm{Cm}$ fraction is passed out of the glove box to the fume hood, where it is evaporated to dryness in a hot-water bath under an air stream. The Am fraction is eluted from the column into a 12-ml centrifuge cone with $3 \mathrm{ml} 6 \mathrm{M} \mathrm{HNO}_{3}$, and evaporated to dryness. 2 drops conc $\mathrm{HClO}_{4}$ are added to the dry Am fraction, which is then evaporated to dryness in a mineral-oil bath. 
Day $7:$

The RE fraction is dissolved in 3 drops of a solution that is composed of $90 \%$ conc $\mathrm{HCl}$ and $10 \%$ ethanol, by volume, saturated with HCl by bubbling the gas through the solution. The sample is loaded onto a 4-mm-diameter AG MP-50 cation-exchange column, preconditioned with conc $\mathrm{HCl}$. After the load is complete, the empty sample cone is washed onto the column several times with 2drop aliquots of saturated alcoholic HCl. After several smallvolume aliquots, $5 \mathrm{ml}$ of the saturated alcoholic $\mathrm{HCl}$ solution is loaded on the column. The column eluant is collected in glass planchets, 8 drops per fraction. After receiving its eluant aliquot, each planchet is heated to dryness under the heat lamp, and the contents are counted for both alpha and beta-gamma activities. Essentially all of the observable activity in the samples is due to the decay of ${ }^{241} \mathrm{Am}$. Fractions from the start of elution through the tail fraction containing $10 \%$ of the activity found in the sample with the most ${ }^{241} \mathrm{Am}$ are discarded to waste. The last planchets are pooled to a $12-\mathrm{ml}$ centrifuge cone with $6 \mathrm{M} \mathrm{HCl}$ washes. The column is stripped with $6 \mathrm{ml} 6 \mathrm{M} \mathrm{HCl}$ into the centrifuge cone, which now contains the RE fraction. The RE fraction is evaporated to dryness, the activity is dissolved in 3 drops saturated alcoholic HCl, and the previous cation-exchange procedure is repeated. The new RE fraction, which should contain less than $1 \mathrm{uCi}$ of ${ }^{241} \mathrm{Am}$, is evaporated to dryness.

The dry $\mathrm{Cm}$ fraction is dissolved in approximately $100 \mathrm{ul}$ of a fresh solution consisting of 1 part conc $\mathrm{HNO}_{3}$ to 9 parts methanol. This solution is loaded onto a 2.5-mm-diameter AG MP1 anion-exchange column, preconditioned with both $8 \mathrm{M} \mathrm{HNO}_{3}$ and $10: 90$ $\mathrm{HNO}_{3}$ /methanol. The load cone is rinsed onto the column several times with small aliquots of the 10:90 mixture to effect an efficient transfer of the sample to the column. The 10:90 column eluant is discarded to waste. $\mathrm{Cm}$ is eluted from the column with a fresh solution that is $5 \mathrm{M}$ in $\mathrm{HNO}_{3}$ and $30 \%$ methanol, by volume. The eluant is collected as 5-drop fractions in glass planchets. Each sample is assayed for alpha radioactivity; fraction collection continues until the first fraction that has a significant amount of ${ }^{241} \mathrm{Am}$. The first two fractions are discarded to waste; all others are transfered to a $12-\mathrm{ml}$ centrifuge cone with $8 \mathrm{M} \mathrm{HNO}_{3}$ washes. This new $\mathrm{Cm}$ fraction is evaporated to dryness in a hotwater bath under an air stream. The dry $\mathrm{Cm}$ fraction is dissolved in approximately $100 \mathrm{ul}$ of 10:90 $\mathrm{HNO}_{3} / \mathrm{methanol}$, and the previous anion-exchange step is repeated. The fractions containing $\mathrm{Cm}$ are pooled to a 12-m1 centrifuge cone with $8 \mathrm{M} \mathrm{HNO}_{3}$ and evaporated to dryness. The dry sample is dissolved in $0.5 \mathrm{ml} 6 \mathrm{M} \mathrm{HCl}$ and evaporated to dryness again, and is then picked up in a minimum volume of $6 \mathrm{M} \mathrm{HCl}$ and transfered to a tungsten filament and volatilized onto a Pt counting disk. 
Day 8:

In the glove box, the Am fraction is dissolved in approximately $10 \mathrm{ml} 6 \mathrm{M} \mathrm{HCl}$. $10 \mathrm{ul}$ of this solution is delivered to a clean 12-ml centrifuge cone and passed out of the glove box to the fume hood. The main Am fraction is evaporated to dryness. The aliquot sample should contain several uCi of ${ }^{241} \mathrm{Am}$. This sample is diluted to $1 \mathrm{ml}$ with $9 \mathrm{M} \mathrm{HCl}$, and 1 drop $8 \mathrm{M} \mathrm{HNO}_{3}$ is added to the solution. The sample is heated briefly and loaded onto a $2.5-\mathrm{mm}^{-}$ diameter Dowex-1x8 anion-exchange column, preconditioned with $9 \mathrm{M}$ $\mathrm{HCl}$. The combined eluants from the load solution and a $1 \mathrm{ml} 9 \mathrm{M} \mathrm{HCl}$ column wash are collected in a 12-ml centrifuge cone as the Am dilution. The ${ }^{241} \mathrm{Am}$ concentration of this solution is determined by taking a quantitative assay to dryness on Pt. Several aliquots containing approximately $6 \times 10^{5}$ alpha disintegrations/minute ( $100 \mathrm{ng}$ ${ }^{241} \mathrm{Am}$ ) are transfered to clean $12-\mathrm{ml}$ centrifuge cones; some of these samples are evaporated to dryness and submitted for massspectrometric analysis, while others are transfered to tungsten filaments and volatilized onto pt counting disks.

A few microliters of the Pu fraction (approximately $1 \mathrm{mCi} / \mathrm{ml}$ solution) is transfered to a clean $12-\mathrm{ml}$ centrifuge cone and passed out of the glove box to the fume hood. The sample is diluted to $1 \mathrm{ml}$ with $6 \mathrm{M} \mathrm{HCl}$, and 1 drop $8 \mathrm{M} \mathrm{HNO}_{3}$ is added to the solution. The sample is heated briefly and loaded onto a 2.5-mm-diameter Dowex$1 \times 8$ anion-exchange column, preconditioned with $6 \mathrm{M} \mathrm{HCl}$. The eluants from the load solution and a $2 \mathrm{ml} 6 \mathrm{M} \mathrm{HCl}$ wash are decanted to waste. $\mathrm{Pu}$ is eluted from the column to a $12-\mathrm{ml}$ centrifuge cone with $2 \mathrm{ml} 1 \mathrm{M} \mathrm{HCl}$. The $\mathrm{Pu}$ concentration of this solution is determined by taking a quantitative assay to dryness on pt. Several aliquots containing approximately $3 \times 10^{4}$ alpha disintegrations/minute are transfered to clean 12 -ml centrifuge cones; some of these samples are evaporated to dryness and submitted for mass-spectrometric analysis, while others are transfered to tungsten filaments and volatilized onto Pt counting disks.

The RE fraction is dissolved in 2 drops of a solution that is composed of $90 \%$ conc $\mathrm{HCl}$ and $10 \%$ ethanol, by volume, saturated with $\mathrm{HCl}$ by bubbling the gas through the solution. The sample is loaded on a 2.5-mm-diameter AG MP-50 cation-exchange column, preconditioned with conc HCl. After the load is complete, the empty sample cone is washed onto the column several times with 2drop aliquots of saturated alcoholic $\mathrm{HCl}$. After several smallvolume aliquots, several $\mathrm{ml}$ of the saturated alcoholic HCl solution is loaded on the column. The column eluant is collected in glass planchets, 6 drops per planchet. After receiving its eluant aliquot, each planchet is heated to dryness under the heat lamp, and the contents are counted for alpha activity. Essentially all of the observable activity in the samples is due to the decay of ${ }^{241} \mathrm{Am}$. Fractions from the start of elution through the tail fraction containing $10 \%$ of the activity found in the sample with 
the most ${ }^{241} \mathrm{Am}$ are discarded to waste. The last planchets are pooled to a $12-\mathrm{ml}$ centrifuge cone with $6 \mathrm{M} \mathrm{HCl}$ washes. The column is stripped with $6 \mathrm{ml} 6 \mathrm{M} \mathrm{HCl}$ into the centrifuge cone, which now contains the $\mathrm{RE}$ fraction. The $\mathrm{RE}$ fraction is reduced in volume by evaporation and is transfered to a single glass planchet. The sample is evaporated to dryness under a heat lamp, 2 drops of conc $\mathrm{HClO}_{4}$ is added to the sample, and it is evaporated to dryness again.

Day 9:

The dry RE fraction is dissolved in 2 drops $0.05 \mathrm{M}$ alphahydroxyisobutyric acid ("alpha-but"). The sample is covered to reduce evaporation, and is heated to $80^{\circ} \mathrm{C}$ in a hot water bath. The warm solution is then loaded onto a 2.5-mm-diameter Dowex$50 \times 12$ cation-exchange column with a Pt-capillary tip, maintained at $80^{\circ} \mathrm{C}$ in a column-heating block, preconditioned with washes of $\mathrm{H}_{2} \mathrm{O}, 0.98 \mathrm{M}$ alpha-but, and $0.05 \mathrm{M}$ alpha-but. The empty sample cone is rinsed onto the column several times with $80^{\circ} \mathrm{C} 0.05 \mathrm{M}$ alpha-but; this effects an efficient transfer of the activity to the column in a minimum load volume. The column eluant is collected as 8drop fractions in glass planchets. Solutions are all heated to $80^{\circ} \mathrm{C}$ prior to loading, and are kept covered when not in use to reduce evaporation. Two fractions of $0.05 \mathrm{M}$ alpha-but eluant are taken, followed by six fractions of $0.15 \mathrm{M}$ alpha-but, then four fractions of $0.23 \mathrm{M}$ alpha-but, then six fractions of $0.32 \mathrm{M}$ alphabut. The solutions in the planchets are evaporated to dryness under a heat lamp and are surveyed for alpha activity to locate the elution position of ${ }^{241} \mathrm{Am}$. The relative elution positions given in Table 7 (main text) can be used to decide which samples to pool to result in Eu and Nd fractions; samples associated with a given fraction are pooled to a single planchet with $6 \mathrm{M} \mathrm{HCl}$ and evaporated to dryness. The ce fraction is stripped from the column with $0.98 \mathrm{M}$ alpha-but, and is also transfered to a single planchet and evaporated to dryness. A drop of conc $\mathrm{HClO}_{4}$ is added to each of the rare earth fractions ( $\mathrm{Eu}, \mathrm{Nd}$, and $\mathrm{Ce}$ ), which are again evaporated to dryness.

All three rare-earth fractions are dissolved in a few drops of $0.5 \mathrm{M} \mathrm{HCl}$ and are loaded on 2.5-mm-diameter Dowex-50x4 cationexchange columns, preconditioned by cycling through conc $\mathrm{HCl}$ and back down to $0.5 \mathrm{M} \mathrm{HCl}$. The column eluants are collected as 9-drop fractions in glass planchets. Two fractions of the eluant from $0.5 \mathrm{M} \mathrm{HCl}$ load and wash solutions are collected from each column, followed by three fractions of $2 \mathrm{M} \mathrm{HCl}$. The samples in the planchets are evaporated to dryness and are examined for the presence of a visible deposit. If the last fractions contain significant (visible) mass, further elution with $2 \mathrm{M} \mathrm{HCl}$ is required. The fractions from the Nd column are surveyed for alpha activity to ensure that $\mathrm{Am}$ and the rare earths have not been removed from the column prematurely. The rare earths are eluted 
from the three columns with $4 \mathrm{ml} 9 \mathrm{M} \mathrm{HCl}$ each into $12 \mathrm{ml}$ centrifuge cones. The eluants are evaporated to dryness in a hot-water bath. A drop of conc $\mathrm{HClO}_{4}$ is added to both the Eu and the $\mathrm{Ce}$ fractions, which are evaporated to dryness in a mineral-oil bath. The samples are dissolved in single drops of $1 \mathrm{M} \mathrm{HNO}_{3}$, which are diluted to $2 \mathrm{ml}$ in isopropanol. These solutions are transfered into cells, where the rare earth samples are electroplated from the isopropanol solutions onto pt counting disks, at $200 \mathrm{~V}$ for 30 minutes.

Day 10:

The Nd fraction is dissolved in 2 drops of a solution that is composed of $90 \%$ conc $\mathrm{HCl}$ and 108 ethanol, by volume, saturated with $\mathrm{HCl}$ by bubbling the gas through the solution. The sample is loaded on a 2.5-mm-diameter AG MP-50 cation-exchange column, preconditioned with conc $\mathrm{HCl}$. After the load is complete, the empty sample cone is washed onto the column several times with 2drop aliquots of saturated alcoholic $\mathrm{HCl}$. After several smallvolume aliquots, several $\mathrm{ml}$ of the saturated alcoholic HCl solution is loaded on the column. The column eluant is collected in glass planchets, 6 drops per planchet. After receiving its eluant aliquot, each planchet is heated to dryness under the heat lamp, and the contents are counted for alpha activity. Fractions from the start of elution through the tail fraction containing $10 \%$ of the activity found in the sample with the most ${ }^{241} \mathrm{Am}$ are discarded to waste. The last planchets are pooled to a 12-ml centrifuge cone with $6 \mathrm{M} \mathrm{HCl}$ washes. The column is stripped with $6 \mathrm{ml} 6 \mathrm{M} \mathrm{HCl}$ into the centrifuge cone, which now contains the Nd fraction. The solution is evaporated to dryness in a hot-water bath, and a partial drop of conc $\mathrm{HClO}_{4}$ is added to the sample, which is evaporated to dryness in a mineral-oil bath. The Nd fraction is submitted for mass-spectrometric analysis.

In the glove box, approximately $10 \%$ of the $\mathrm{Pu}$ fraction $(\sim 100$ $\mathrm{mg} \mathrm{Pu}$ ) is transfered to a 40-ml centrifuge cone and is evaporated to dryness in a hot-water bath under an air stream. $5 \mathrm{ml} 8 \mathrm{M} \mathrm{HNO}_{3}$ is added to the sample, which is again evaporated to dryness. The dry deposit is dissolved in $1 \mathrm{M} \mathrm{HNO}_{3}$, using the hot-water bath, and is transfered to a 60-ml separatory funnel with $1 \mathrm{M} \mathrm{HNO}_{3}$ washes of the centrifuge cone, to result in $20 \mathrm{ml}$ solution. $\mathrm{Pu}$ is extracted into $20 \mathrm{ml} 0.2 \mathrm{M}$ thenoyltrifluoroacetone (TTA) in xylene. The aqueous phase is discarded, and the organic phase is washed with two 10-ml aliquots of $1 \mathrm{M}^{-} \mathrm{HNO}_{3}$, which are also discarded. $\mathrm{Pu}$ is back-extracted into two $10-\mathrm{ml}$ aliquots of $8 \mathrm{M} \cdot \mathrm{HNO}_{3}$, which are pooled into a 40-ml centrifuge cone and evaporated to a moist deposit in a hot-water bath. This cleaned $\mathrm{Pu}$ fraction is then sealed and set aside to allow the ingrowth of daughter activities.

- At least three weeks must elapse before proceeding with the chemistry. 
Day 30 (approximately):

In the glove box, the Pu fraction from the TTA procedure is evaporated to dryness and dissolved in $1 \mathrm{M} \mathrm{HNO}_{3}$ using the hot-water bath. The solution is transfered to a new 60-ml separatory funnel with washes of $1 \mathrm{M} \mathrm{HNO}_{3}$, to result in $20 \mathrm{ml}$ of solution. $\mathrm{Pu}$ is extracted into $20 \mathrm{ml} 0.2 \mathrm{M}$ TTA in xylene, which is discarded to waste. $0.5 \mathrm{ml} 308 \mathrm{H}_{2} \mathrm{O}_{2}$ is added to the aqueous phase, and after 30 minutes $\mathrm{Pu}$ is once again extracted into $20 \mathrm{ml} 0.2 \mathrm{M}$ TTA in xylene. The organic phase is discarded to waste, and the aqueous phase is washed with $10 \mathrm{ml}$ xylene, which is also discarded to waste. The aqueous phase (the U-milk fraction) is evaporated to dryness (cautiously).

The U-milk fraction is dissolved in $1 \mathrm{ml} 9 \mathrm{M} \mathrm{HCl}$ and 1 drop $8 \mathrm{M}$ $\mathrm{HNO}_{3}$, heated briefly, and loaded onto a 6-mm-diameter Dowex-1x8 anion-exchange column, preconditioned with $9 \mathrm{M} \mathrm{HCl}$. The column is washed with $10 \mathrm{ml} 9 \mathrm{M} \mathrm{HCl}$, followed by $10 \mathrm{ml}$ of a warm solution of 1 part conc $\mathrm{HI}$ and 12 parts conc $\mathrm{HCl}$; the column eluants are discarded to waste. $U$ is eluted from the column to a clean $40-\mathrm{ml}$ centrifuge cone with $15 \mathrm{ml} 1 \mathrm{M} \mathrm{HCl}$. This fraction is passed out of the glove box to the fume hood, where it is evaporated to dryness. The sample is dissolved in $1 \mathrm{ml} 8 \mathrm{M} \mathrm{HNO}$ and 1 drop saturated $\mathrm{NH}_{4} \mathrm{NO}_{2}$, heated briefly, and loaded onto a 4-mm-diameter Dowex-1x8 anionexchange column, preconditioned with $8 \mathrm{M} \mathrm{HNO}_{3}$. The eluant from the initial load solution is discarded to waste; $U$ is eluted to a 12$\mathrm{ml}$ centrifuge cone with $10 \mathrm{ml} 8 \mathrm{M} \mathrm{HNO}_{3}$, which is evaporated to dryness.

In the glove box, the main Am fraction (dry) is dissolved in $1 \mathrm{ml}$ conc $\mathrm{HCl}$ and 1 drop $8 \mathrm{M} \mathrm{HNO}_{3} ;$ heated briefly, and loaded onto a 2.5-mm-diameter Dowex-1x8 anion-exchange column, preconditioned with conc HCl. The eluant from the load solution and $3 \mathrm{ml}$ conc $\mathrm{HCl}$ column washes are discarded to waste. The Np-milk fraction is eluted from the column to a $12-\mathrm{ml}$ centrifuge cone with $5 \mathrm{ml} 1 \mathrm{M} \mathrm{HCl}$. The solution is passed out of the glove box to the fume hood where it is evaporated to dryness in a hot-water bath. The dry Np-milk fraction is dissolved in $1 \mathrm{ml} 8 \mathrm{M} \mathrm{HNO}$ and 1 drop saturated $\mathrm{NH}_{4} \mathrm{NO}_{2}$, heated briefly, and loaded onto a 2.5-mm-diameter Dowex-1x8 anionexchange column, preconditioned with $8 \mathrm{M} \mathrm{HNO}_{3}$. The eluants from the load solution and column washes with $2 \mathrm{ml} 8 \mathrm{M} \mathrm{H^{2 }}, 2 \mathrm{ml}$ conc $\mathrm{HCl}$, and $3 \mathrm{ml}$ warm $1: 12$ conc $\mathrm{HI} / \mathrm{conc} \mathrm{HCl}$, are discarded to waste. Np is eluted from the column to a $12-\mathrm{ml}$ polycarbonate cone with $3 \mathrm{ml}$ of a solution $4 \mathrm{M}$ in $\mathrm{HCl}$ and $0.1 \mathrm{M}$ in $\mathrm{HCl}$. The Np-milk fraction is evaporated to dryness in a hot-water bath.

Day 31:

The dry U-milk fraction is dissolved in $1 \mathrm{ml}$ of a warm solution composed of 1 part conc HI to 12 parts conc HCl, and loaded onto a 2.5-mm-diameter Dowex-1x8 anion-exchange column, preconditioned with conc $\mathrm{HCl}$. The eluant from the load solution 
and from column washes with $3 \mathrm{ml}$ warm $1: 12 \mathrm{conc} H I / \mathrm{conc} \mathrm{HCl}, 1 \mathrm{ml}$ $9 \mathrm{M} \mathrm{HCl}$, and $2 \mathrm{ml} 4 \mathrm{M} \mathrm{HCl} / 0.1 \mathrm{M} \mathrm{HF}$, are discarded to waste. The Umilk fraction is eluted to a $12-\mathrm{ml}$ centrifuge cone with $5 \mathrm{ml} 0.5 \mathrm{M}$ $\mathrm{HCl}$, evaporated to dryness, transfered to a tungsten filament with a minimum volume of $6 \mathrm{M} \mathrm{HCl}$, and volatilized onto a Pt counting disk.

The dry Np-milk fraction is dissolved in $1 \mathrm{ml}$ warm $1: 12$ conc $\mathrm{HI} / \mathrm{ConC} \mathrm{HCl}$, and loaded onto a 2.5-mm-diameter Dowex-1x8 anionexchange column, preconditioned with conc HCl. The eluants from the load solution and column washes with $2 \mathrm{ml}$ warm $1: 12$ conc $\mathrm{HI} / \mathrm{conC} \mathrm{HCl}$ and $1 \mathrm{ml}$ conc $\mathrm{HCl}$, are discarded to waste. Np is eluted from the column into a $12-\mathrm{ml}$ centrifuge cone with $5 \mathrm{ml} 0.5 \mathrm{M}$ HCl. The solution is evaporated to dryness, the activity is dissolved in a minimum volume of $6 \mathrm{M} \mathrm{HCl,} \mathrm{transfered} \mathrm{to} \mathrm{a} \mathrm{tungsten}$ filament, and volatilized onto a Pt counting disk. 